Portland State University

PDXScholar

1976

\title{
A methodology for determining mass movement susceptibility for land-use planning
}

Vern Walter Cimmery

Portland State University

Follow this and additional works at: https://pdxscholar.library.pdx.edu/open_access_etds

Part of the Human Geography Commons, and the Physical and Environmental Geography Commons Let us know how access to this document benefits you.

\section{Recommended Citation}

Cimmery, Vern Walter, "A methodology for determining mass movement susceptibility for land-use planning" (1976). Dissertations and Theses. Paper 2360.

https://doi.org/10.15760/etd.2357

This Thesis is brought to you for free and open access. It has been accepted for inclusion in Dissertations and Theses by an authorized administrator of PDXScholar. For more information, please contact pdxscholar@pdx.edu. 
AN ABSTRACT OF THE THESIS OF Vern Walter Cimmery for the Master of Science in Geography presented October 25, 1976.

Title: A Methodology for Determining Mass Movement Susceptibility for LandUse Planning.

\section{APPROVED BY MEMBERS OF THE THESIS COMMITTEE:}
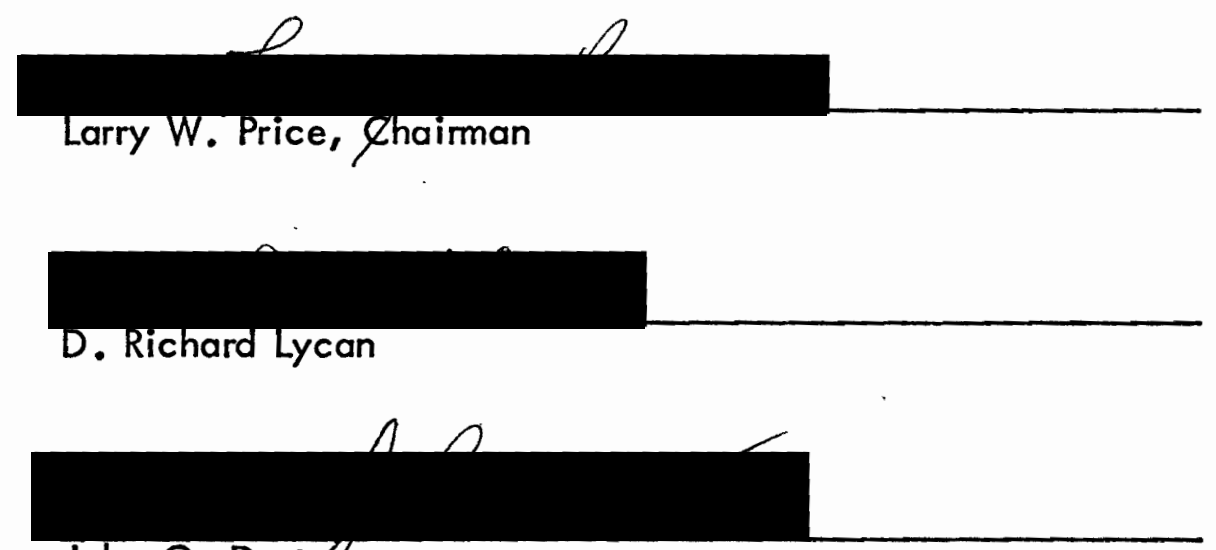
John O. Dart/] .

Land-use planning takes into consideration geologic hazards in order to protect both life and property. One type of geologic hazard is mass movement. Mass movement is a collective term for the downslope movement of mass units of debris, e.g., bedrock, soil, and subsurface material, resulting from the influence d. of gravity and involving transporting media such as ice, snow, water, and air. As population increases, further pressures are placed on existing land use. Many areas once considered unsuitable for development due to steep slope or other physical characteristics are now experiencing problems. These areas, due to 
their physical characteristics, can be susceptible to mass movement. The problem is, information related to the areal distribution of susceptibility is most often not available for input to the land-use planning process. This thesis is proposing a methodology to provide general-level mass movement susceptibility maps.

The methodology is a computer application utilizing the Harvard I.M.G.R.I.D. (IMGRID) System. IMGRID is a system using grid cells as the basic units of data storage, analysis, retrieval, and display. Basically, the methodology consists of three major components or phases: (1) providing the computer with data acceptable to the machine and computer programs (input);

(2) manipulation of the data and storage of map results within the machine's memory (processing); and (3) the retrieval and display of results (output).

The processing of the data is organized around susceptibility models which generate computer maps identifying areas susceptible to mass movements. Areas susceptible to mass movements are defined as portions of the landscape characterized by a set of natural characteristics existing in a stable state which will yield a failure of the material if acted upon by an external or internal triggering event either natural or man-induced.

The methodology was applied to a small area in Southwest Washington as a demonstration of how one mechanically follows it from beginning to end. Nine mass movement models were constructed based on the Varnes' classification system and applied to a data bank containing eleven data variables. The susceptibility maps generated were analyzed to determine the significant mapping classes using the statistical output from IMGRID. 


\title{
A METHODOLOGY FOR DETERMINING MASS MOVEMENT SUSCEPTIBILITY FOR LAND-USE PLANNING
}

\author{
by \\ VERN WALTER CIMMERY
}

A thesis submitted in partial fulfillment of the requirements for the degree of

\section{MASTER OF SCIENCE \\ in \\ GEOGRAPHY}

Portland State University

1976 


\section{TO THE OFFICE OF GRADUATE STUDIES AND RESEARCH:}

The members of the Committee approve the thesis of Vern Walter Cimmery presented October 25, 1976.

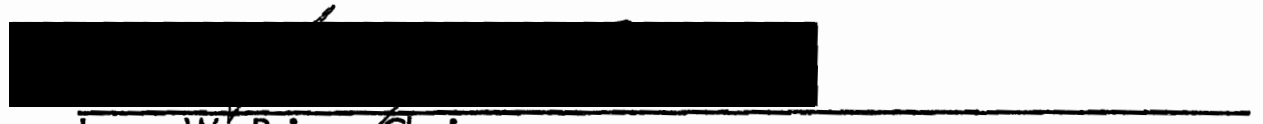

Larry W. Price, Chairman

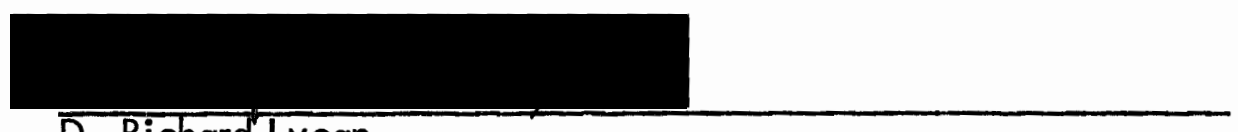

D. Richard Lycan

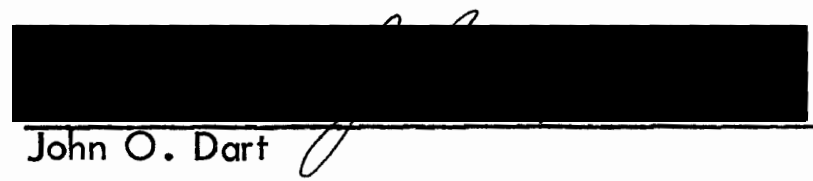

APPROVED:

D. Richard Lycan, Head, Department of Geography

S. E. Rauch, Dead of Graduate Studies and Research 


\section{ACKNOWLED GMENTS}

I would like to take this opportunity to express my appreciation to those people who have provided valuable assistance at various stages of the research and writing of this thesis.

Dr. Larry Price, my graduate committee chairman, has offered many constructive suggestions at all stages of this endeavor. He has greatly facilitated the educational process associated with this thesis.

The utilization of the Harvard I.M.G.R.I.D. (IMGRID) System would not have been possible without the willing assistance of my good friend Bruce Rowland. Bruce took on the responsibility of handling the technical aspects related to the storing of the data bank and application of the models via IMGRID.

I would like to thank Drs. Lycan and Dart for their suggestions, comments, and valuable questions related to this thesis. In addition, I would also like to express my appreciation to other members of the Geography Department faculty, staff, and fellow graduate students, for their interest and continuing flow of encouragement in my thesis adventure.

I want to thank my wonderful wife, who has sacrificed many weekends and vacations. Paula, without your support, encouragement, and understanding, this thesis would not have been possible in any form. 
TABLE OF CONTENTS

PAGE

ACKNOWLEDGMENTS $\ldots \ldots \ldots \ldots \ldots \ldots \ldots \ldots \ldots$ iii

LIST OF TABLES $\ldots \ldots \ldots \ldots \ldots \ldots \ldots \ldots \ldots \ldots \ldots \ldots$

LIST OF FIGURES $\ldots \ldots \ldots \ldots \ldots \ldots \ldots \ldots \ldots \ldots$ vii

CHAPTER

I INTRODUCTION ................... I

II A PROPOSED MASS MOVEMENT SUSCEPTIBILITY

DETERMINATION METHODOLOGY .......... 7

1. Introduction ................ 7

II. The Proposed Methodology ............. 10
Phase One
Phase Two
Phase Three
Phase Four
Phase Five
Phase Six
Phase Seven
Phase Eight
Phase Nine

III APPLICATION OF METHODOLOGY ........... 41

I. Introduction ................ 41 
CHAPTER

PAGE

II. Application $\ldots \ldots \ldots \ldots \ldots \ldots \ldots$

Phase One

Phase Two

Phase Three

Phase Four

Phase Five

Phase Six

Phase Seven

Phase Eight

Phase Nine

IV DISCUSSION AND CONCLUSIONS .......... 66

APPENDICES

A THE COMPUTER APPROACH: HARDWARE AND

SOFTWARE .................... 70

B MASS MOVEMENT SUSCEPTIBILITY MAPS ....... 114

C DATA VARIABLE MAPS ............. 125

D MODEL BOOKLETS ................. 137

E SOIL TYPES AND CHARACTERISTICS OF STUDY

AREA IN SOUTHWEST THURSTON COUNTY,

WASHINGTON ..................... 154

A SELECTED BIBLIOGRAPHY ................. 169 
I Data ltem List .................... 54

II Model Weights Listing ............... 57

III Soil Characteristics of Study Area: Type, Percent

Slope, Parent Material, and Position on

Landscape $\ldots \ldots \ldots \ldots \ldots \ldots \ldots \ldots$.......... 161

IV Soil Characteristics of Study Area: Precipitation

(Inches), Subsoil Texture, Subsoil Structure,

and Subsoil Consistence .............. . 163

V Soil Characteristics of Study Area: Profile Depth

(Inches), Available Water Capacity (Inches/

Profile), Load Carrying Capacity, and

Substratum .................. 166 


\section{LIST OF FIGURES}

FIGURE

PAGE

1 The Methodology Structure $\ldots \ldots \ldots \ldots \ldots \ldots \ldots$

2 The Weighting Format $\ldots \ldots \ldots \ldots \ldots \ldots \ldots$

3 Statistical Output for Debris Avalanche Map ....... 35

4 Study Area Base Map . . . . . . . . . . . . . . . . . . 44

5 River Basin Study Soil Map ... . . . . . . . . . . 51

6 Computer Worksheet .................. 61

7 The "Hardware" Components of a Computer System .... 76 


\section{CHAPTER I}

\section{INTRODUCTION}

Mass movements or landslides as they are more popularly termed (landslides are only one of many types of mass movements) can be disastrous, often resulting in loss of life and damage to existing buildings and homes. Population increase with corresponding pressure on land use, has yielded an increasing shortage of suitable building sites in many areas. Sites once considered marginal because of slope gradient or other physical characteristics are now being developed. Proper control must be exercised to avoid disasters caused by landslides, but in order to accomplish this, mass movement susceptibility information must be available. In most cases it is not. The problem is: How does a small planning office, with a minimum of staff and small financial base, gather adequate mass movement susceptibility information from which to base general level decisions related to proper control for their planning unit to avoid mass movement disasters? This thesis is an investigation of a possible solution to that problem. The morphology or form of the earth's surface is the result of interaction of internal and external energy. Internally generated energy is responsible for the lifting, fracturing, and wrinkling of the earth's surface. External energy from the sun and atmosphere, i.e., wind and rain aided by the force of gravity, is responsible for the breakdown, erosion, and transport of exposed earth 
materials. These interactions contribute to the formation and evolution of the earth's landforms and are termed geomorphic processes. The concern here is with the transport portion of this system, erosion. Slowly, and usually imperceptible except through long ferm observations, the action of wind, water, ice, and gravity are wearing down the earth's surface and transporting debris to the oceans. One of the more observable erosional processes is that of mass movements.

Mass movement is a collective term for gravity induced movement of weathered materials, i.e., soil and rock debris, that move as a coherent body in which neighboring particles remain close together during movement (Carson and Kirkby, 1972, p. 99). Mass transport is a process that normally accompanies mass movement. After the dislocation of material due to gravitational force overcoming resistance, a transporting media such as air, ice, snow, water or a combination of media, directly carries the material downward (Hutchinson, 1968, p. 688). Technically, mass movement and mass transport are two processes merging or working together to "move" the material. In reality, both processes occur simultaneously. Throughout this thesis mass movement is considered to be a collective term for the downslope movement of mass units of debris, e.g. , bedrock; soil, and subsurface material, resulting from the influence of gravity and involving transporting media such as ice, snow, water, and air.

Confusion exists in the literature as to the relationship between mass wasting and mass movements. Mass wasting is defined by the American Geological Institute (1962, p. 309) as "A general term for a variety of processes by which large masses of earth material are moved by gravity either slowly or 
quickly from one place to another." It would thus appear that mass movements are one of the processes referred to in this definition.

Mass movements are much more complex than this definition, however. Sharpe (1938, p. 20) divides mass movements into four basic groups: slow flowage, rapid flowage, sliding, and subsidence. His criteria were primarily on the basis of the kind of movement involved. The mass movement classification developed by Sharpe was modified in 1958 by Varnes (1958, p. 20-47). The Varnes classification system is discussed later during the model construction phase of the application of the proposed methodology in Chapter III.

Mnss movement susceptibility is not easy to define. Webster's New Collegiate Dictionary (third edition, 1974) defines susceptible as follows:

"1. Capable of submitting to an action or process or operation. 2. Open, subject, or unresistant to some stimulus. 3. Impressionable or responsive." Based upon the above definition, the author is defining mass movement susceptibility in the following manner:

1. Those portions of the landscape characterized by a set of natural characteristics existing in a stable state which will yield a failure of the material if acted upon by an external or internal triggering event either natural or man-induced.

There are many examples of disastrous mass movements. A disastrous mass movement can be said to have occurred if it takes place or affects an area where man lives or works. These types of events draw public attention and are very costly both in terms of damage and control. The list of mass movements which have caused damage is long and forever increasing. 
Cooke and Doornkamp (1974, p. 128) suggest that one reason for the occurrence of new slides is that man's power to alter a hillside has increased with technological developments, e.g., excavations into the earth are able to go deeper and man-made structures are getting larger. In addition, areas once considered marginal for civil engineering sites are now being developed.

In California, level land is being expended for public facilities and private housing. The result is a shortage of suitable land around cities, forcing consideration for development of sloping land or areas of greater relief with many consequent problems. One of the most serious of these problems is the possibility of landslides. Consequently, interest in landslides has greatly increased. Morton and Streitz (1967, p. 124) underline this interest by concluding that "either natural or man-induced landslides can occur in areas where development is not properly controlled."

The problem is how to acquire mass movement susceptibility data for "proper control." One way would be to contract a consulting firm to complete a detailed mass movement susceptibility or slope instability survey for the planning unit. This is usually not financially feasible. Another method is to attempt to handle the job in-house. This method would most likely be used in small planning offices in areas adjacent to major population centers. Present population within the planning unit may be relatively small, but with increased outmigration from cities, the peripheral areas experience population expansions necessitating "proper control" for urban development. 
My goal is to suggest a methodology for the land-use planner in the situation where, due to the landscape characteristics and the population trend within the planning area, general-level mass movement susceptibility information is needed for input to the planning process. Also, because of budget resfrictions or manpower limitations, it is not possible to employ specialists to gather these data. Map form information will allow landscape areas to be identified which have various levels of susceptibility to specific types of mass movements. By being aware of these areas, certain constraints or restrictions can be placed upon the potential land developer which must be satisfied prior to development. These constraints or restrictions could require the developer to complete a detailed site analysis related to slope stability, they could require certain correction procedures to be followed in order to avoid damage:from a specific type of failure. These maps could also be used in conjunction with other data as a tool for developing zoning maps. They may have application in road construction by flagging potential hazardous areas at the planning stage. These are but a few potential applications.

The methodology is a computer application. Computers are an increasingly important tool in solving land-use problems. Massey (1968, p. i) points out that the problem of the human mind is (1) it cannot remember everything required; and (2) the human memory produces no visible record of its content. Without some type of artificial aids, society would be limited by human ability to remember transactions and their. willingness to trust each other's. honesty. and memories. 
Men and machines must work together. The computer-man relationship

is aptly described by the following quote:

... symbiotic relationship, a relationship in which each can perform the kind of activity for which it is best suited. Man is quite good at inventing and organizing patterns and stripping away irrelevant detail; he is creative, unpredictable, sometimes capricious, sensitive to human values. The computer is almost exactly what man is not. It is capable of paying undivided attention to unlimited detail; it is immune to distraction, precise and reliable; it can carry out the most intricate and lengthy calculation with ease, without a flaw and in much less than a millionth of the time that would be required by its human counterpart. It is emotionless, or so we suppose. It suffers from neither boredom nor fatigue. It needs to be told only once; thereafter it remembers perfectly until it is told to forget, whereupon it forgets instantly and absolutely... (Miller and Nieman, Jr., 1972, p. 4).

The proposed methodology is an application of the computerized Harvard I.M.G.R.I.D. System to provide a land-use planner spatial data depicting landscape areas susceptible to mass movements. 


\section{CHAPTER ॥}

\section{A PROPOSED MASS MOVEMENT SUSCEPTIBILITY \\ DETERMINATION METHODOLOGY}

\section{INTRODUCTION}

The purpose of this methodology is to generate mass movement susceptibility information in a spatial format for utilization in the land use allocation process. The output will be in map form. As stated by Hopps (1969, p. ii),

A map is usually the most effective way to transmit information to most persons. Often a map is the best means of presenting interrelationships vividly and dramatically--especially to the intelligent, concerned, nonmathematically oriented person who needs to know.

In order to generate this map or set of maps depicting mass movement susceptibility for a study area, a computer approach was chosen because of the ease in handling, deriving, manipulating, and displaying large volumes of data. The system that meets these requirements and of which this proposed methodology is an application, is the Harvard I.M.G.R.I.D. (IMGRID) System.

The IMGRID System is used for manipulating information in a grid cell data file and has been developed by David F. Sinton of the Department of Landscape Architecture in the Harvard University Graduate School of Design. Sinton provides the following comments concerning the IMGRID System: 
The IMGRID System is designed to provide a link between a small, highly structured data base with a distinct set of characteristics and persons wishing to use the data base who have no experience in computer programming. The IMGRID System is intended for use by professionals with responsibility for the planning and management of natural resources and land use activities (Sinton, 1975a, p. 5).

In summary, IMGRID is an analysis tool that uses the grid cell as the spatial unit for the input, storage, retrieval, analysis, and output of geographic information. The analysis or data manipulation is accomplished by the application of an overlay technique. These aspects of the system are presented in Appendix A.

Prior to implementing this proposed methodology, the user must determine accessibility to the IMGRID System at a computer facility within a reasonable distance. In most cases, such a facility would be located in either a federal, state, local government agency, or an institution of higher education. The application of the methodology presented in Chapter III was accomplished through the use of IMGRID on the IBM 360 Computer System at Harvard University. When IMGRID is acquired by other organizations which have different hardware systems, the software may require modifications to yield it compatible with varying hardware configurations. This may result with slightly different techniques than will be described for this methodology.

The user should work closely with the staff responsible for IMGRID in the computer facility once an arrangement has been made for them to process the data bank and models. The staff will primarily provide technical assistance as the user is responsible for implementing the methodology. Technical advice may deal with such things as software modifications, coding formats, map symbols, etc. 
The methodology can be described simply in three phases: (I) providing the computer with data acceptable to the machine and software (input); (2) manipulation of the data and storage of map results within the machine's memory (processing); and (3) the retrieval and display of results (output).

The input portion consists of mapped information describing characteristics of a specific geographic area. This is often referred to as the data bank. In order for these data to be accepted by the computer and in turn displayed as a map, they must be available or made available in a form which is compatible with the hardware and software with which the processing will be accomplished. In addition, every possible location on the surface of the map to be prepared must be identified by the computer. The most common approach is to employ an $X$ and $Y$ referencing or coordinate system to which the computer can refer whenever it must identify the location of any one point in relation to all other points on the map (Steinitz et al., 1969, p. 7). The data inventory must translate all data which describes the study area into digital form. The translation should record the basic attributes of the measurement: location, the data element to be measured, and the data item. By using a grid as the spatial locator, the location of a recorded measurement need not be fully reported as it is implied by its relative location in a data file.

Manipulation of the data values can take place once the computer has been supplied with values for a given location. The computer is programmed to perform a multitude of arithmetic and logical operations upon these data via the model structure. Whether the final value mapped is one put into the computer or 
one derived by the computer, the resulting map image is constructed by numbers or other graphic symbols based on coordinate locations.

\section{THE PROPOSED METHODOLOGY}

More detailed aspects of the methodology will now be discussed. The proposed methodology is illustrated graphically by a flow chart (Figure 1).

\section{Phase One}

Assessment of Need. The need of mass movement susceptibility information must be established and documented prior to embarking on a program to generate such data. There are many possible situations which would justify this need.

In Chapter I of this thesis it was pointed out that one justification can be directly related to population increases due to proximity of major urban centers. If developed, areas may experience construction activity involving new road building, increased vehicle traffic, vegetation removal, etc. The existing drainage system may be disrupted. Slopes will be exposed to new geomorphic and anthropomorphic processes. Road cuts could result with the possible upset of slope stability, and so on.

The above comments relate to the effects of development from a non-land use planner. They are offered as potential considerations in justifying the acquisition of mass movement susceptibility information. Several key questions might be asked. How much suitable land for development remains in the planning 


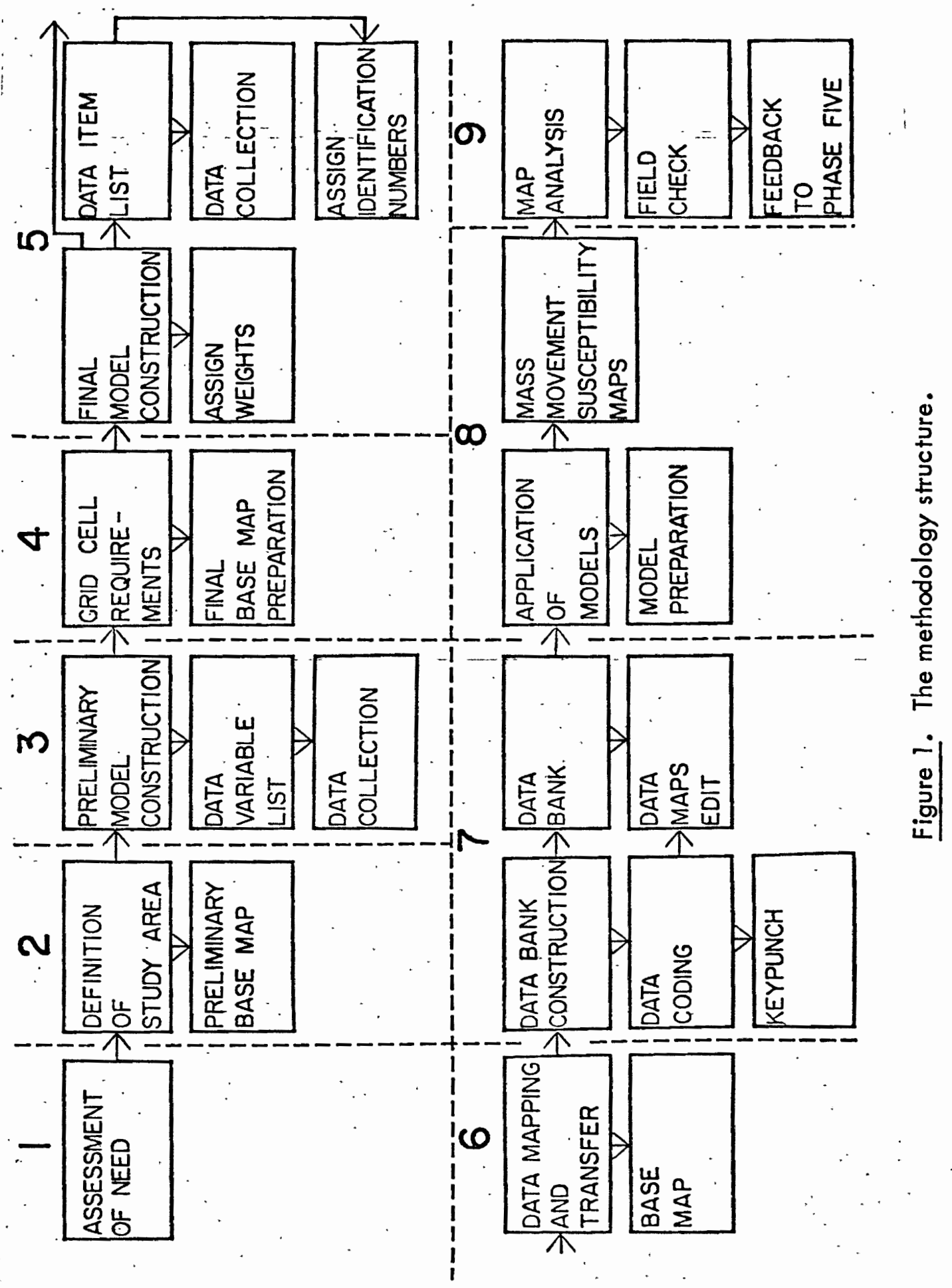


unit? What are the population trends? What are the trends for industrial development?

Once an initial decision has been made as to whether lands evaluated as unsuitable for building sites are going to be considered for development or are already being developed, the planner may desire to collect further evidence to support implementation of this methodology. This evidence could be directly related to mass movements in areas within the planning unit which have experienced logging or highway construction resulting in slope failures.

Phase Two

Definition of Study Area. The study area needs to be delineated for which the methodology will be applied. Ideally, boundaries must be placed around the smallest area which encloses all the data categories and systems which influence the geographical area and natural phenomena being studied. Once this has been done, it is assumed that most data and systems influencing the subject under study are within the area. Political and physiographic boundaries will usually not be as satisfactory as a somewhat arbitrary, larger border (Steinitz et al., 1969, p. 21). Invariably, the need for an all-inclusive geographical boundary must be weighed against the resources available for the study.

Preliminary Base Map Preparation. Once the task of identifying and delineating a study area has been completed it is necessary to select and prepare a preliminary base map. The base map will serve three functions. The most important is as a coordinating framework for data collection. The information which 
will go into the databank will in many cases be available at different scales and forms. As will be discussed in Phase Six of this methodology, this may necessitate the transfer of mapped information at various scales onto a common base map as a step towards grid cell coding. The base map will provide the physical base upon which the study area will be delineated. It is also quite possible that the base map will be used in graphic displays to convey to other members of the planning team and the public, the process that has been followed to generate mass movement susceptibility information. The third function of the base map is to relate information to known features within the study area, such as the transportation system, residential areas, steep slope, etc. Obviously, if these functions are to be fulfilled, the selection of a map base is very important.

A base map will usually be prepared from existing published or unpublished maps. Maps that may be used include County Highway Maps, plat maps, U.S. Geological Survey (USGS) maps, etc. Probably the most useful existing maps for this purpose are the USGS quadrangle maps, $1: 24,000$ or 1:62,500 scale. An advantage of using quadrangles as the base map for the study area is the amount and kind of primary data which may be extracted directly from them such as slope and hydrology. A second advantage is the large amount of data contained which can serve as control points if information needs to be transferred from other map sources. In addition, geographic coordinates in latitude and longitude, Universal Transverse Mercator (UTM) coordinates, and Township/ Range/Section information are depicted. Thus, these coordinate systems would be available as an $X$ and $Y$ referencing system for geographic location if desired. 
The desirability of being able to use these various geographic referencing systems could be to interface the data bank with one already existing built by the local planning organization or some other organization hoving some responsibility for the planning unit.

It is not necessary to do anything to this map once the study area has been delineated since it is primarily for use as a work map.

\section{Phase Three}

Preliminary Model Construction. Two phases of the methodology are dependent upon input from specialists outside of the planning office. These are the phases involved with the construction of the mass movement susceptibility models, this phase and Phase Five. It is at this point that at least two experts in the phenomena of mass movements must be consulted. These specialists should fulfill three requirements: (1) they must be knowledgeable of the geomorphic processes that produce mass movements; (2) they must be somewhat familiar with the physical characteristics of the planning area; and (3) they must be willing to provide assistance.

The models are to be built based on the coincidental occurrence of physical characteristics that if acted upon by a triggering event may cause a failure. They are not intended to determine the probability of a triggering event or of a mass movement but rather to determine the spatial distribution of areas that are susceptible to mass movements based on physical characteristics. 
One of the first decisions that must be made is: How many models should be established? If the purpose has been defined as acquiring information related to areas susceptible to mass movements as compared to areas susceptible to specific kinds of mass movements, then less time will be involved in constructing one general mass movement model. But, the results will be correspondingly general. If the purpose is to acquire information related to areas susceptible to specific types of mass movements, more time will be required but the results will have wider application. This would allow for the development of different "control" or "preventive" requirements for land use based on the expected type of failure. Preventive measures for a slump mass movement will differ from those for an earthflow. Secondly, the latter approach still allows the user to aggregate the results. This means that once each model has been applied to the data bank, the models can be combined to produce one map which delineates the spatial distribution of areas susceptible to mass movements in general. It is suggested that this latter approach be used because the results will allow for better planning decisions. Also, the results will better correspond with the amount of time invesiea in building the data bank.

The first step is to determine which mass movements are most likely to occur in the study area. This is best accomplished by consulting one of the several major classification systems (e.g., Ladd, 1935; Sharpe, 1939; Ward, 1945; Savage, 1951; Varnes, 1958; Jones ef al., 1961; and Hutchinson, 1968) and reviewing the general criteria for each failure included in the classification. The classification systems that have been suggested have been variously based on the kind of 
material, type of movement, causes, and other factors. Terzaghi (1950, p.

has commented on classification systems as follows:

A phenomenon involving such a multitude of combinations between materials and disturbing agents opens unlimited vistas for the classification enthusiast. The result of the classification depends quite obviously on the classifier's opinion regarding the relative importance of the many different as pects of the classified phenomena.

According to Ward (1945, p. 172),

A classification of the types of failure is necessary to the engineer to enable him to distinguish and recognize the different phenomena for purposes of design and also to enable him to take the appropriate remedial or safety measures where necessary. The geographer and geologist need a classification so that they may interpret the past and predict trends of topography as revealed by their observations.

Once one of these classification systems is selected and reviewed it might be found, for example, that the mass movement called rockfall requires areas of exposed bedrock with $55 \%+$ slopes. Knowing that this characteristic never occurs in the study area eliminates the need for building such a model. Once the various potential types of mass movement have been identified, it is most efficient to follow a consistent format so that when the methodology is completed, each model will have a unique booklet to document the process.

The preliminary model construction should establish the intent of each model. For slumping, the intent might be:

.. . to evaluate every grid cell within the study area for its susceptibility to slumping. A slump failure is a sub-category of the movements termed slides. A slide is a movement caused by finite shear failure along one or several surfaces which are visible or whose presence may be reasonably inferred. A slump type slide consists of material in motion which is not greatly deformed. The moving mass may consist of one or a few units. The maximum dimension of units is greater than displacement between units. Movement may be controlled by surfaces of weakness such as faults, bedding planes or 
joints. In a slump, movement is only along internal slip surfaces, which are usually concave upward. Backward tilting of units is common. The evaluation is to be accomplished by considering the coincidental occurrence of specific physical characteristics that have been identified by researchers as characteristic of areas experiencing slump type mass movements.

Data Variable List. The next step is to identify the data variables for which information is needed. The IMGRID System allows for up to twenty variables to be used in each model. This maximum number can be increased in certain situations. The data variables are the physical characteristics the specialists have identified as being important for an area which would experience a mass movement if a triggering event were to occur. Continuing with the example for slump given above: The variables identified as important to this mass movement type are slope, subsoil consistency, precipitation, and profile depth.

In Phase Five, these variables will be further broken down into data items. The preliminary models are completed when this process has been followed for each. The result is a verbal description based on a recognized classification system and a list of data variables that have been identified by experts as important for that mass movement type. The lists of data variables must now be combined into one comprehensive list. This inventory provides the input to the data collection.

Data Collection. Data collection involves the acquisition of data in map form or data which are transformable to map form that provide information for the variables. The data should be at a scale that is acceptable for the level of results desired based on the purpose of the study. The sources will vary depending on 
the location of the planning area. The primary data sources will be state and federal agencies. The result of the data collection should be a map or set of maps or tabular data related to the data variables. A more detailed approach can be taken in Phase Five. The approach taken in this phase might be termed a reconnaissance level collection effort.

\section{Phase Four}

Grid Cell Requirements. Prior to construction of the final base map, a grid cell system must be selected. As indicated at the beginning of this chapter, a grid cell system is a format used to store, retrieve, manipulate, analyze, and display data by the use of uniform modular cells. These modular cells can be of any uniform shape; however, the square or rectangular shaped grid cell is most commonly used. The IMGRID System works best with a square grid cell.

The grid system is basically a row-column geographic reference system covering the entire study area. Often, a system based on geographic latitude and longitude or UTM coordinates is used. It should be noted that if a cell system based on latitude and longitude increments is implemented the cell will be trapazoidal in shape varying in size in a north and south direction, whereas, using the UTM system the cell will be square and of constant size. The system selected may be one that will allow interface of the data bank with that of some other agencies already in existence. It is not necessary to use any existing recognized coordinate system as the basis for the grid system. An arbitrary one 
can be set up if desired. Whatever system is used, the study area boundaries may require adjustment so they coincide with the grid cell system boundaries.

Having selected a grid coordinate system for geographic referencing, the next decision is the size of the grid cell. The three important factors in this determination are the size and scale of the available data, the scale requirements of the analysis to which the data are to be applied, and the time and energy which can be allocated for coding.

In order to determine the appropriate cell size that should be used, the rule of "least common denominator" is often employed. According to this rule, the best cell size would be that which most adequately captures the scale and texture of the individual data sources while losing the least amount of necessary detail in the process.

The scale of the decisions required of the analysis is directly related to the choice of the grid cell size. For example, if the results are directed toward location of land use allocations of five acres in size, it would be advantageous to have the data for site analysis at that scale or finer. This consideration, however, is one which varies according to various analysis tasks.

The cell size is then evaluated for its practical efficiency in data handling. There is a necessary compromise in choosing between a small or large data unit. When the data unit is small, the "natural" borders of larger data boundaries can be more closely approximated. 
Time is also a consideration. The smaller the cell size the greater the number of cells that will constitute an area and the greater the amount of time spent during the coding phase.

In summary, there are no set rules for selecting a grid cell size. Modifications must be made and flexibility is required to select a grid cell size appropriate for the purpose of the study and the amount of data, time and energy available. Sacrifices will probably have to be made. The end result must be logical and, in fact, be a "least common denominator" for the three considerations discussed above.

Once the grid coordinate and cell size decisions have been made and determined to be reasonable, the grid cell system must be placed on the base map. The grid cells need not be numbered to be interpreted by the IMGRID System. The coding format to be discussed later will make this clear. For purposes of organizing the various stages, interpreting and analyzing the results, it is convenient to establish an $X$ and $Y$ referencing number system. Probably the most logical and convenient to use is a reference system based on row/column position. If the study area was rectangular, as in the application in Chapter III, the cell in the southwest corner would be row one, column one. The adjacent cell to the east would be row one, column two, and so on. If the study area is irregular shaped, the longest row and longest column must be identified. The reference system would still begin as in a rectangular shaped study area with the maximum $X$ and $Y$ values corresponding to the maximum row and column lengths. But only 
cells within the irregular shaped study area would be considered. Cells outside of the area are rejected using an IMGRID keyword command.

Final Base Map Preparation. The final map is the base map selected in Phase Two with the grid system placed upon it with any boundary adjustments already made. It is important to decide whether the base map is to be reproducible. Many factors will contribute to this decision. If a large number of data sources is going to be used at varying scales, they somehow have to be organized according to the grid cell system.

This can be handled in two ways. One method would be to transfer all sets of data onto copies of the base map containing the grid cell system. The second procedure would be to produce griri seflicverlays at the various scales of the sources of data. The coding would be accomplished by laying the appropriate scale overlay on the source map and coding directly. The method used will depend upon the availability of accurate techniques for transferring data from one scale to another, source maps variability and the cost involved for developing a reproducible base map with the grid cell system on it. This cost will vary according to the size of the selected base map. Another consideration is the grid cell size. They should not be so small at the various scales that the information cannot be coded accurately (see Phase Seven). The second method may appear to be a viable alternative. Certain characteristics of the source maps must be considered with that approach. For example, are the map projections compatible? That is, will unacceptable error be introduced if the grid cell system cannot be translated into a coordinate system on the source map? And, as previously mentioned, will 
the grid cell size at small scales be practical? The most important consideration in whatever approach is chosen, is for the grid cells on one map to correspond exactly with grid cells on another source map.

The best approach would be a reproducible base map as this would make the coding in Phase Seven much easier and create less problems.

\section{Phase Five}

Final Model Construction. Phase Five involves reviewing the preliminary models and data, identifying specific data items within the variables as relevant to the mass movement type, assigning relative weighting factors, making modifications, and any additional data collection.

Data Item List and Data Collection. The specialists should now be consulted a second time. They will review the preliminary models and the data collected to determine the adequacy of the data sources. This can be decided once the data variables are subdivided into specific characteristics or data items important to the mass movement model. An example follows.

For slumping it was determined that slope, subsoil consistency, precipitation, and profile depth are important data variables for the susceptibility of an area to a slump mass movement. The slope information collected divides slope into seven classes. Each of these would become a data item. The specialists would determine whether these slope classes can adequately provide the proper information to the model. If the slope data is insufficient, additional data collection is necessary. If the data are still not available, the model will have to 
be modified, combined with a similar one, or eliminated. Although it may be determined that only two slope classes are important for slumps, information must be available for the remaining slope classes. The data list may include items not used in the models. However, this information should be collected and coded as it may be relevant for other applications.

The models are nearly complete. The data list should be added to the preliminary model description in a similar manner as in the case of the data variables.

Assign Identification Numbers. Data items should be assigned identification numbers ranging from zero through nineteen. Data item numbers are unique within each variable. Thus, percent slope might be variable number 01 with the following data items: $00=0-3 \% ; 01=3-8 \% ; 02=8-15 \% ; 03=15-30 \%$; $04=30-50 \% ; 05=50-65 \% ; 06=65 \%+$. Precipitation may be variable number 04 with the following data items: $00=00-80^{\prime \prime} ; 01=81-100 "$; and $02=100^{\prime \prime}+$. The reason for assigning identity numbers is that the computer deals with numeric or digital data only. Data are being translated into numeric language.

Assign Weights. The data variables within each model must be weighted as to their relative importance to that particular model. If a variable is important to several of the models, its relative importance may vary from model to model. The normal range of these weights is 1.0 through 10.0 , although higher weights are acceptable. A similar process must be followed for the data items for each variable within the model. These relative weightings must be on a zero 
to nine scale. The process should be completed according to the correct format (Figure 2).

You will note that, in Figure 2, the variable numbers are on the vertical scale. The data item numbers are on the horizontal scale. For this particular model, slump, it was determined that slope and precipitation were each twice as important as subsoil consistency and profile depth. These weightings are in the far right column. Beneath the data item numbers in the columns are the relative weightings for each data item on a zero to nine scale. A weighting of nine is higher than a weighting of three. If the particular item is not relevant to the model the weighting is zero, the same for nonexistent data items.

This format sheet should be prepared for each model and cudded to the preliminary model sheets. This completes the models. There is a feedback loop in the methodology from the field check phase that allows for the weightings to be manipulated for a best fit of known mass movements.

Phase Six

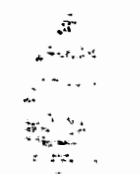

Data Mapping and Transfer on to Base Map. This phase involves preparation for the data bank step. The data that are to be used in the models must be prepared or transformed into a computer compatible format. The first step is to transfer the information from the collected maps onto the base maps which contain the grid cell system. This will result with all the data source maps "converted" to the same scale as the base map which contains the grid cells. The alternative, as mentioned previously, is to build grid cell overlays for the 
桌

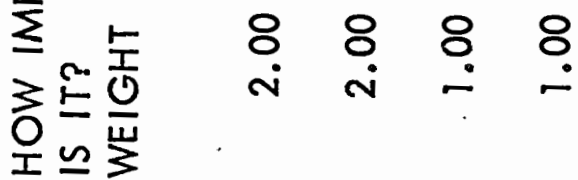

옹

$$
\begin{aligned}
& \begin{array}{lllll}
\infty & 0 & 0 & 0 & 0 \\
\infty & 0 & 0 & 0 & 0
\end{array} \\
& \text { त } 0000 \\
& \therefore 00000 \\
& \text { n } 000000 \\
& \begin{array}{llllllllllllll}
1 & 0 & 0 & 0 & 0
\end{array} \\
& \begin{array}{lllll}
m & 0 & 0 & 0 & 0
\end{array} \\
& \text { I } 00000 \\
& =00000 \\
& \text { ‥ 으인 } 0000 \\
& \text { 5月 } 000000 \\
& Z_{\infty} \quad 0 \quad 0000 \\
& \text { Ỗ } \\
& \text { In a } 000 \\
& \begin{array}{lllll} 
& 0 & 0 & 0 & a
\end{array}
\end{aligned}
$$

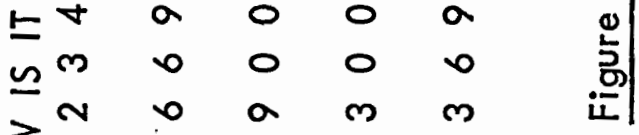

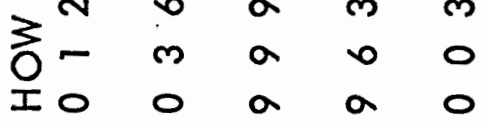


various data source maps at their respective scales. This will essentially transform the data to the same scale via the grid cell system. The danger is that the coding may be inaccurate due to the cells being too small to interpret within or errors due to map projection differences.

Once all the maps have been transferred to the same scale as the base map, the coding phase can be started.

\section{Phase Seven}

Data Bank Construction. The data that have been prepared in the previous phase must be translated into a format compatible to the computer hardware and the IMGRID software. The computer must be able to identify every possible location on the surface of the maps in order for it to accept the map for storage, retrieval, manipulation, analysis, and for display of the results. As previously mentioned, the IMGRID System does this by utilizing the grid-cell system which has been placed on the base map in Phase Four. Each cell is a unique geographic spatial unit for which must be indicated the existence of the data items. This is done through coding.

Data Coding. Coding involves extracting the information on a cell by cell basis from the base maps or the original source maps (with grid cell overlays) and placing a coded value on a computer keypunch card worksheet. Eventually, these values will be recorded on a keypunch card, magnetic tape or disk in a row and column position corresponding with the grid cell the phenomena occupy. 
There are several ways the data maps can be converted or coded into a computer compatible format for the IMGRID System. One way would be to use a digitizing system. Digitizing hardware allows for the recording of points, lines, or areas in an $X$ and $Y$ machine coordinate referencing system onto keypunch cards, magnetic tape, or disk. In this case, the hardware would record the boundaries of various map units or point phenomena. Computer software would transform this digitized information from machine coordinates into geographic coordinates (or some other $X$ and $Y$ referencing coordinate system) and output the data as frequency, linear distance, or area of cell, whichever would be appropriate.

Digitizing systems can be broken down into two general types: manual and automatic. The manual type requires an operator to guide a free-moving cursor over the points or lines to be digitized. Many state and federal agencies and some private organizations have a manual digitizing system. An automatic system, such as a scanning process, will scan and digitize a map in a matter of seconds. This type of system is relatively new in the United States. Both types of digitizing systems may be too costly to be feasible for use. It must be remembered that no matter which one of these two is used, software must be available to manipulate the digitized data into a format compatible to the IMGRID programs. Therefore, the technique recommended in this methodology is to manually code the data without assistance from a mechanical digitizing device. 
There are several types of coding, each of which has inherent advantages and disadvantages. The types are percent or percentile, predominant, "presence or absence," frequency, and linear.

Percentile coding is the percentage of a cell occupied by the particular data item of a variable. For example, hypothetical cell number 1015 is spatially occupied by $20 \%$ of silty loam soil (data item 72 ), $37 \%$ clay loam (data item 77 ), and $43 \%$ silty clay soil (data item 70 ). The total is equal to unity or 100 percent. Converting this to its numeric coded form would mean that cell 1015 is occupied by $20 \% 72,37 \% 77$, and $43 \% 70$. Percentile coding has the advantage of being detailed for the basic spatial unit of analysis, the grid cell. If needed, the percent can be divided even further to reflect subdivisions of a percent such as tenths or hundredths of a percent. In the opposite direction, the percentile coding can be adjusted to the nearest $5 \%$ or $10 \%$. If coding to the nearest $10 \%$, the numeric coding for cell 1015 would be as follows: $20 \% 72 ; 40 \% 77$, and $40 \% 70$. The total is equal to 100 percent. This allows for the "generalness" or inexactness of some data to be adjusted or taken into consideration through the coding process.

The disadvantage. of percentile coding is that the spatial unit of resolution for the data is the grid cell. Thus, even though the data have been coded by percent of cell, the location within the cell of the coded data is not known to the computer. All the computer knows is that a certain percent of that cell is occupied by the phenomena. Since IMGRID is an overlay technique the map units that are overlayed on each other may not necessarily coincide resulting 
with inaccurate products. For example, if a slope class of $55 \%+$ occurs with soil type 77 , an unstable condition may exist. But since the computer does not know if the two phenomena coincide within a cell (coded as two separate variables, slope and soils) the result of an overlay would be that the smallest percent for the two items would be the percent of the cell recorded as unstable. Thus, the results can be very ambiguous. This is an important weakness of the grid cell -system of analysis. The second disadvantage of this coding technique is the time and energy necessary to code the data. This type is the most time consuming.

There are several considerations in determining whether percent coding should be used. If the purpose of the cell is to provide information with a very high spatial resolution, nearest percent or finer coding may be utilized providing the data sources are at a scale to match the detailed resolution. The grid cell should also be of a corresponding size. There would be no purpose in going to a fine level if the grid cells are extremely large and the data sources are very general. If the data sources are of a general nature, the boundaries of the data delineations are probably not very exact. In addition, some data are by their nature of a general scale, e.g., vegetation groups. The topographic information contained on USGS quadrangles is subject to certain standards of accuracy. By coding beyond the indicated accuracy level you will be investing extra time for results that could be obtainable using a less time-consuming coding procedure more compatible with the data source.

The second type of coding is the predominant or dominant type. In the dominant coding type, cell 1015 would receive the value of 100 percent soil 
type 70. The phenomena that occupy the largest percent of the cell are stored as 100 percent for the spatial unit. Obviously, this is a generalization of the data. The advantage is time. It is much less time-consuming to use this technique. No longer is the location of the phenomena a problem. Basically, time has been saved but the same disadvantage is present whether the percent or dominant coding is used. Data will be lost since other phenomena present will not be stored at all for the cell. This is an additional sacrifice. Using time as the deciding factor, dominant coding would be best. The results will be iust as ambigvous as with percentile coding.

The third type of coding is "presence or absence." This is extremely general. If the data item is present a one (1) is stored for the data item; if absent a zero $(0)$. This method should only be considered when the data are very general or need to be generalized.

Frequency coding is directed toward frequency of occurrence per cell of point phenomena. The value recorded and stored for a cell is the summation of occurrences of the data item. Linear coding is applied to linear features such as streams and transportation networks.

As previously stated, the methodology being proposed by this thesis is of a general nature. The purpose of the methodology is most compatible with the dominant type of coding. As noted, this coding method is also the most time efficient. Utilizing this method may also allow for analyzing a larger study area or decreasing the cell size with a corresponding increase in the number of cells. Frequency and linear type coding could be used where appropriate. 
The coding process involves the interpretation of cells and recording the results on a keypunch worksheet. The coding form is eighty columns across which is the number of columns contained on a computer keypunch card. The rows and columns are equated to cells. For example, row one, column one is the southwest corner grid cell if a single digit is to be recorded. If a data variable contains ten data items or less, the appropriate identification number zero through nine (zero equal to the first item, one to the second, and so on) can be recorded in the row and column corresponding to the cell. If more than ten data items are being interpreted, two columns can be used for each cell. Thus, the identification number for the data item occupying the majority of the cell is entered on a worksheet in the row and column corresponding to the correct grid cell. This process is followed until all the data have been coded for the study area map. The aspect of coding is discussed in more detail in Chapter III.

Keypunch. Once the data have been coded from the base maps onto the computer keypunch worksheets, the next step is to have the worksheets keypunched. Any additional card identifiers to be punched will be determined by the IMGRID staff at the computer facility. The result of the keypunching will be one deck of cards per variable. These decks are called the data bank and each individually is termed a data deck.

Data Bank. Technically, the data decks are the data bank. Realistically, as far as the proposed methodology is concerned, the data bank exists once the decks have been entered into the computer system using the appropriate IMGRID keywords. This would be accomplished at the computer facility. 
Once the data bank has been received by the institution it will be checked to insure that the data are in the proper format. If it is found to be in a different format than required, it is a minor process for a programmer to write a small program to reformat it. The data bank will then be entered into the computer system via IMGRID keyword commands. The various IMGRID keywords are discussed in Appendix A.

Data Map Edit. One of the first sets of output from the bank will be the computer data maps. It will be up to the user to edit these maps. There are a number of ways this can be approached. The first step might be to visually review the various patterns portrayed. If a linear pattern exists on a data map that is supposed to be polygon pattern data only, the user should check the base map for the corresponding position. If it is a mistake, extract the incorrect card from the data deck, make the correction, and resubmit it. The second step might be to randomly select a few cells and match them up to the original base map that they were coded from. There are a number of ways this editing can be done. There should be no difficulty as it is a straightforward procedure.

\section{Phase Eight}

Application of Models and Model Preparation. All that is required of the user in this phase is to furnish the model sheets created in Phase Five to the computer facility having IMGRID. The data bank is now in a form that can be manipulated. The model sheets must be keypunched into the IMGRID format and applied to the data bank utilizing the appropriate keyword commands or subroutines. 
Basically, applying the models to the data bank is an overlay technique using the weightings. This method combines various weighted data maps by superimposing two or more on top of another and summing. This procedure is described in more detail in the next section. Since all data used in the data bank have essentially been transformed to the same scale through the base map, coding, and a common gr id cell system, overlaying the maps is not a problem.

Mass Movement Susceptibility Maps. The output from this procedure consists of one map for each model. Each symbol on the computer map represents one cell. Most computer facilities will use rectangular shaped symbol sets. In the border of each of the maps are sets of three digit numbers along the horizontal and vertical edges. These are the row and column numbers. The numbers along the top and bottom are read from top to bottom beginning on the left side of the map going to the right. Thus each cell may be identified by a unique pair of coordinates. For example, the cell in the upper right hand corner of a sixty-four row by eighty column study area would be labeled 064,080 , or referred to as row 64 , column 80 .

Below the computer map will be text specified by the user. This could include the name of the study area along with the title of the study or application. The remaining text is standard and is not user specified. It consists of the legend portraying the mapping symbols used for each of the ten equal-interval mapping classes. These classes are equated to relative levels of susceptibility. Most often, the symbol set used is a gray-scale. That is the convention or standard approach. The darker the symbol on the map the more susceptible the cell 
will be for that particular mass movement. Below each mapping class in the legend is a figure which represents the frequency of occurrence of the symbol or the number of cells that fell into that class.

Statistical output, besides frequeric $\ddot{y}$, includes the minimum and maximum values or the range of values following manipulation of the data based on the weightings and the model structure. The standard is to output these manipulated values in ten classes of equal class interval ranges. Thus the value range is divided into ten classes and the cell values assigned to their appropriate classes. An example will follow. In addition, the mean and standard deviation of the values are calculated and printed out.

In the application described in the next chapter, the mass movement model for debris avalanche uses four data variables: slope, precipitation, subsoil structure, and parent material. The mass movement susceptibility map for this model is contained in Appendix B. The four data variable maps are contained in Appendix C. The statistical output is portrayed in Figure 3. It can be determined from this output that the minimum and maximum values for the weighted and combined data variables were 165.00 and 435.00 . The range of these manipulated values was, therefore, $270(435.00-165.00)$. By dividing this range into ten equal classes the class interval becomes 27.00 . The class boundaries or limits are provided. The first class has a lower limit of 165.00 and an upper limit of 192.00, the second class 192.00 and 219.00 , etc. By working through the model structure it can be shown how the value and the final map display were determined. The northwest corner cell, referenced as row 64 , column 01 , is mapped on the mass 


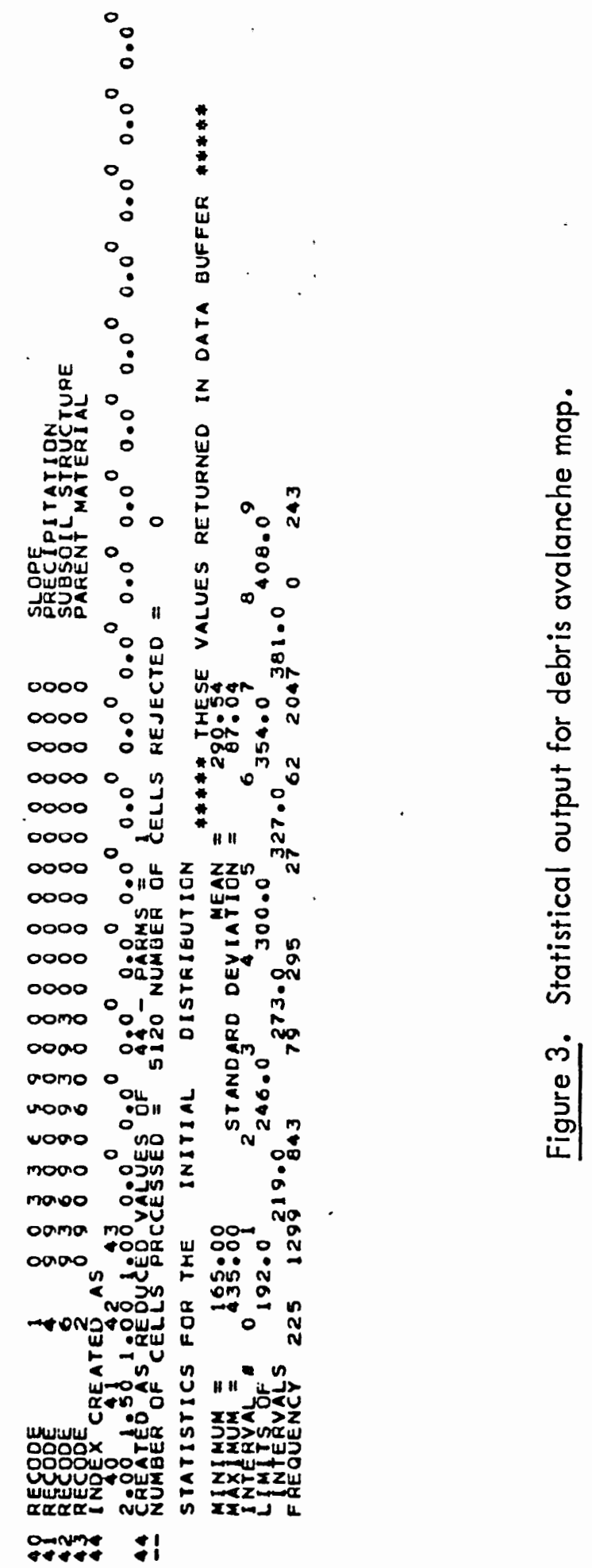


movement susceptibility map for debris avalanche in the second mapping class using a small circle symbol. Referring to the data maps in Appendix $\mathrm{C}$ and the data item and the variable weights (in Figure 3), it can be determined that this cell has a slope of $3-8 \%$, experiences a maximum precipitation of approximately 99 inches, and its soil has a singular grain subsoil structure with a glacial outwash parent material. Respectively, these characteristics or data items received weightings of zero, nine, six, and zero. This means that for this cell, the value was determined based on precipitation and the subsoil structure. These two data variables were weighted 1.50 and 1.00 . The INDEX keyword in IMGRID is used to combine these variables. The first step is to multiply the variable weightings by a factor of ten. The result is 15 and 10 . The second step is to multiply these manipulated variable weightings by the data item weightings and sum. Thus, the computations become $(15 \times 3)+(10 \times 6)=195$. The value 195 falls into the second class on the debris avalanche legend, ranging from 192.00 to 219.00 . The mapping symbol for that class is a small circle. This process has been followed for each cell in the study area and for each model.

Further analysis of the maps will be described in the last phase, Phase Nine.

Phase Nine

Map Analysis and Field Check. An important step in the map analysis is to develop a clear picture of the relationship between the computer map and the study area. This can be accomplished in several ways. The easiest way would 
be to build a clear acetate overlay of significant physical and cultural features that can overlay onto the computer map. This allows the interpreter to relate the grid cells to known ground features. Another technique is more difficult depending on whether the print chain of the symbol set of the line printer that generated the computer maps was rectangular shaped or square. If it was square, the maps can be photographically reduced or enlarged to fit the USGS topographic quadrangle maps covering the study area and directly overlayed. If it was rectangular, this would be impossible unless rectangular shaped grid cells were used in proportions to the rectangular shape of the symbol dimensions. Once a better understanding of the relationship between the computer map and the study area has been gained, the user is ready to focus attention on the phenomenon itself, i.e., mass movement susceptibility.

A key to interpreting and analyzing the model maps is to remember that the model is structured to identify cells as susceptible when, first, the important variables are present, and secondly and most importantly, when specific data items within those variables occur coincidentally. Regardless of whether all the important variables (those that have a weight) occur or all the important data items (as reflected by a non-zero weight) occur; a value for every cell will be calculated. Thus, the first step to interpreting and analyzing the model maps is to determine which map classes actually reflect the presence of a weighted data item from each variable with none dropped out. This determination can be accomplished simply by selecting a cell from each of the map classes beginning with the highest (the darkest symbol) and computing the actual cell value 
following the process described in the previous phase. There will be some cell value for which one or more of the important data items were not utilized. The mapping class in which this value falls will become a threshold for which all mapping classes above it are significant. In the example of debris avalanches this threshold occurs in elass five. Thus, classes six through nine are the only ones relevant to debris avalanche mass movement susceptibility. Within those four classes, nine is obviously more susceptible to a debris avalanche than six due to the various weighting factors utilized. This threshold may be different for other models.

The process outlined above will also verify whether or not the models have been executed properly when applied to the data bank. If the results are accurate, the models as given by the experts have been verified. Remember also, the results may be no susceptibility if the criteria are not found. The methodology is designed so the user can rely heavily on the models as "givens." Any further verification is difficult. This will be discussed later in this section.

A final step in the map analysis is to determine whether the results are reasonable. How well do they fit known data? One way to determine this is to relate some known existing mass movements to the cells. This may be difficult due to the nature of some of the various failure types. If the known failures occur in cells that have been identified as highly susceptible, the results are probably reasonable. If not, the various weights may need to be adjusted and the model rerun to try to fit the computer map to the known failure(s). If in the previous example of debris avalanches the known failure occurred in a cell that was 
mapped in class eight or below but should be mapped in a higher class, the weight(s) of the variable(s) could be raised. This will raise the cell value up to the desired level. This is obviously a very subjective approach.

Another way to assess reasonableness is to subjectively ask: Are the areas - mapped in the various classes too large? or too small? Based on intuition, do they seem reasonable? At this level of application, without further in-depth research, this is the extent of analysis a user can expect.

The probability or actual occurrence of a mass movement is difficult to assess due to the complexity of the phenomenon itself. The normal approach is to conduct extensive field surveys, laboratory testing, collection of soil and rock samples, and application of highly complex mathematical formulae. The verification of susceptibility is probably even more difficult and complex. The approach taken in this methodology has essentially been to classify an inventory of physical characteristics according to the coincidental occurrence of various combinations. These combinations are the models representing the various mass movement types. The characteristics have then been weighted to allow levels of importance to be considered in the susceptibility of an area for a failure. As such, this approach is different from the more objective processes followed in detailed surveys. If further verification of the process is desired, one approach might be to field check selected cells out of the highest susceptibility mapping class. The assumption being, that if a cell is highly susceptible to a mass movement, there should be observable evidence within the cell. It is not the purpose of this description of the methodology to go into detail concerning this particular 
approach, but briefly, observable evidence could be old mass movement scars, hummocky surface appearance, disturbed drainage, old landslide deposits, etc. The difficulty is that evidence for some mass movement types is more observable than for other types. 


\section{APPLICATION OF METHODOLOGY}

\section{INTRODUCTION}

A description of the proposed methodology has now been given. This chapter describes how the methodology has been applied to a small study area in Southwest Washington. Basically, this application is a demonstration of how one mechanically follows the methodology from beginning to end. There are certain restrictions in the application inherent in a student situation. A real situation was not feasible since no means were available to solicit professional expertise as described in Phases Three and Five. This leaves these phases in the application open to criticism. They have been based on literature survey and on input from John Beaulieu (1975), Oregon State Department of Geology and Mineral Industries. Thus, the results of this application are intended as an example of a product from the methodology and not to be construed as entirely realistic. The results are, however, probably quite reasonable for this level of application since they are based on input from published research and the personal experience of Mr. Beaulieu. The remainder of this chapter is an application of the proposed methodology. 


\section{APPLICATION}

\section{Phase One}

Assessment of Need. Hypothetically, an assessment of need can be suggested. The "planning unit" is located within fifteen miles of Olympia, Washington. Olympia, and the nearby cities of Centralia and Chehalis, have experienced population increases during the past two decades. It appears that this trend will continue. Agricultural land and grasslands in adjacent areas are rapidly being developed for housing, particularly the Mound Prairie area. Once these areas have been "urbanized, " development will take place on the upland areas. In addition to cultural and urban pressures on land uses, the area experiences an abundant annual precipitation, most of which falls between October and June in the form of rain. Sedimentary geologic strata underlie a portion of the study area. These two physical attributes, high precipitation and sedimentary bedrock in coincidence with cultural and urban pressures on the land have necessitated the acquisition of mass movement susceptibility information for input to the planning process. Remember, this is a hypothetical situation.

\section{Phase Two}

Definition of Study Area. The study area or "planning unit" selected is an area in the southwest portion of Thurston County, Washington. The area is approximately eight miles wide and ten miles in length covering eighty square miles. It is rectangular in shape. It does not necessarily enclose all the various natural systems impinging upon it since this would have resulted with a larger 
area and a corresponding increase in the amount of time to complete the methodology. Time and energy are legitimate considerations for the delineation of a study area by a user and may necessitate trade-offs such as a smaller size study area. The town of Tenino is located in the northeast corner. The smaller town of Bucoda is located about four or five miles south of Tenino. The Interstate Highway 5 traverses in a north and south direction through the western half of the area paralleled by a railroad track. State Highway 507 serves both Tenino and Bucoda. A secondary road serves Gand Mound, a small hamlet on the western study area boundary, and Tenino. This road follows a fairly straight route through Mound Prairie which is a natural grassland up to three miles in width in the study area. Scatter Creek flows through this grassland area. The Skookumchuck River flows in a southerly direction across the southeast corner near Bucoda.

Preliminary Base Map Preparation. Several different map scales and bases were considered for the preliminary base map. It was previously noted that the primary purpose of the base map is to organize the data. The final choice for the base was the USGS Tenino and Rochester 15' quadrangles, 1:62,500 scale, with 40' contour intervals (Figure 4). These maps, as do all the USGS quadrangle maps, contain a vast amount of information including transportation and cultural features as well as physical features such as forested areas and hydrological phenomena. 


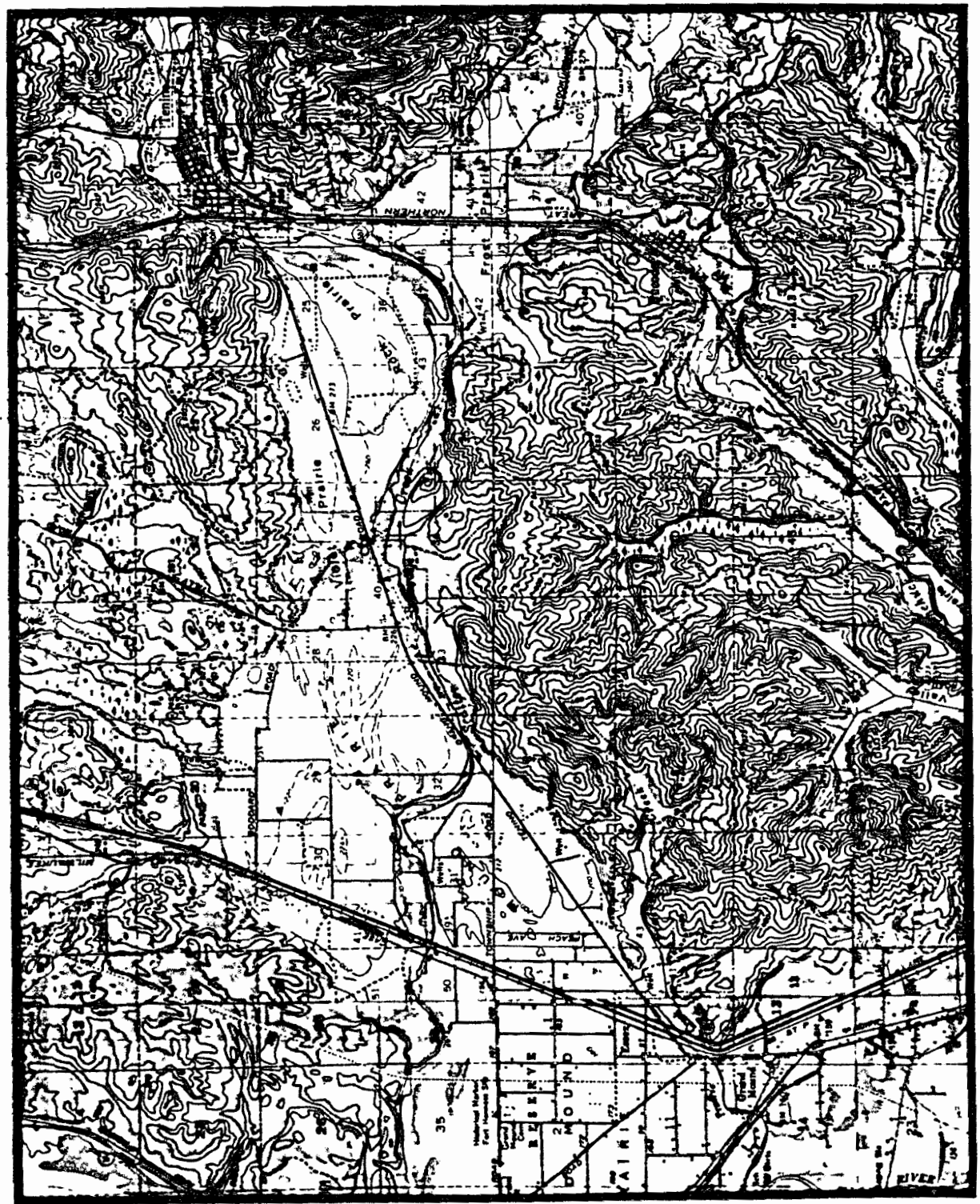

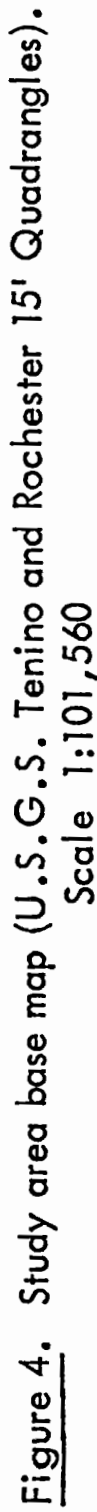


Phase Three

Preliminary Model Construction. The suggested procedure in this phase of the proposed methodology is to solicit professional input from several experts on the phenomena of mass movements. As explained earlier, it was not feasible to adhere to this approach. Instead, an extensive literature review was undertaken, the purpose of which was to extract general information related to the causes of mass movements. In addition, a geologist with the Oregon State Department of Geology and Mineral Industries, Mr. John Beaulieu (1975), was consulted. Mr. Beaulieu provided valuable data related to the construction of the models based on his investigations of mass movements in Oregon during the past several years.

In order to determine which mass movements to model, the mass movement classification developed by Varnes (1958, pp. 20-47) has been utilized.

Varnes' classification system is directed toward factors that have some bearing on prevention or control (Varnes, 1958, p. 20). Two main variables were considered: (1) the type of material involved according to its state prior to initial movement and (2) the type of movement involved. Materials were classified into bedrock and soils. Soils are defined in the engineering sense and include clastic material, rock fragments, sheared or weathered bedrock, and organic matter. Material was further classified according to its state prior to initial movement. Types of movement are divided into three major groups: falls, slides, and flows. 
The mass movement types expected to occur in the study area can now be defined in a preliminary format. This should be considered a work guide. The pages that follow contain the preliminary descriptions of the various models including a definition and factors relevant to conditions associated with their occurrence. The definitions were derived from Varnes (1.958, pp. 20-47) while the factors resulted from the literature review and communication with John Beaulieu (1975).

(1) Mass movement susceptibility model no. 1; rock movement: flow, slide, or fall. This failure involves material in motion which may travel through the air by free falling, moving by leaps and bounds, and rolling. It involves material which appears to move as a mass, similar to a viscous fluid or it may be a movement caused by finite shear failure along one or several surfaces which are visible or whose presence may be reasonably inferred. This failure consists of predominantly bedrock material. Slope, parent material, precipitation, subsoil structure, and substratum are identified as important variables in the occurrence of this movement.

(2) Mass movement susceptibility model no. 2; falls: soil fall. Falls are mass movements involving a mass in motion which travels most of the distance through the air. This travel includes free fall, movement by leaps and bounds, and rolling of rock and debris fragments without much interaction of one fragment with another. This failure involves the fall of soil material. Soil material is defined as clastic material, including rock fragments, sheared bedrock, organic material, etc. The variables identified as being important for the occurrence of 
this failure are slope, subsoil structure, precipitation, position on the landscape, and profile depth.

(3) Mass movement susceptibility model no. 3; slides: slump. A slide is a movement caused by finite shear failure along one or several surfaces which are visible or whose presence may be reasonably inferred. A slump type slide consists of material in motion which is not greatly deformed. The moving mass may consist of one or a few units. The maximum dimension of units is greater than displacement between units. Movement may be controlled by surfaces of weakness such as faults, bedding planes or joints. In a slump, movement is only along internal slip surfaces, which are usually concave upward. Backward tilting of units is common. The variables identified as important to this mass movement type are slope, subsoil consistency, precipitation, and profile depth.

(4) Mass movement susceptibility model no. 4; slides: block glide. A slide is a movement caused by finite shear failure along one or several surfaces which are visible or whose presence may be reasonably inferred. A block glide slide involves material which is not greatly deformed. The moving mass consists of one or a few units. The maximum dimension of units is greater than displacement between units. Movement may be controlled by surfaces of weakness such as faults, bedding planes or joints. In a block glide, movement of a single unit is out and down along a more or less planar surface of weakness, generally a bedding plane. A block may glide far out on an original ground surface. Variables that have been determined important to this mass movement type are slope, subsoil 
structure, precipitation, parent material, substratum, and load carrying capacity.

(5) Mass movement susceptibility model no. 5; slides: debris slide. A slide is a movement caused by finite shear failure along one or several surfaces which are visible or whose presence may be reasonably inferred. The material involved is natural soil and rock detritus that contains a relatively high percentage of coarse fragments. Other features are similar to those of a rock slide. Slope, subsoil consistency, and subsoil texture have been identified as important variables for this mass movement type.

(6) Mass movement susceptibility model no. 6; slides: failure by lateral spreading. A slide is a movement caused by finite shear failure along one or several surfaces which are visible or whose presence may be reasonably inferred. This failure is caused by the spreading of softer material beneath firmer material. Five variables have been determined to be important for this failure to occur: substratum, position on landscape, subsoil texture, available water capacity, and load carrying capacity.

(7) Mass movement susceptibility model no. 7; wetflow: debris avalanche. A flow is a mass movement for which the mass or moving material appears to take a form of a viscous fluid or the apparent distribution of velocities and displacements within the moving mass resemble those of a viscous fluid. Slip surfaces with in the mass are usually not visible or are short lived. The boundary between moving mass and material in place may be sharp or a zone of distributed shear. The material is unconsolidated at the time of flow but may consist of rock 
fragments, fine granular material, mixed debris and water, or plastic clay. A debris avalanche is the rapid failure of an entire mass consisting of natural soil and rock detritus. Generally it is quite wet and moves as a tumbling flow downward, commonly along a stream channel. The variables that have been determined important to this mass movement type are slope, precipitation, subsoil structure, and parent material.

(8) Mass movement susceptibility model no. 8; wetflow: debris flow. A flow is a mass movement for which the mass or moving material appears to take the form of a viscous fluid or the apparent distribution of velocities and displacements within the moving mass resemble those of a viscous fluid. Slip surfaces within the mass are usually not visible or are short lived. The boundary between moving mass and material in place may be sharp or a zone of distributed shear. The material is unconsolidated at the time of flow but may consist of rock fragments, fine granular material, mixed debris and water, or plastic clay. A debris flow involves material that contains a relatively high percentage of coarse fragments and moves as a flow with a high water content. Slope, precipitation, subsoil texture, and substratum have been identified as being important for the occurrence of a debris flow.

(9) Mass movement susceptibility model no, 9; flow: earthflow. A flow is a mass movement for which the mass or moving material appears to take a form of a viscous fluid or the apparent distribution of velocities and displacements within the moving mass resemble those of a viscous fluid. Slip surfaces within the mass are usually not visible or are short lived. The boundary between moving 
mass and material in place may be sharp or a zone of distributed shear. The material is unconsolidated at the time of flow but may consist of rock fragments, fine granular material, mixed debris and water, or plastic clay. An earthflow is slow to very rapid in velocity involving mostly plastic or fine grained nonplastic material. Four variables have been identified with earthflows. They are slope, precipitation, subsoil consistency, and parent material.

Data Variable List. The preliminary models are now outlined. The next step is to compile a data variable list so that data collection can begin. The preliminary data variable list is as follows:

Slope

Parent material

Position on the landscape

Precipitation

Subsoil texture

Subsoil structure

Subsoil consistency

Substratum

Profile depth

Available water capacity

Load carrying capacity

Information is needed for eleven variables. It should be noted that this

list follows automatically from the preliminary model descriptions.

Data Collection. Data collection can now proceed.

Thurston County, in which the study area is located, has been surveyed by the U. S. Department of Agriculture, Soil Conservation Service (SCS). A considerable amount of information is available covering the data variable list. Figure 5 is a soils map, 1:62,500, delineating soil types for the study area. This map is a portion of a study called Type 4: Southwest Washington River Basin 


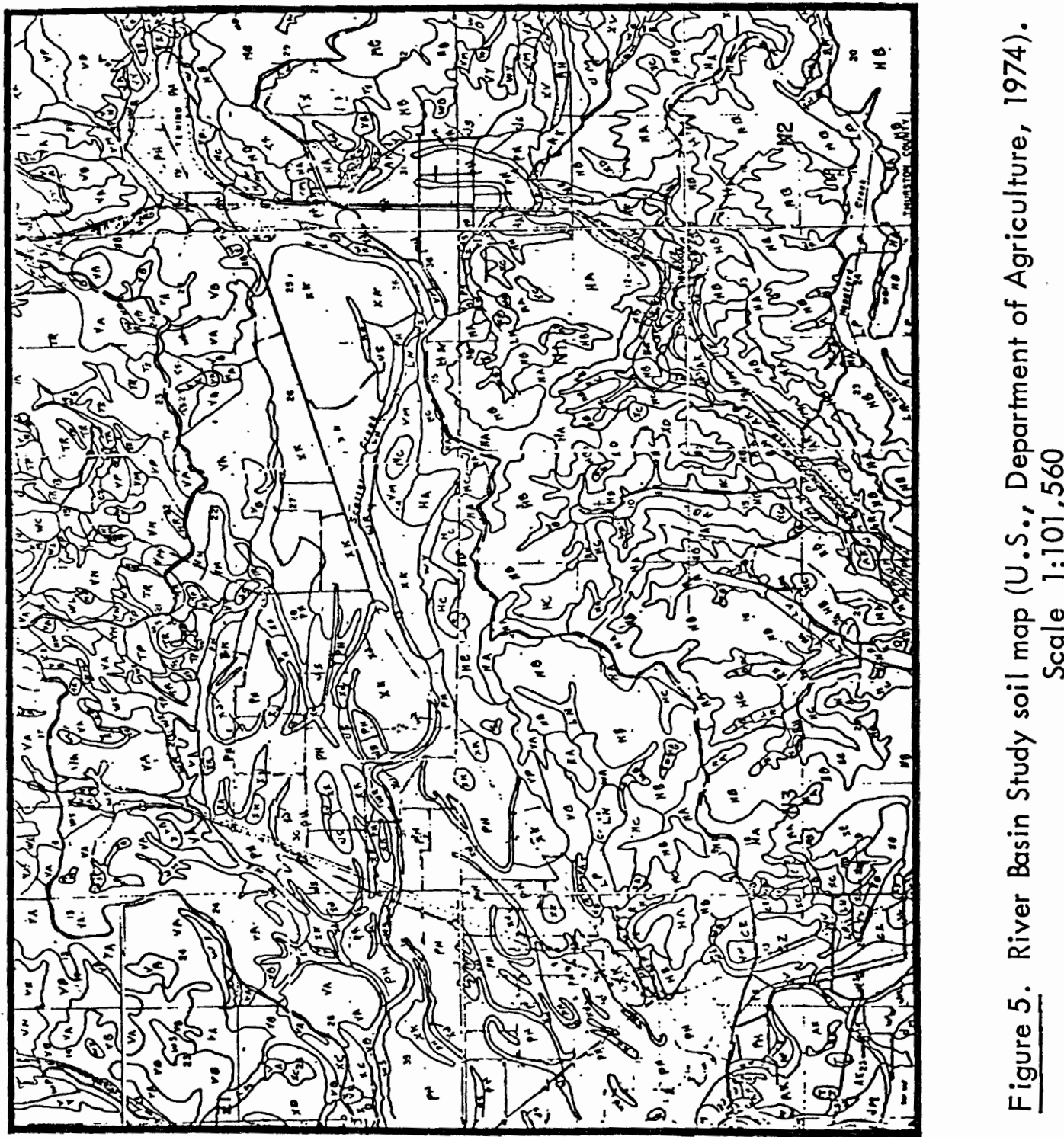


Study completed by the SCS in 1974 for Southwest Washington. Appendix E provides a table of the soil types occurring in the study area and the various attributes associated with each that are needed for the models. After reviewing this information, it appears adequate for this siudy.

The preliminary data collection has been completed.

\section{Phase Four}

Grid Cell Requirements. The first step is the selection of a grid cell system. The one chosen was not based upon an existing coordinate system such as the UTM or geographic latitude/longitude but was arbitrarily selected. The author was not operating under any constraints such as interfacing with an already existing geographic reference system used in a planning process. Situations will differ from one study area to another, however.

The next decision made was: What size should the grid cell be? A square cell of forty acres was selected. It was felt that this cell size would be quite adequate for the available data and the purpose of the application. Given the data source, the cell size could have been smaller. Another consideration was time available. Using a forty acre cell divides the study area into 5,120 cells. This size is a macro or regular cell size. If a micro-cell size was selected of .256 acres there would be 800,000 cells (Tsao, 1975, p. 32). This would significantly increase the coding time. Normally, a micro-cell size (less than .256 acres at $1: 62,500$ scale) is considered when data is to be automatically digitized by a scanner or some other digitizing instrument. 
The forty acre cell size allows for eighty cells across and sixty-four down. The size and shape of the cell did not require adjustment of the study area boundaries. If this had not been the case, the boundaries could easily have been adjusted.

Final Base Map Preparation. There are two possible choices for this step. If a large number of data sources are to be used, at varying map scales, then a reproducible map would be the most efficient method of organizing the data. Since there is only one data source and it is at the same scale as the preliminary base map, it was not necessary to construct a reproducible base map. It was decided that using a grid cell overlay at the base map scale would be adequate for organizing the data into the proper format. Two important factors were considered in this decision: time and finances. Thus, in addition to having only one data source, it was decided that the time and finances needed to generate a reproducible base map were not justified.

The final base map, in this case, becomes the grid cell overlay. The overlay will serve as the mechanism to convert the data to the grid cell system.

Phase Five

Final Model Construction. Normally, in an application the experts would be brought together a second time at this point to review the data sources along with the data variables and to generate a data item list. The review would determine whether adequate information has been located and collected for variables and whether or not the specific data item requirements have been satisfied. 
Data Item List. The data item list for the variables appears in Table I.

TABLE I

DATA ITEM LIST

\begin{tabular}{cccc} 
Variable No. & Variable Name & Data Item No. & Data Ite \\
\hline 01 & Percent slope & 00 & $0-3 \%$ \\
& 01 & $3-8 \%$ \\
& 02 & $8-15 \%$ \\
& 03 & $15-30 \%$ \\
& 04 & $30-50 \%$ \\
& 05 & $50-65 \%$ \\
& 06 & $65 \%+$
\end{tabular}

02

$\begin{array}{lll}\text { Parent material } & 00 & \text { lacustrine } \\ & 01 & \text { sedimentary rock } \\ & 02 & \text { till } \\ & 03 & \text { alluvium } \\ 04 & \text { pumice } \\ & 05 & \text { basic igneous rock } \\ 06 & \text { outwash } \\ 07 & \text { organic } \\ & 08 & \text { aeolian sand }\end{array}$

03

$\begin{array}{ll}\text { Position on the } & 00 \\ \text { landscape } & 01 \\ & 02 \\ & 03 \\ & 04 \\ & 05 \\ & 06 \\ 07 \\ 08 \\ 09 \\ 10 \\ 11 \\ 12\end{array}$

basin

lacustrine basin

bottom land

alluvial fan

alluvial terrace

outwash terrace

06

07

08

09

10

12

till terrace

pumice terrace

loess terrace

lacustrine terrace

outwash plain

basic igneous upland

sedimentary upland

04

Precipitation

00

low $=00-79 " 1$

01

moderate $=00-99 "$

02

high $=00-100^{\prime \prime}+$ 
TABLE 1--Continued

\begin{tabular}{|c|c|c|c|}
\hline Variable No. & Variable Name. & Data Item No. & Data Item Name \\
\hline 05 & Subsoil texture & $\begin{array}{l}00 \\
01 \\
02 \\
03 \\
04 \\
05 \\
06 \\
07 \\
08 \\
09 \\
10 \\
11\end{array}$ & $\begin{array}{l}\text { sand } \\
\text { loamy sand } \\
\text { sandy loam } \\
\text { loam } \\
\text { silt } \\
\text { silt loam } \\
\text { sandy clay loam } \\
\text { clay loam } \\
\text { silty clay loam } \\
\text { sandy clay } \\
\text { silty clay } \\
\text { clay }\end{array}$ \\
\hline 06 & Subsoil structure & $\begin{array}{l}00 \\
01 \\
02 \\
03 \\
04 \\
05 \\
06 \\
07 \\
08\end{array}$ & $\begin{array}{l}\text { blocky } \\
\text { massive } \\
\text { singular grain } \\
\text { columnar } \\
\text { platy } \\
\text { prismatic } \\
\text { fibrous } \\
\text { granular } \\
\text { crumb }\end{array}$ \\
\hline 07 & Subsoil consistence & $\begin{array}{l}00 \\
01 \\
02 \\
03\end{array}$ & $\begin{array}{l}\text { nonplastic (po) } \\
\text { slightly plastic (ps) } \\
\text { plastic (p) } \\
\text { very plastic (vp) }\end{array}$ \\
\hline 08 & Substratum & $\begin{array}{l}00 \\
01 \\
02 \\
03 \\
04 \\
05 \\
06 \\
07 \\
08 \\
09 \\
10\end{array}$ & $\begin{array}{l}\text { bedrock } \\
\text { sedimentary } \\
\text { igneous-pumice, ash } \\
\text { igneous-basalt } \\
\text { sand } \\
\text { loamy sand } \\
\text { sandy loam } \\
\text { loam } \\
\text { silt } \\
\text { silt loam } \\
\text { sandy clay loam }\end{array}$ \\
\hline
\end{tabular}


TABLE 1-- Continued

\begin{tabular}{|c|c|c|c|}
\hline Variable No. & Variable Name & - Data Item No. & Data Item Name \\
\hline 08 & Substratum & $\begin{array}{l}11 \\
12 \\
13 \\
14 \\
15\end{array}$ & $\begin{array}{l}\text { clay loam } \\
\text { silty clay loam } \\
\text { sandy clay } \\
\text { silty clay } \\
\text { clay }\end{array}$ \\
\hline 09 & Profile depth & $\begin{array}{l}00 \\
01 \\
02 \\
03 \\
04\end{array}$ & $\begin{array}{l}10-20^{\prime \prime} \\
20-30^{\prime \prime} \\
30-40^{\prime \prime} \\
40-60^{\prime \prime} \\
60^{\prime \prime}+\end{array}$ \\
\hline 10 & $\begin{array}{l}\text { Available } \\
\text { water capacity }\end{array}$ & $\begin{array}{l}00 \\
01 \\
02 \\
03 \\
04 \\
05 \\
06\end{array}$ & $\begin{array}{l}10+ \\
7.5-10.0 \\
5.0-7.5 \\
3.75-5.0 \\
2.0-3.75 \\
1.5-2.0 \\
<1.5\end{array}$ \\
\hline 11 & $\begin{array}{l}\text { Load-carrying } \\
\text { capacity }\end{array}$ & $\begin{array}{l}00 \\
01 \\
02\end{array}$ & $\begin{array}{l}\text { low } \\
\text { moderate } \\
\text { high }\end{array}$ \\
\hline
\end{tabular}

Data Collection and Assign Identification Numbers. Information provided by the River BasinStudy meets the requirements of the various models. No modifications or additional data collection will be needed. The preceeding list is final. The numbers on the list are for identification purposes.

Assign Weights. Before a final version of the models can be compiled and recorded, it is necessary to complete the final task of assigning weights. The weights reflect the relative importance of each variable in each model. In addition, the data items within each variable are relatively weighted on a ' 0 to 9 ' 
scale as to their level of importance for that variable in that model. These weights will be unique to each model; thus, they may change from model to model if necessary. The ones used in these models (Table II) are based on the literature research and personal communication with John Beaulieu (1975).

\section{TABLE II}

MODEL WEIGHTS LISTING

\begin{tabular}{lll}
\hline $\begin{array}{c}\text { Variable } \\
\text { Weights }\end{array}$ & Flow, Slide, or Fall & Data Item Weights \\
\hline \multicolumn{3}{c}{ Model 1: Rock Movement } \\
\hline 2.00 & Slope (1) & 0000789000000000000 \\
1.50 & Parent Material (2) & 0900090000000000000 \\
1.50 & Substratum (8) & 9909000000000000000 \\
1.00 & Subsoil Structure (6) & 9609990000000000000 \\
1.00 & Precipitation (4) & 3690000000000000000 \\
\hline
\end{tabular}

Model 2: Soil Fall

\begin{tabular}{lll}
\hline 2.00 & Slope (1) & 0000369000000000000 \\
1.50 & Subsoil Structure (6) & 9609990000000000000 \\
1.00 & Precipitation (4) & 3690000000000000000 \\
1.50 & POL (3) & 0009300000000060000 \\
1.00 & Profile Depth \#44 (9) & 0036900000000000000 \\
\hline
\end{tabular}

Model 3: Slump

$\begin{array}{lll}2.00 & \text { Slope (1) } & 0366999000000000000 \\ 1.00 & \text { Subsoil Consistency (7) } & 9630000000000000000 \\ 2.00 & \text { Precipitation (4) } & 9990000000000000000 \\ 1.00 & \text { Profile Depth (9) } & 0036900000000000000\end{array}$


TABLE II--Continued

\begin{tabular}{lll}
\hline $\begin{array}{c}\text { Variable } \\
\text { Weights }\end{array}$ & \multicolumn{1}{c}{ Flow, Slide, or Fall } & Data Item Weights \\
\hline \multicolumn{3}{c}{ Model 4: Block Glide } \\
\hline 2.00 & Slope (1) & 0666999000000000000 \\
1.50 & Subsoil Structure (6) & 9609990000000000000 \\
1.00 & Precipitation (4) & 9990000000000000000 \\
2.00 & Parent Material (2) & 0900060000000000000 \\
1.50 & Substratum (8) & 0906000000000000000 \\
1.50 & Load Carrying Capacity (11) & 0900000000000000000 \\
\hline \multicolumn{3}{c}{ Model 5: Debris Slide } \\
\hline 2.00 & \multicolumn{1}{c}{ Slope (1) } \\
2.00 & Subsoil Consistency (7) & 0003630690000000000000 \\
1.00 & Subsoil Texture (5) & 6699996363330000000 \\
\hline \multicolumn{3}{c}{} \\
\hline
\end{tabular}

Model 7: Debris Avalanche

$\begin{array}{lll}2.00 & \text { Slope (1) } & 0033690000000000000 \\ 1.50 & \text { Precipitation (4) } & 9990000000000000000 \\ 1.00 & \text { Subsoil Structure (6) } & 9369993930000000000 \\ 1.00 & \text { Parent Material (2) } & 0900060000000000000\end{array}$

Model 8: Debris Flow

$\begin{array}{lll}2.00 & \text { Slope (1) } & 0669999000000000000 \\ 1.50 & \text { Precipitation (4) } & 9990000000000000000 \\ 1.00 & \text { Subsoil Texture (5) } & 3699999666630000000 \\ 1.00 & \text { Substratum (8) } & 3000000009600000000\end{array}$


TABLE II--Continued

\begin{tabular}{lll}
\hline $\begin{array}{l}\text { Variable } \\
\text { Weights }\end{array}$ & Flow, Slide, or Fall & Data ltem Weights \\
\hline \multicolumn{3}{c}{ Model 9: Earthflow } \\
\hline 2.00 & Slope (1) & 06699990000000000000 \\
1.50 & Precipitation (4) & 9990000000000000000 \\
1.00 & Subsoil Consistency (7) & 9963000000000000000 \\
1.00 & Parent Material (2) & 0900060000000000000 \\
\hline
\end{tabular}

The final model is a combination of the preliminary model description and the information generated in this phase. The completed booklets appear in Appendix $D$.

Phase Six

Data Mapping and Transfer onto Base Map. The scale of the base map is the same as that of the River Basin Study soil map. The only task needed is to code the various soil units by cell and to redefine these units according to the characteristics required in the models. A grid overlay was prepared to place on top of the River Basin Study map. This was the only task needed for this phase.

\section{Phase Seven}

Data Bank Construction. The most time-consuming portion of the methodology is the data bank phase. The River Basin Study soil type map is the primary data source. Each soil type delineated on the map is interpreted in the River Basin Study report for fifty-five different attributes. The coding step involves 
relating some of these characteristics to each soil type present in the study area (Appendix E).

Data Coding and Keypunch. The first step in the coding process was to overlay the forty acre grid cells on the soil map and record the predominant soil type unit for each cell. The second step was to interpret each different unit and recode the predominant coded soil types on worksheets for the various characteristics required by the models.

The process involved several types of input. Figure $5(p .51)$ is a reduction of the soils map. A standard computer worksheet is contained in Figure 6. Note that it is eighty columns across. Since this is single digit coding, each column represents one cell. The study area is eighty cells or columns across. One row on the worksheet represents a row of eighty grid cells in the study area. Once the coding had been completed, the worksheets needed to be keypunched onto computer keypunch cards. This was accomplished on an IBM 029 keypunch machine. The resulting cards or "data decks" are essentially the data bank.

Data Bank and Data Map Edit. At this point, the data bank of eleven variables had been keypunched. The card decks were sent to Mr. Bruce Rowland, at that time a graduate student at Harvard University in the Graduate School of Design, Deparment of Landscape Architecture. He agreed to input the data decks to the Harvard IBM Computer System and apply the various mass movement susceptibility models. Once the data decks were in the computer, the data bank had been constructed. The first task was to map the data using the computer and 


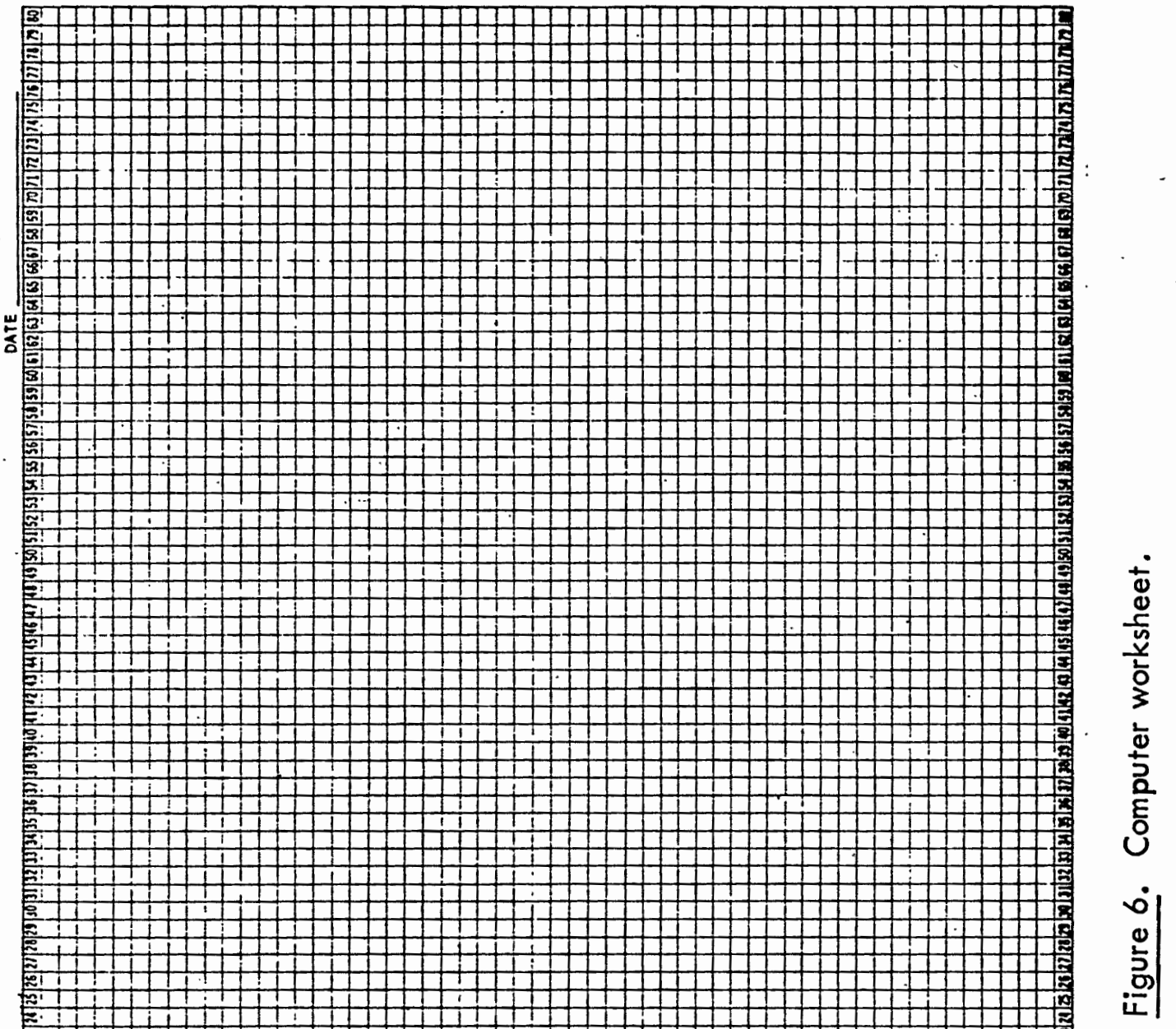


check for errors in the data (see Appendix C). This step was not followed closely as it was not feasible due to time considerations on Mr. Rowland's part for me to review the maps in Portland and return them to Harvard with corrections. He checked the maps to determine their reasonableness and made corrections where necessary. Normally, the user will be located close enough to the computer facility to allow proper editing.

Phase Eight

Application of Models and Model Preparation. In addition to the data decks, Bruce Rowland also received the completed model booklets. The numeric information contained in the booklets was converted to IMGRID format and keypunched. These cards along with specific IMGRID keyword commands were applied to the data bank to generate the mass movement susceptibility maps (Appendix B).

Mass Movement Susceptibility Maps. There is one map for each mass movement susceptibility model plus a composite map showing overall mass movement susceptibility for the entire study area. Each symbol on the maps represents one grid cell. The symbols used depict a gray scale. The bar graphs under each map indicate that the highest level of susceptibility is represented by the darkest symbol. This symbol was created by a series of character overprints. The lowest level of susceptibility is represented by a symbol which visually depicts the cell in a light gray shade. The darker the gray tone of the cell, the greater the susceptibility of the cell for that mass movement. 
A unique characteristic of the Harvard Computer System is demonstrated by these maps. In Appendix A, a description of the computer approach, it is indicated that one type of output from the C.P.U. is a hard-copy of the results generated on the line printer. Most line printers have a rectangular shaped print-chain. The Harvard system has a square one, each character being $1 / 10 "$ by $1 / 10^{11}$. For mapping purposes, this means that the scale in both the $X$ and $Y$ directions will be the same. This will, of course, not be the case for non-square print chain generated computer maps. Maps generated by the Harvard IBM system can be photographically reduced or enlarged to overlay a planimetric base map such as the USGS 1:62,500 map used in this application.

The coordinate referencing system begins with the southwest corner cell referenced as row one, column one. The northeast corner cell is referenced as row 64 , column 80 . Each cell may be referenced by a row and column coordinate.

At the top of the map is the title of the model for which the map was generated. Below the map is the name of the study, researcher, and where the map was generated (the maps reproduced in the appendices of this thesis have a slightly different arrangement due to publication considerations). The bar graph appearing below the text provides a frequency count of cells mapped in each of the ten classes of susceptibility. Since the size of each cell is constant, it would be possible to compute total area of land in each class. For example, 419 cells in the study area are highly susceptible (mapping level ten) to slump. Since 
each cell is 40 acres in size, this means that 16,760 acres or a little over 26 square miles of the study area fall into this susceptibility class.

\section{Phase Nine}

Data Analysis and Field Check. One of the most important goals of the map analysis is to develop a clear picture of the relationship between the susceptibility maps and the study area. One way this can be done is by using an overlay on the maps themselves. In the sleeve of the back cover is a clear film positive of physical and cultural features to the scale of the mass movement maps. As can be seen, this overlay contains features which aid in assisting interpretation and analysis of the grid cell maps by allowing the user to better relate them to the study area.

The next step was to verify whether the computer maps were reflecting the model structure as given by the experts. After working through the computations as outlined in Chapter II, Phases Eight and Nine, it was concluded that the computer maps do depict the model structures. Taking the interpretation further, it was determined that for debris avalanche and earth flow (Models 7 and 9), mapping classes 6 through 9 were significant; for debris slide (Model 5), mapping classes 7, 8, and 9; for rock movement, slump, block glide, and debris flow (Models 1, 3, 4, and 8), only class 9; and soil fall (Model 2) and failure by lateral spreading (Model 6) were not significant. In the case of the latter two, the appropriate conclusion would be that the study area is not susceptible to these types of failures because the correct combination of physical characteristics do 
not occur coincidentally. With a better understanding and knowledge of the study area, it is possible that these two models could have been dropped back in Phase Three.

Since the models were not developed according to the methodology and since further access to the Harvard University IMGRID System was no longer possible, additional analysis was not accomplished. Several approaches would have been feasible (see Chapter II, Phases Eight and Nine). Any further interpretation and analysis might be more appropriately termed calibration of the model. Adjustments would be made to the model(s) better fit to the real world through a combination of field check and weight adjustments. 


\section{CHAPTER IV \\ DISCUSSION AND CONCLUSIONS}

There are advantages and disadvantages in the application of this methodology. One of the more important disadvantages is related to coding, storage, and analysis procedures for data associated with the grid-cell approach. This was discussed in Chapter II. Several important questions remain to be considered which are relevant to the practical application of the methodology. How comprehensive is or can the methodology be? How flexible is it? Can the methodology be adapted for other uses besides mass movement susceptibility? How much cost and time are involved? What is the availability of the IMGRID System?

The comprehensiveness of the methodology is directly related to the models. The models can be constructed in a very complete manner taking into consideration many aspects of mass movements. The limiting factors are the knowledge and expertise of the experts consulted, data availability, and the IMGRID software. The importance in carefully selecting experts should be obvious. If the data required by the model are not available then the model must be changed and some comprehensiveness sacrificed for a more general approach. The IMGRID software can handle up to twenty variables per model. This is probably enough to allow comprehensive results to be generated. The last factor is the grid cell size. The models can be constructed in a highly comprehensive 
manner but if applied to a very large cell the results will be extremely general and ambiguous. Thus, the model must be equated with cell size. The methodology is directed toward "general" results, and as such, is not completely comprehensive. The potential exists for generating highly comprehensive results.

Flexibility is built into the methodology in several ways. Options are provided in many of the phase descriptions in Chapter II. The choice of a coordinate system upon which to base the grid cells is dependent on the user and the need to interface with an existing data system. The choice of generating a reproducible base map or a series of overlays is dependent upon the data sources. The basic organizing system is IMGRID. A very high degree of flexibility is achieved through the keyword commands. If it is found that a particular model is not accomplishing what was expected, changes in the model structure or weights can easily be made via the keyword commands. New variables can be added at any time or generated from already existing variables. The methodology follows a basic framework, but within that framework there exists a wide range of options.

Another aspect of flexibility, which might be termed external flexibility, is whether the methodology can be adapted for other uses. The methodology can definitely be applied to other phenomena outside of mass movements. This may be costly, however, if a large amount of additional data are required. For example, if the methodology is to be applied for determining the suitability of areas for recreation, a whole new set of variables and data items may have to go into the data bank. The methodology can most easily be adapted for phenomena 
somewhat related to mass movements such as soil erosion or for land use characteristics related to natural phenomena such as suitability for septic tanks, etc. In other applications, new variables may be required but many of these would already be in the data bank.

The most time-consuming and costly phase of the methodology is the data bank construction phase. The application of the methodology described in Chapter 111 required about 200 man hours for coding and keypunching of data. The cost for the computer use was about $\$ 75.00$. A general estimate for a study area about eighty square miles-in size, 5120 cells (each forty acres in size), eleven variables and twelve models, would be $\$ 1,000.00$. This is using a figure of $\$ 4.00 /$ hour for the coding and keypunching of data. One can estimate about two to three man months for a study with these parameters. The time and cost of a project are directly related to the size of the grid cell, the total number of cells, the number of variables, and coding techniques.

Presently, the availability of IMGRID is very limited. It is accessible at Harvard University, the Tennessee Valley Authority in Knoxville, Tennessee, and the Holcomb Research Institute in Indianapolis, Indiana. It has been acquired (but not yet operational) by the University of Washington and Colorado State University. An updated version of the system is expected to be available for distribution in September, 1976. This version will be fully documented and it is very likely that during the next year IMGR ID will experience a wide dis-. tribution. Information related to the availability of the IMGRID System should 
be requested from Dovid Sinton; Graduate School of Design, Department of Landscape Architecture, Harvard University, Cambridge, Massachusetts.

In conclusion, the methodology is capable of producing mass movement susceptibility maps of value to land use planning. The methodology is both qualitative and quantitative. Further research is needed to increase the quantifications aspects. In particular, the weights used in the models need to be objective rather than subjective. This would involve a major research effort, however, which is beyond the present purpose. Presently, the methodology is quite satisfactory for land use planning applications. With further research involving quantitative techniques such as factor analysis, principal components analysis, and multiple regression, the process can be quantified to the point where it would have wider application in not only land use planning but in engineering applications as well. 
APPENDIX A

THE COMPUTER APPROACH:

HARDWARE AND SOFTWARE 


\section{APPENDIX A \\ THE COMPUTER APPROACH: \\ HARDWARE AND SOFTWARE}

The computer approach involves two basic components: (1) hardware or the physical equipment within the system, and (2) software or computer programs which provide instructions to the hardware. The two components may be thought of as performing four interrelated functions: (1) input, (2) storage, (3) processing, and (4) output. The description of the hardware component which follows has been adapted from Computers: Their Place in Land Use Analysis (Blank, 1974, pp. 4-11).

\section{THE HARDWARE APPROACH}

The computer hardware system consists of a collection of equipment that accepts, stores, analyzes, and outputs information. The central piece of hardware is the Central Processing Unit (C.P.U.). It is in this equipment that the manipulation of the data actually occurs. Other equipment are considered peripheral devices to the C.P.U.

In addition to the peripheral devices and the C.P.U., there are two other necessities for the effective use of the computer. The first, referred to 
earlier, is software or computer programs. The second is a body of data upon which the operations or calculations are to be performed.

The computer programs instruct the C.P.U. to perform operations on the data. A program is a set of explicit instructions which gives meaning to data "and makes it possible to utilize the capabilities of the computer.

The data or data files are measurements used to describe the real world. These data and how they are put into the computer is of great importance. Hopps (1969, p. iv) has stated,

Electronic data processors are very efficient at storage and retrieval of data, and can carry out very complex searches of correlates ... These machines cannot do the essential selection and preprocessing of data, which includes a value judgment as to the validity of the data which is fed to them.

Most often, data that are to be used by the computer are entered into the system by the keypunch card method. The card system is widely used because it represents the best current solution to the problem of providing a data file that can be examined either manually or mechanically.

The standard card on which the data are recorded has 80 vertical columns and 12 horizontal rows. Data are entered on the card initially by a pie $œ$ of equipment called a keypunch machine which is very similar to a typewriter. For each alphabetic or numeric symbol typed, the machine punches a pattern of holes in the column and that pattern of holes serves as a code for that symbol. The machine can also print the symbol at the top of the column. The computer, on the other hand, reads or senses only the holes in the cards and ignores the line of printing. 
Files or data banks consisting of only punched cards have many disadvantages. The cards are easily lost, infermixed and are very susceptible to bending or tearing. Also, the speed at which data can be read from or transferred to punched cards is relatively slow when compared with other methods.

The main advantage of punched cards is that they are the least expensive form of data storage. The major weakness is that data cards cannot be erased or overwritten. Punched data cards are still the method most used in originating data which will later be stored in a more sophisticated manner. Magnetic tape, similar to the tape for an ordinary tape recorder, is a more efficient storage medium for data once it has initially been punched onto cards. The data is stored or represented by magnetizing certain areas on the tape. A magnetized area can be easily demagnetized and remagnetized. This fact gives tape stored data an inherent advantage over cards. In addition, the data cannot become disarranged within the file because the tape is a continuous length. A tape can be erased, revised, and reused many times. It also has a very large storage capacity. The most important point is that tape stored information can be processed 25 to 100 times faster than the best card equipment available.

There are some disadvantages to a tape stored data system. One major disadvantage is that one must have tape handling equipment. This is often very expensive and may equal as much as one-third of the equipment costs of an electronic data processing system. Another disadvantage is that a tape stored file cannot be examined without a C.P.U. Also, the entire file must be read from the beginning until a particular point which needs correction or addition is found. 
This type of access, when the entire data file must be read from the beginning until the desired section is found, is known as sequential access. Its main disadvantage is that much valuable time is wasted while the desired data is being sought.

A storage system that permits one to proceed directly to the place in the data file where the desired information has been stored is called a random access storage system. The use of a magnetic disk or a series of disks stacked together, will allow random access to stored data. The method of recording data is the same as that used to store data on tape. One simply places magnetized spots on the medium used to cover the disk. A magnetic disk storage system is very similar to a stack of records placed on a phonograph in that several disks can be stacked together. The disks are then rotated at very high speeds thus making access to stored data nearly instantaneous as compared to data which must be read from punched cards. The storage capacity of a disk is limited and somewhat less than the storage capacity of a magnetic tape. A magnetic disk storage system is also more expensive than a tape storage system. The user must decide if the higher access speed and cost of the magnetic disk is a greater advantage than the slower access speed and increased storage capacity of the magnetic tape system. The data storage units or systems are linked electronically to the C.P.U. Their function is to receive data from the C.P.U., record it and transmit it back to the unit upon demand. After the initial data have been read into the C.P.U. and placed in one of the storage systems, this entire process will take place without additional intervention by humans. The program, which has also been read 
into the C.P.U., is the component which gives meaning to the information in the data files and makes it possible to utilize the capabilities of the computer.

The C.P.U. (the computer) is composed of two major parts. They are the main memory or core and the processor itself. The processor is the physical piece of equipment which contains the electrical circuitry through which the basic mathematical and logical operations are carried out as called for by the various programs used. The memory is a high speed random access storage system. It is of limited capacity and is used to store programs and data which are currently in use. As the data is processed in the C.P.U., the results are either returned to storage or are displayed as output for the user. The output is usually in the form of punched cards, visible displays on cathode ray tubes, or as printed information in the form of numeric, or symbolic patterns printed on paper.

All pieces of equipment which are electronically connected to the C.P.U. are called peripheral devices: All other machines are simply supporting pieces of equipment. Peripheral devices have either one way or two way connection to the C.P.U. The card punch and the paper printer only receive information from the C.P.U. The tape units, the magnetic disks, and the operator's console have two way connection to the C.P.U. They may either supply information to or receive information from the C.P.U.

The physical pieces of equipment, the hardware, which make up the system, may be located several hundred miles apart. The entire arrangement and connection of the hardware components of the system may be diagrammed as follows (Figure 7): 


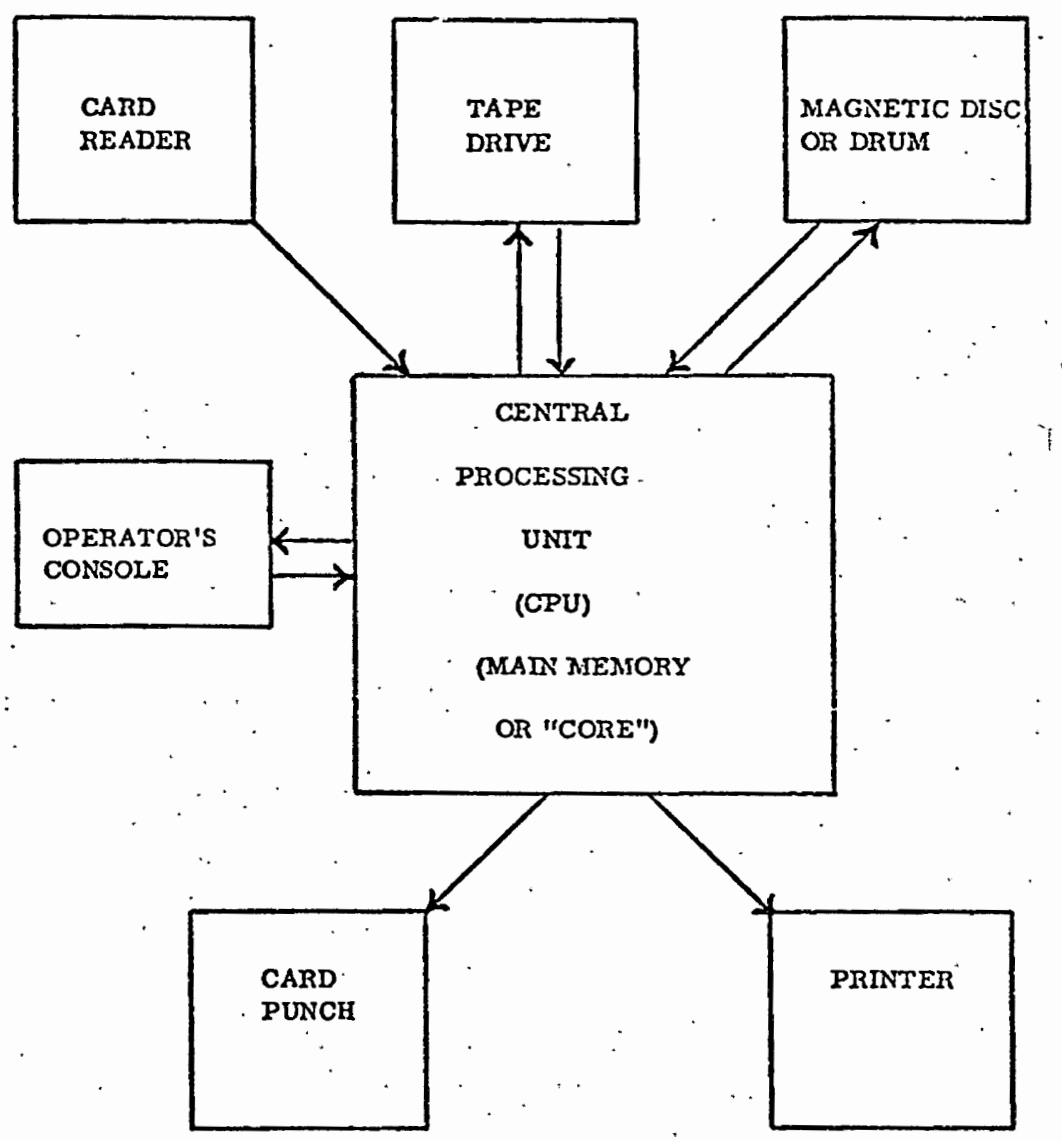

Figure 7. The "hardware" components of a computer system (Blank, 1974, p. 10). 


\section{THE SOFTWARE COMPONENT}

The software or program portion of this two component approach is the Harvard I.M.G.R.I.D. (IMGRID) System. IMGRID is a system for manipulating information in a grid cell data file. This system was designed and developed by David F. Sinton of the Department of Landscape Architecture, Harvard Graduate School of Design, Harvard University. A users' manual is not available. The information contained here has been compiled from two unpublished descriptions of IMGRID by Sinton (1975a and 1975b).

\section{Data Element Description}

The basic organizational unit of the IMGRID System is the concept of an element of storage which contains all values for one set of information for all grid cells making up a study area. This set of values will be referred to as a data element throughout this appendix. Each data element is referenced by a unique, absolute, three digit number for the location or "address" of that particular set of cell-by-cell values in the data bank. This number refers to file location only and does not reference the actual contents of the storage space. This organizational system allows the user to process in any fashion all numerical information within a data element on a cell-by-cell basis according to spatial coordinates and/or data item codes and then to move on to process a new set of information. The rectangular dimensions of each data element in the data base remain constant and it is assumed that each grid-cell position represents the same geographic point on all such elements. 
Data Base Size

IMGRID uses a relatively small data base with an absolute limit imposed by the programming software and hardware constraints of $2^{15}$ or 32,768 cells which can be processed. Extensive reprogramming would be required to exceed this limit. The present form of the system is only sef up to handle a data base of 10,800 cells. This is one-third of its absolute capacity. The data file creation routines will provide space for 100 data elements each containing 10,800 cells. The number of elements capable of being handled increases to a maximum of 300 on a data base as the number of cells decreases to 3,600 . The number of data elements in the data file is the total space available for both basic data storage and system workspace.

\section{Data Values}

While several of the IMGRID keyword operations relate to supportive functions not directly affecting actual data base values, most involve active procedures for the manipulation of numerical data copied from and returned to computer memory on an element-by-element basis. In order to maximize processing efficiency, certain conventions are recognized concerning the nature of the stored data.

Natural resource and land use planning data most often take on integer values and rarely have large ranges. The types of analysis usually applied to these data are integer oriented. Due to these considerations, the actual data item value assigned to each cell must be an integer and conform to several 
conventions with respect to precision, range, and numerical scale. All noninteger values such as fractions or decimal figures will be automatically truncated. The total range of integer values which may be generated or stored to a grid-cell position is $\pm 2^{15}$ or $\pm 32,768$. Specific keywords which tend to produce extreme values approaching these limits set maximum value defaults or provide scaling procedures to automatically reduce such figures by factors of ten. Non-IMGRID procedures may be applied to convert any valid range of data element values to a standard scale. Most of the keyword subroutines are designed to function over standard ranges of 0 through 9,19 , or 100. Values below or above the specified range for a particular keyword will be interpreted and processed according to the range-maximum default (beyond the absolute data value limits the actual value assigned to error cells is computed by subtracting twice the value of the exceeded limit from the true excess figure so that false results may be difficult to trace).

The multiplication and addition processes used in many keyword operations require that data input be defined in terms of consistent interval scales and compatible units of measure. The keyword commands usually transform the numerical values within a logical modeling structure. This process ultimately yields interval scale output from nominal, ordinal or interval scale input. Within this structure and regardless of functional keyword operation, it is important to clearly define and control the units, range, and actual meaning of all processed data. It must be assumed that all input values to be used initially relate to each other in a quantitative as well as qualitative manner. 
Given the input elements representing soil types 0 through 12 and vegetation classes 1 through 9, for example, nothing more can be inferred from the additive combination of those data elements without further specification unless each item relates to a consistent numeric scale of homogenous units such as vulnerability levels, cost equivalents or suitability score. "Apples and oranges" may be mixed through IMGRID processing but only if the expected product is defined as "fruit."

\section{IMGRID System Organization}

Data manipulation is accomplished in the IMGRID System by keyword instructions. When a keyword instruction is processed, the data element(s) to be treated are retrieved from the data element file and placed in the C.P.U. memory while the processing takes place. The storage space in the C.P.U. memory reserved to hold these data elements is referred to as the buffers. This feature permits the user to retrieve a data element from one location, transform the values of that element and place the new value in the same location.

Because the contents of the data element file are constantly changing, the system maintains the element record file which contains information about the contents of the data element file at any point in the processing. As a further safeguard the data element file is usually partitioned into three segments.

The first segment contains the basic descriptive data for the study area which should remain constant once it has been collected and checked. These data are placed in the segment which is "absolutely protected," where they can 
be retrieved for display or used to generate subsequent output but may not be altered themselves except by re-storage or special keyword code. Absolute protection is provided to prevent the loss of basic data by simple error.

The second segment usually contains values which have been derived by any analytic procedure from the basic descriptive data which must be stored for future use. This segment is called the "semi-protected" space and only a few of the system instructions are permitted to write new values into the data base in this space.

The third segment is the user "workspace" which is used to store any intermediate set of values that will be needed for future procedures. With the exception of a few display procedures and some system control procedures all keyword procedures will create a new data element in the workspace of the data element file.

\section{IMGRID Keywords}

The primary controls of the IMGRID System are a series of keyword instructions each of which performs a defined operation. Once the nature of the operations is understood the system can be used with no further knowledge of the programming.

Each of the IMGRID keywords acts as a discrete command within an integrated programming system to maintain, manipulate, and display graphic information. Each relates to a larger body of FORTRAN programming, stored within the system, to direct a series of algebraic and logical procedures for the manipulation 
of numerical data copied from and returned to computer memory on an elementby-element basis. Once the IMGRID processing system is stored, the system may be controlled through keyword commands without direct reference to actual FORTRAN programming. System parameters not expected to change during normal operation such as those defining the size, structure, and storage requirements of each data base may likewise be stored and maintained without further reference.

\section{Keyword Card Format}

The input formats for the keyword commands of the IMGRID System are in a fixed format mode. The primary format is the keyword card which initializes any process. In order to avoid continual reference to this format, it is now described once. In the future, the controls for each process will be referred to by the format field names listed below. In general, the control instructions on the keyword card are specified as three digit integer fields.

Each keyword card has space for a descriptive title. Any time the process specified creates a new element in the file, the title on the keyword card is inserted in the element record file to describe the contents of the data stored in the file. It is suggested that titles should be assigned to keyword cards at all stages in the use of the system.

To achieve maximum flexibility columns $20-39$ are used in two separate formats depending on the process involved. For simple rescale processes these columns are used as 19 single digit fields to specify a set of rescale values. For the other processes three digit fields are used to specify control instructions. 
The keyword card format is:

Cols. 01-03 NV File location number of output data element to be generated by the keyword process.

Cols. 04-10 Always specifies the keyword, left justified to column 4.

Cols. 11-13 IV File location number of input data element to be

Cols. 14-16 IU manipulated by the keyword process.

Cols. 17-19 IW

Cols. 20-22 IX

Cols. 23-25 IY

Cols. 26-28 IZ

Cols. 20-39 IR

Contain for certain keywords, single digit rescale values (see SEARCH, MATRIX, REJECT, RECODE, OVERLAY).

Cols. $40-79$

Contain an alpha-numeric title for each new element on display.

The simple rescale procedures have the capability of combining several data elements in one keyword instruction. The first element is specified on the keyword card and the rest on continuation cards (one per card). The format for the continuation cards is as follows:

$\begin{array}{lll}\text { Cols. 01-03 NV } & \begin{array}{l}\text { Should be left blank. } \\ \text { CONT is the keyword indicating a continuation } \\ \text { Cols. 04-07 }\end{array} \\ \text { card. } \\ \text { Cols. 11-13 } & \text { IV } & \begin{array}{l}\text { Element to be rescaled. } \\ \text { Cols. 20-39 }\end{array}\end{array}$

\section{User Specified Formats}

User specified formats are always read from a card following the keyword card. The format should be specified in columns $1-40$ of the card. The IMGRID System requires that these formats be specified in the normal FORTRAN mode. The user should provide that portion of format statement which follows the word FORMAT, including the parentheses. 
The standard form of the format is:

$$
(x \times F n . m)
$$

or

$$
(x \times \ln )
$$

where

' $F$ ' and ' $l$ ' are the format codes indicating REAL or INTEGER values respectively.

' $x x^{\prime}$ ' defines the number of repetitions of the data field.

' $n$ ' defines the number of columns on the card assigned to each value.

' $\mathrm{m}$ ' defines the number of digits to the right of the decimal point on the 'F' type code only.

For example, to define forty real fields of two columns each with no decimal place the format would be:

$(40 \mathrm{~F} 2.0)$

Or to define two integer fields of four columns followed by one integer field of two columns the format would be:

$$
(214,12)
$$

Be certain that the correct type of format code has been specified as called for in the detailed descriptions of the keywords. Even if decimal points are not punched and the instructions specify real fields, use the 'F' type code. Regardless of input type all buffer values are stored as integers.

\section{Keyword Commands}

A list of all the standard IMGRID keyword commands follows. This list is organized according to type, level, and quantity of expected input values. 
Note that the major functional categories include storage, manipulation, display and system control operations. This list will be discussed in detail.

\section{IMGRID KEYWORD PROCEDURES}

I. Storage Procedures

A. Cell Specific Procedures

1. UPDATE

B. Element Specific Procedures

1. STORE

2. RELOC

I. Manipulation Procedures

A. Non-Spatial Procedures

1. Single Element Procedures

(a) Item Specific Procedures

(1) RECODE

(2) REJECT

(3) XRECODE

(b) Element Specific Procedures

(1) REDUCE

(2) NORMAL

2. Multiple Element Procedures

(a) CONT

(b) Non-Additive Procedures

(1) multiple RECORD (with CONT)

(2) multiple REJECT (with CONT)

(3) double XRECODE (initialized)

(4) selective REDUCE (with REJECT)

(5) selective NORMAL (with REJECT)

(6) OVERLAY (with CONT)

(c) Additive Procedures

(I) Item Specific Procedures

(i) MATRIX (with CONT)

(ii) XMATRIX

(2) Element Specific Procedures

(i) MULT PLY

(ii) INDEX

(iii) double INDEX (initiälized) 
B. Spatial Procedures

I. Single Element Procedures

(a) Item Specific Procedures

(1) SEARCH

(b) Element Specific Procedures

(2) ASEARCH

2. Multiple Element Procedures

(a) Element Specific Procedures

(1) Non-Additive Procedures

(i) selective ASEARCH (with REJECT)

III. Display Procedures

A. Spatial Graphics Procedures

1. SYMBOL

2. MAP

3. selective MAP (with REJECT)

B. Literal/Tabular Procedures

1. Single Element Procedures

(a) RENAME

2. Multiple Element Procedures

(a) SUMMARY

(b) selective SUMMARY (with REJECT)

(c) LIST

3. Data Independent Procedures

(a) TEXT

(b) MODEL

IV. System Control Procedures

A. CLEAR

B. END

Storage Procedures

The storage keywords consist of UPDATE, STORE and RELOC. These instructions provide for the creation and maintenance of data files on an elementby-element basis. UPDATE allows for card input of data item values to specific cell locations. STORE operates in a similar manner but-with broader capabilities 
to define values over an entire data element. Once stored, element values may be transferred from one file location to another through the RELOC keyword.

Cell Specific Procedures: UPDATE. The UPDATE keyword allows for the placing of new values in an old element. The values are read from cards on a cell by cell basis with one value per card. The format should specify three integer fields: the first will contain the row number of the cell, the second the column number of the cell, and the third contains the new value assigned to the cell. The end of the cards containing the new values is specified by a card containing a negative value in the row field defined by the format. The controls are:

NV Specifies the new element created by the update.

IV Specifies the old element to be updated.

IU Provides the format exclusion.

$I U=0 \quad$ The format is specified on a card immediately following the keyword card. The new values follow the format card.

$I U=-1$ The program uses the last specified format. If no format has been specified the system defaults to $(213,12)$.

Element Specific Procedures: STORE and RELOC. STORE allows a new

set of values to be entered to the element file. The values are read from cards under a user specified format. The IMGRID System expects the user to specify the row by row format of the new values and will read each row as a logical record. The controls are:

NV Specifies the new element created.

IV Is not used.

IU Provides for format exclusion.

$I U=0$ The format is specified on a card immediately following the keyword card. The new values follow the format card.

$\mathrm{IU}=-1$ The system uses the last specified format. If no format has been specified the system defaults to $(3 x, 7711)$. 
The RELOC keyword is used to move a data element from one location to another in the data element file. In particular it is used to place values in the "semi-protected" space on the data file. Typically when entering new values they would first be placed in the "workspace" and checked. On a subsequent run the RELOC keyword would be used to move the values into the "semiprotected" space. The name specified in columns $40-80$ is assigned to the new element. The information in the element record file is also moved. Thus,

NV Specifies the new location.

IV Specifies the old location.

\section{Manipulation Procedures}

The manipulation commands represent a major portion of the IMGRID processing system. These are RECODE, REJECT, XRECODE, REDUCE, NORMAL, CONT, OVERLAY, MATRIX, MULTPLY, INDEX, SEARCH and ASEARCH. Most of the manipulation keywords deal directly with initial data item code or numeric value assigned to each cell regardless of its spatial location in the study area. Such values are computed and assigned by generic item-category such that the overall pattern of spatial boundaries in the input element is not significantly altered by the keyword modification of on-site values. One of the manipulation procedures used by some of the above keywords is called rescaling.

Rescaling. Rescaling is basic to the operation of the IMGRID System and several of the system design limits were set with this process as the limiting factor. A variety of keywords provide minor variations. The principal of the process is 
simple: a qualitative or descriptive numerical scale is assigned a new set of values which may be processed as an interval scale.

It should be remembered that the IMGRID System is designed for use with natural resource and land use planning data which have been coded from the typical sources of such data. These sources usually are descriptive or qualitative categories of data and a map is prepared which identifies the category occurring in each area or zone on the map. The result of digitally encoding this type of data is a series of data elements which have data scales that are either nominal or ordinal scales rather than interval or ratio scales which are normally used in numerical processes on digital machines.

To use this data for more than a few simple operations, the critical step of converting these qualitative scales to interval scales must take place. This process has been described as:

\section{RAW DATA ELEMENT}

Apply Professional Judgment

\section{ANALYSIS COMPONENT}

The IMGRID System is specificaily designed to be used with data which usually requires this simple process as the starting point of an analysis. As the application of "Professional Judgment" appears to be an integer process the system relies heavily on integer operations. This also conserves resources on some computing systems.

The IMGRID-System was designed with two levels of data rescaling. - The simple rescale process provides a set of fixed format instructions which assume 
that the data is within the limits identified above. The extended rescale process provides for those situations which are not within these limits and where the simple rescale would constrain the potential applications of the system. The limits built into the system are:

(a) that the values which are to be rescaled (i.e., those in the old element) may be in the range $0-19$;

(b) that the simple rescale process will assign values in the range $0-9$; and

(c) that graphic displays will process values in the range $0-19$, or a maximum of twenty levels of symbolism.

The IMGRID System obeys these limits rigorously and within them the following keywords can be used to rescale data elements: MATRIX, OVERLAY, RECODE, REJECT, SEARCH. For values outside of these ranges, use the extended rescale keywords: XMATRIX, XRECODE. To display values which are outside the range of 0-19 a preparatory step must be used to reduce these values to such a scale (see the section on Data Standardization).

All the rescale keywords operate in the same mode for assignment. The new values or rescale values are recorded in an ordered list and the IMGRID System identifies the old value associated with each new value by the relative position of the new values in the list. For example a raw data element has values in the range $0-12$ and it is desired to assign new values such that:

$\begin{array}{lll}0 & \text { becomes } & 0 \\ 1 & " & 9 \\ 2 & " & 9 \\ 3 & " & 8 \\ 4 & " & 2 \\ 5 & " & 3 \\ 6 & " & 4 \\ 7 & " & 4\end{array}$




$\begin{array}{rrr}8 & \text { becomes } & 5 \\ 9 & \text { " } & 6 \\ 10 & " & 7 \\ 11 & " & 7 \\ 12 & 1 & 1\end{array}$

The rescale list is: 0998234456771 .

For simple rescale procedures this list would be punched in columns 20-32 on the rescale keyword cards. As the values to be rescaled were in the range 0-12, thirteen values must be assigned, twelve plus one for the zero value.

The rescale process has several important characteristics that sometimes cause problems for the unwary and provide useful capabilities for the imaginative user. Be careful to always take into account the following considerations:

(a) The IMGRID System recognizes zero as a valid value in any data range and assumes that the first value in a rescale list is assigned to the zero condition. This applies even if the data element does not contain a zero value. Zero is assumed to be the low end of the value range to be rescaled. A common mistake when using the XMATRIX or XRECODE keywords is to omit the values for the zero condition.

(b) The IMGRID System expects a rescale value for every integer value within the range. This applies even if the old data element does not contain one or more of the integer values in the range. This requirement is caused by the method of assignment of the rescale values. The assignment is made by the positional order of the rescale values in the list and the system is not normally aware that a value within the range does not exist.

(c) The IMGRID System must know the maximum value in the range of values to be rescaled. For the simple rescale processes the system will assume that the maximum value to be rescaled is 19 or the maximum possible value which can be rescaled using the simple rescale procedure. Consequently it is only in a few exceptional circumstances that it is necessary to specify this control parameter on simple rescales.

(d) When using the extended rescale processes the maximum value of the old value range to be rescaled must be specified as these processes are designed to extend the normal system limits. Without this specification the system has no knowledge of the extent of the values to be rescaled and may give unpredictable results which are difficult to trace. 
(e) When using the extended rescale procedures the user is expected to specify the format in which the new values are to be read. The section on formats described this process. As the IMGRID System assumes that the range to be rescaled begins with zero, the format specification must provide space for the zero values. In general this implies that the number of fields specified will be one greater than the maximum value on the range of values to be rescaled. Beware as this is a common mistake. Symptomatically it can be identified by the loss of the next card in the data stream, always a keyword card, as the system will read an extra card to find the extra value.

(f) If a value falls outside the specified rescale range from zero to the maximum value specified, the IMGRID System will print an error message and assign the rescale value associated with the specified maximum value to locations with the error conditions. This procedure permits the user to assign a default value to these error conditions if they occur. On a simple rescale the maximum value is set at 19 . If this is a significant value which should have a different rescale value than the error condition use the XRECODE procedure and set the maximum value to 20 to assign a rescale value to the error condition.

Non-Spatial Procedures, Single Element. Within the group of "nonspatial" keyword commands a further distinction is recognized between those which address and transform a single data element and those which combine two or more. RECODE, REJECT and XRECODE each address an individual input element and generate output by direct transformation on an item-by-item basis.

RECODE and REJECT each accept initial values in the range 0 through

19. RECODE may be used to assign new values of 0 through 9 while REJECT provides a simple yes or no distinction through assigned values of 0 and -99 . The -99 code may be used to actually eliminate cells from further processing. This is particularly useful in designating areas of absolute unsuitability or masking the boundary of an irregular study area. XRECODE or extended RECODE operates according to a modified input format which, although less convenient than that of RECODE or REJECT, is considerably more flexible. Here, any positive or 
negative integer value may be assigned to any existing item code greater than or equal to zero. XRECODE is particularly useful in converting large values to smaller equivalents within a manageable map.

(1) Item specific procedures: RECODE. The keyword RECODE creates a new element by assigning new values to a set of old values. The new value is associated with the old value by its position in the IR field on the card. When continuation variables are specified the subsequent rescale values override the previous values if the rescale value is non-zero. The controls are:

NV Specifies the new element created.

IV Specifies the old element to be rescaled.

IU Unused.

IW Specifies the maximum old value to be rescaled. Values less than zero and values greater than IW will be assigned the rescale value of IW. The default value of IW is 19.

IR Specifies rescale values in the range $0-9$.

(2) Item specific procedures: REJECT. Within any study area there may be conditions which would create abnormal results for a particular analysis procedure. A typical example is a large water body. It is useful to be able to reject these types of conditions when some of the keyword procedures are invoked. Also for some of the keyword procedures it is useful to define a limited subset of locations to be processed (e.g., a town or all schools).

The IMGRID System permits the specification of a reject condition which may be used to eliminate specified locations from some of the keyword procedures. The reject condition is specified by a simple rescale procedure, which creates a new data element which can be invoked as it is needed. The rescale values assigned on the keyword card are 0 for conditions not rejected and 1 for conditions 
to be rejected, while the values contained in the new reject element are 0 for locations not rejected and -99 for locations rejected. As this is a simple rescale procedure the creation of a reject condition on a data element with values outside the normal range will require a preliminary step using the XRECODE keyword.

Careless use of the reject condition may cause the loss of significant information in locations rejected. The use of the reject is a form of binary analysis (e.g., yes or no) and suffers from all the limitations of such analysis. It is suggested that in preliminary analysis the reject condition should not be used and the results studied with care before a reject is specified on subsequent runs. Because of the special nature of the values in the reject condition, the use of a data element containing a reject condition in some manipulative procedures can cause unpredictable results. This is particularly the case with INDEX and MULTPLY. If it is necessary to process a data element in a procedure which does not normally permit a reject condition it is advisable to use a simple RECODE procedure to assign a new value to the reject condition. The reject conditions will appear as error cells and be assigned the rescale value for the error condition.

The reject value is associated with the old value by its position in the IR field on the card. The controls are:

NV Specifies the new element created.

IV Specifies the old element to be rescaled.

IU Unused. 
IW Specifies the maximum old value to be rescaled. Values less than zero and values greater than IW will be assigned the rescale value of IW. The default value of IW is 19.

IR Specifies the rescale values as follows:

$\mathrm{IR}=0$ not rejected,

$\mathbb{R}=1$ reject condition (stored at -99 ).

(3). Item specific procedures: XRECODE. XRECODE creates a new element in which the rescale values replace the values in the old element on a one for one basis. Using XRECODE elements with values outside the ranges $0-19$ can be rescaled and values outside the integer range $0-9$ can be assigned. Thus,

NV Specifies the new element created.

IV Specifies the old element to be rescaled.

IU Specifies a second old element which can be overridden by a nonzero rescale value to create the new element (default IU $=0$ ).

IW Specifies the maximum old value to be rescaled. IW must be specified. The maximum permissible value for IW is 999 .

A format card is automatically read following the keyword card. It specifies the format for the rescale values which are read from cards immediately following the format card. The ' $F$ ' format must be used. It should be noted that as the IMGRID System recognizes zero as a valid value the format statement must provide IW +1 locations and the first rescale value replaces the old zero value.

Data Standardization. The data standardization procedures convert values of an unknown range to a defined set of value ranges. There are two standardization procedures in the IMGRID System and both are based on the statistical properties of the value distribution in the data element being standardized. 
(a) Assuming a unit normal distribution, the values are standardized using the mean and standard deviation of the values. The equation is as follows:

$$
N V=50+(O V-X M)(25 / S D)
$$

where

$$
\begin{aligned}
& N V=\text { new value } \\
& O V=\text { old value, } \\
& X M=\text { mean of old values, and } \\
& S D=\text { standard deviation of old values }
\end{aligned}
$$

(b) Assuming a uniform distribution, the values are standardized using the maximum and minimum of the values. The equation is as follows:

$$
N V=100 \frac{(O V-M N)}{(M X-M N)}
$$

where

$$
\begin{aligned}
N V & =\text { new value } \\
O V & =\text { old value } \\
M N & =\text { minimum of old values, and } \\
M X & =\text { maximum of old values }
\end{aligned}
$$

The NORMAL keyword uses both of these procedures. The mean and standard deviation will be used unless the other is specifically requested on the keyword card. Also, with this keyword the user is not permitted to intervene in the setting of the parameters of the standardization.

The REDUCE keyword only uses the maximum and minimum for the standardization, but it permits the user to intervene in the process and specify the number of intervals, the maximum of the range, the minimum of the range, or the relative size of the intervals, or any combination of the former. When either the maximum or the minimum are specified the system adds one to the number of levels specified. If both are specified it adds two intervals. When the minimum 
is specified the 0 interval represents the values less than the specified minimum. When the maximum is specified the highest interval represents the values which are greater than the specified maximum.

When using the mean and standard deviation about $5 \%$ of the values will fall beyond the range of $0-100$. As the unit normal distribution is assumed, the extremes are set at two standard deviations either side of the mean. For display purposes these values are standardized to a range of $0-11$ in both the NORMAL procedure and the special option of the REDUCE procedure. The maximum is set to 100 and the minimum is set to 0 , with ten equal intervals. These standardization procedures are commonly used to satisfy the range limit requirements of other keyword operations.

(1) Element specific procedures: REDUCE. A new element is created by the REDUCE keyword command by assigning each value in a set of values to an interval within the range of the values. The maximum number of intervals permissible is 20 and the values in the element created will be in the range $0-19$. The default option is to assign the values to ten equal intervals between the minimum and maximum of the values being reduced. A reject condition may be specified which will exclude the cells rejected from the parameters of the reduction and return the reject code in the new element. The controls are:

NV Specifies the new element created.

IV Specifies the element to be reduced.

IU Specifies the element containing the reject condition.

IW Specifies the option to be used in the reduction process. IW $=0$ default option, 
IW $=1$ uses ten equal intervals between a maximum of 100 and a minimum of 09 (useful for reducing elements which have IW $=2$ previously been standardized),

to

IW $=20$

IW $=99$ indicates that the full option set is specified on the following card in the format below:

Cols. 01-04 number of intervals (maximum $=20$ ), Cols. 05-08 options as specified by JPT (see below), Cols. 09-14 maximum of the range (if specified in JPT),

Cols. 15-20 minimum of the range (if specified in JPT),

Cols. 21-80 the relative size of each interval (see the section on manipulation). There are ten real fields of six digits on this card; therefore, if the number of intervals is greater than ten a second card must be added, with the same format but only using Cols. 2180. Note: this applied even if JPT is less than 4,

JPT $=0$ or 4 standard option, $J P T=1$ or 5 minimum specified, $J P T=2$ or 6 maximum specified, $J P T=3$ or 7 maximum and minimum specified, JPT $=0-3$ equal intervals used, $J P T=4-7 \quad$ user specified intervals are used.

(2) Element specific procedures: NORMAL. NORMAL creates a new element by standardizing any set of values on a scale in which the values have a range of 0 to 100. A reject condition may be specified which excludes cells rejected during determination of the parameters of the standardization and inserts the reject code into the new element. This process returns two sets of values: the first is in the range of $0-100$, which is stored as the new element, the second is reduced preparatory to a call to the map routine. This second set of values is maintained in a buffer and can be displayed by a MAP keyword immediately 
following the NORMAL keyword. Only a TEXT keyword may be inserted between the two keywords. The controls are:

NV Specifies the new element created.

IV Specifies the old element to be standardized.

IU Specifies the element containing the reject condition.

IW Specifies option to be used in the standardization process. IW $=0$ mean and standard deviation used to standardize the values, IW $=1$ maximum and minimum used to standardize the values.

Non-Spatial Procedures, Multiple Element. The second major group of non-spatial keyword commands includes those which deal with more than one input element. Each involves a combination of two or more initial elements on a direct overlay basis to create a single output composite. Values are assigned to each cell as a function of two or more independent values associated with that coordinate point. Input format may vary according to the nature of the keyword process specified. In some cases, this may involve the use of a CONT (continue) keyword to extend the input format of a preceding card. This keyword is used to identify continuation cards for the following keywords: RECODE, REJECT, OVERLAY, MATRIX, and SEARCH.

(1) Multiple element procedures--non-additive: RECODE, REJECT, XRECODE, REDUCE, NORMAL, and OVERLAY. Each of the previously discussed single-element manipulation keywords (RECODE, REJECT, XRECODE, REDUCE, NORMAL, and OVERLAY) may also incorporate multiple input. REJECT may be extended through CONT cards to address an unlimited number of initial data elements. The reject code assigned to a cell in any one of those elements will designate that cell in the REJECT composite. In order to affect 
subsequent processing, the final REJECT element itself must then be combined with some other element in a later keyword instruction. REDUCE, NORMAL and several other keyword operations may be used to incorporate REJECT codes. RECODE, like REJECT, also allows for an unlimited number of CONT cards. Here, the actual value assigned to a cell is equal to that of the most recent nonzero rescale code assigned to that cell over the CONT card sequence. In this manner, a composite suitability evaluation for commercial development, for example, might proceed according to logic as follows: Rank each cell according to the type of road in that cell; if no road, rank by land use; if no land use, rank by soil type. XRECODE allows for a similar process but does not accept CONT card extension and is, therefore, limited to one overlay element. A slightly different approach is offered through the OVERLAY keyword. Here, the value ultimately assigned to a cell is equal to that of the greatest rescale code assigned to that cell over a series of CONT card designations. In this case a cell's suitability for commercial development might be computed as "the best of its highway, land use or soil conditions." OVERLAY is subject to the same input value limitations as RECODE and, without CONT card input, performs the same data manipulation functions.

OVERLAY creates a new element by assigning new values to a set of old values. The new value is associated with the old value by its position in the $\mathbb{R}$ field on the card. When continuation variables are specified the subsequent rescale values override the previous values when the rescale value is greater than the previous value. 
NV Specifies the new element created.

IV Specifies the old element to be rescaled.

IU Specifies the number of continuation cards following the keyword card in the format specified previously (default is $I U=0$ ).

IW Specifies the maximum old value to be rescaled. Values greater than IW will be assigned the rescale value of IW. The default value of IW is 19.

IR Specifies values in the range $0-19$.

Multiple Element Procedures, Additive. Note that each of the multipleinput procedures described has computed output value through a process of sorting and choosing one of the rescale values initially assigned to each cell. Such processes are non-additive in that they do not reflect a collective synthesis of all contributing values. MATRIX, XMATRIX, MULTPLY, and INDEX are "additive" in that they do reflect a synergistic combination of two or more initial data elements. Unlike the previous multiple element operations, each must be supplied with at least two sets of input values. MATRIX uses a single CONT card format to identify and recode two elements whose assigned values then define the horizontal and vertical axes of an imaginary two-dimensional matrix. Each row-column position within the matrix represents a unique pair of item values. Recode values may then be assigned to each matrix position so as to redefine every input cell according to its particular pair of initial item values. In this manner, for example, a site evaluation procedure for commercial development might combine highway, land use, and soil considerations not by any standardized method of item sequence or value but by a totally flexible system of direct assignment to each three value combination. The dual recode MATRIX procedure is also limited to the $0-19$ input and $0-9$ output ranges of OVERLAY, 
REJECT, and RECODE. XMATRIX (extended matrix), like XRECODE, provides for greater range flexibility through a more complex input format, but otherwise provides the same MATRIX ability to address each input cell position according to a specific pair of initial item codes associated with that coordinate point.

Several of the multiple element keyword procedures operate according to general rules without explicitly addressing every possible matrix combination of initial item values. Given a series of input values associated with each cell in a study area, it is possible to call for the total or average value per cell without further specification. MULTPLY and INDEX operate in this manner on an element-by-element basis, without directly addressing specific item codes.

(1) Item specific procedures: MATRIX. MATRIX creates a new element which identifies the relative matrix position of each cell when two elements are compared. These elements are rescaled to specify which row or column position the old values should identify. The column element is specified on the keyword card and the row element is read from a continuation card which automatically follows the keyword card. Because of the limits of a simple rescale process the maximum number of rows or columns is 9 . When larger matrices are involved, XMATRIX is used.

A 0 row or column generates matrix position 0 for that entire row or column. The relative position is calculated as follows: 
NV = (row value minus one) (IU) plus column value. Graphically the positions are:

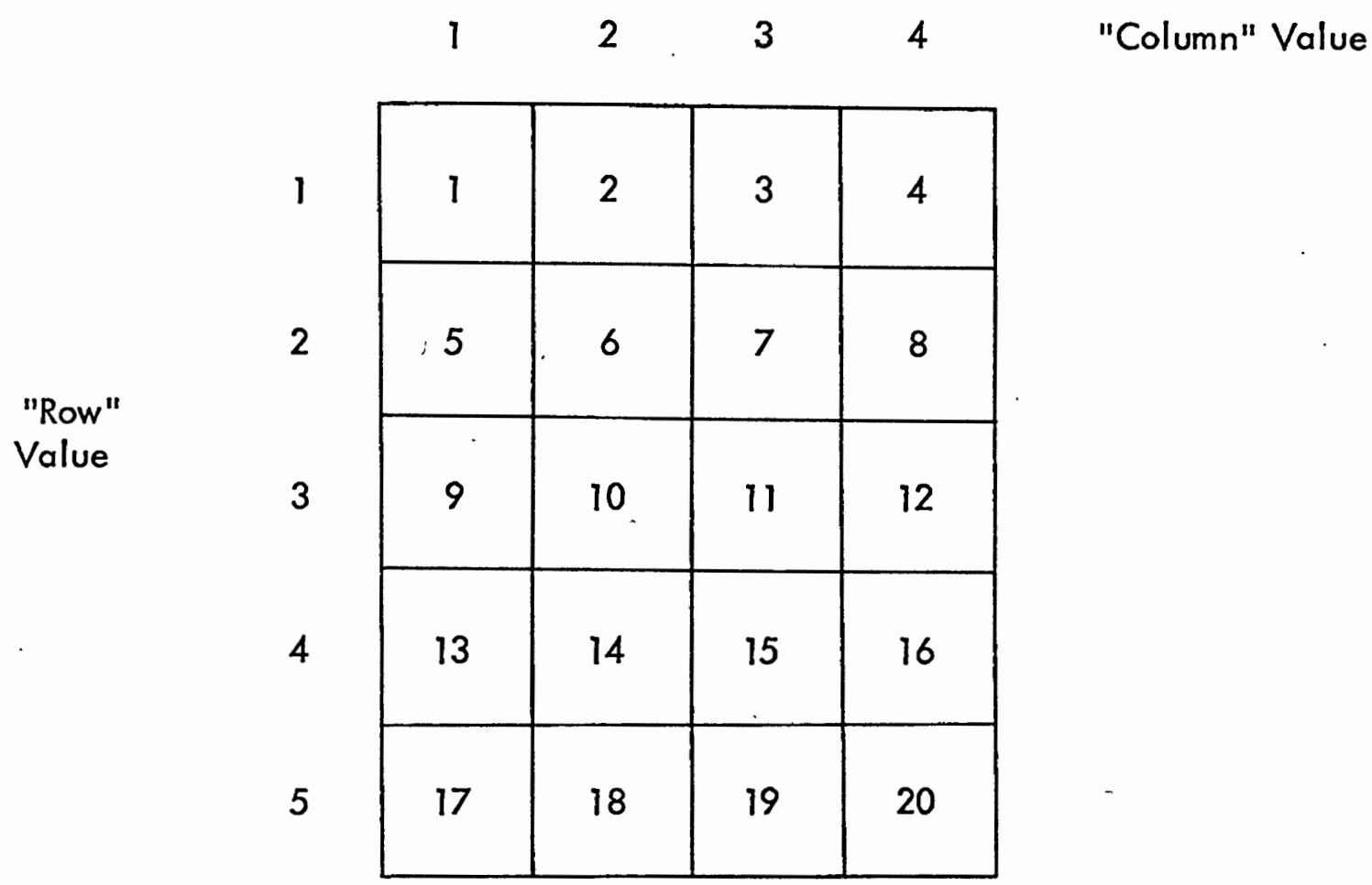

In this example the column (first) element has values of 1 to 4 and the row (second) element has values for 1 to 5 . IU must be specified as 4 in this example. Remember MATRIX automatically reads a continuation card which contains the rescale value of the row element.

NV Specifies the new element created.

IV Specifies the column element to be rescaled. The row element is automatically read from a continuation card.

IU Specifies the number of columns in the matrix.

IW Specifies the maximum old value to be rescaled in either element. Values greater than IW will be assigned the rescale value of IW. The default value of IW is 19.

IR Specifies the rescale values which identify the row and column positions in the range $0-9$. 
(2) Item specific procedures: XMATRIX. The keyword XMATRIX creates a new element in which the rescale values are identified by two elements which define the rows and columns of a matrix. Using XMATRIX, elements with values outside the range $0-19$ can be. used and values outside the integer range $0-9$ can be assigned. The maximum number of values in the matrix may not exeed 999.

NV Specifies the new element created.

IV Specifies the column element.

IU Specifies the row element.

IW Specifies the maximum value on the column element. IW must be specified. The maximum permissible value for IW is 999 .

IX Specifies the maximum value on the row element. IX must be specified. The maximum permissible value for IX is 999.

A format card is automatically read following the keyword card. It specifies the format for the rescale values which are read from cards immediately following the format card. The ' $F$ ' format must be used. As the IMGRID System recognizes zero as a valid value the matrix size is $(I W+1)(I X+1)$. The format statement must provide space for the values of the zero row and zero column.

(3) Element specific procedures: MULTPLY. The keyword command MULTPLY creates a new element by the cell by cell multiplication of two old elements. If the result exceeds the limit of 32,000 for any cell the process will be repeated with the values scaled down by a factor of 100 . This scale down process is repeated three times, then the system rejects the entire analysis and sets the values in the new element to 0 . 
No reject condition may be specified on this process. If a reject condition exists in one of the elements to be multiplied the results may be unpredictable. The controls are:

$\begin{array}{ll}\text { NV } & \text { Specifies the new element created. } \\ \text { IV } & \text { Specifies the first old element. } \\ \text { IU } & \text { Specifies the second old element. }\end{array}$

(4) Element specific procedures: INDEX. This command operates in a similar manner but with considerably greater flexibility and wider application. The INDEX keyword probably represents the best overall procedure for combining the component parts of a logical model into a composite model. This provides the greatest opportunity for manipulating multiple input on an element-byelement basis. Up to 20 input elements may be specified through a single INDEX format and more may be added through reference to previous INDEX operations. The relative value assigned to each cell is computed as the sum of each value multiplied by a relative weighting factor associated with each input element. As it is common to specify the relative weights of the components as real values with the precision of the weight in the decimal place, it is necessary to take precautions to avoid loss of significant digits in the system buffers which are defined as integers. Currently the fix-up procedure multiplies the values by 100.00 before they are placed in the buffer. This can cause values which exceed the allocated space for each value in the buffer. Should this happen the IMGRID System will store the value 32,000 and print an error message. The user can adjust for this problem by scaling the values of the weight down by one or two decimal places using 0.1 or 0.01 as multipliers. The large and unpredictable ranges of values 
produced by INDEX generally are standardized through REDUCE or NORMAL for subsequent processing.

NV Specifies the new element created.

IV Specifies the old element to initialize the sum (default IV $=0$ ).

IU Specifies the number of elements in the index. IU must be specified.

Two subsequent cards are automatically read as follows:

lst card contains the element numbers of the components of the index. The element numbers are read from integer fields of four digits successively across the card (2014).

2 nd card contains the weights for each element in the index. The weights are read from real fields of four digits successviely across the card (20F4.0).

Spatial Procedures, Single Element. The manipulative keywords described so far have dealt with the transformation of values on a discrete cell-bycell basis such that the output value assigned to a particular row and column position is in no way dependent upon the initial value of any other row and column position. REDUCE and NORMAL reflect an overall frequency and range of values over a multi-cell area but never directly address the spatial configuration of individual cells. A cell of low density residential development on a medium duty road and the qualitative value of a particular cell immediately adjacent to the ocean, for example, is identical to that of a similar cell 200 miles inland unless the spatial relationship between that cell and the ocean is somehow taken into account. The two final manipulation keywords, SEARCH and ASEARCH, provide for a consideration of proximity, quality and quantity in a spatial context. Proximity is measured in terms of integral grid-cell-edge length units as a horizontal or vertical component of planar distance between grid-cell centers. 
Quality and quantity are measured as the total item value of all whole cells within a specified proximity of selected coordinate points.

(1) Item specific procedures: SEARCH. The SEARCH keyword is related only to proximity and is characterized as a condition-oriented search (as compared to ASEARCH which is a cell-oriented search). It is a simple rescale process. SEARCH creates a new element which measures the number of cells (edge to edge) from the condition specified in the simple rescale of the old element(s) to every cell in the grid. Output values are computed for each row and column position according to its nearest distance to selected geographic areas. The output takes on values 0 through 9 representing a series of concentric zones around each search "core" to indicate the relative proximity of all surrounding cells. The maximum distance is set at 19 cells.

The results of the search may be rescaled using the RECODE instruction. The search value is associated with the old value by its position in the IR field on the card. The controls are:

NV Specifies the new element created.

IV Specifies the old element to be rescaled.

IU Specifies the number of continuation cards following the keyword card in the format specified previously (default is $I U=0$ ).

IW Specifies the maximum old value to be rescaled. Values greater than IW will be assigned the rescale value of IW. The default value of IW is 19.

IR Specified the rescale values as follows:

$\mathbb{R}=0$ not searched,

$I R=1 \quad$ search condition.

(2) Element specific procedures: ASEARCH. ASEARCH (additive SEARCH), a cell-oriented search, is a manipulative process that computes quality 
and quantity over a fixed proximity to individual cells. The process involves an additive search around each grid-cell position to sum the total input value of all surrounding cells within a specified radius. The radius defined indicates the number of cells that the search includes in all four directions from the center cell. This is a square search, with the number of cells searched equal to $(I U * 2+1)^{2}$ where IU defines the distance of the search. As it is often unnecessary to search every cell, the ASEARCH command may also incorporate REJECT to identify cells which are not to be searched from. The controls are as follows:

NV Specifies the new element created by the search.

IV Specifies the element containing the values summed by the search.

IU Specifies the number of cells being searched from the center cell in all directions.

IW Specifies the options for the search as follows:

IW $=0$ center cell included in the sum,

IW $=1$ center cell not included in the sum,

IW $=2$

to not yet implemented,

IW $=19$

IW $=20$ a user written subroutine is called a SUBROUTINE USSEAR (IW, IB, IE, JB, JE, IA, IB).

IX Specifies the element which contains a reject condition. Default is for all cells to be searched when IX $=0$.

\section{Display Procedures}

Storage and manipulative keywords involve active procedures to modify the contents of the data element file. The display and system control keywords must be used to effectively make use of these operations, although none actually alter the stored information. Most are optional and may be placed anywhere within the keyword card sequence without affecting logical structure. The display keywords include SYMBOL, MAP, SUMMARY, MODEL, TEXT/ENDTEXT, 
RENAME, and LIST. Each provides for some type of control over printed output. Some involve the use of stored values, independent of those in the data element file, while others operate solely on a temporary basis.

Spatial Graphics Procedures: SYMBOL. The command SYMBOL provides for the creation and storage of up to five specified sets of graphic characters which may be selectively applied to map output on an individual map basis. Up to 20 characters may be specified in a single set such that each relates to a corresponding data item value in the range of 0 through 19. Rejected cells and any cells of value greater than 19 will appear as blanks on all graphics output. The controls are as follows:

NV Specifies the symbolism sets as follows:

$N V=0$ is the standard ten level symbolism,

$N V=1$ is twenty level symbolism which prefers the first fifteen levels,

$N V=2$ is special symbolism reserved for the current land use set, $N V=3$ is available for user specification,

$N V=4$ is available for user specification.

The symbols are read from four subsequent cards, one card for each overprint. They are specified in columns $1-25$ on the card where column one represents level zero and column 20 represents level 19. The background symbolism is specified in column 25 .

Spatial Graphics Procedures: MAP. The actual display of graphic data is controlled through the MAP keyword. Each MAP command must specify the element to be mapped and symbol set to be used for that particular display. Maps may be placed at any point within a keyword sequence to display the current contents of any element file location. 
Displays can only be made of elements which have values in the range of 0 - 19. At the base of the display the number of cells outside this range are listed as "error" cells. Values outside this range should be processed by either a REDUCE or a NORMAL keyword before the MAP keyword is used.

NV Specifies the element to be displayed.

IV Specifies the number of levels (or intervals) on the display (default is ten levels).

IU Specifies symbolism set. See the SYMBOL keyword for the options (default is 10 levels at gray symbolism).

IW Specifies the element containing the reject condition.

A reject element may also be incorporated into the output display format without affecting stored values.

Literal and Tabular Procedures

Each of the IMGRID keywords will produce a certain amount of standard output to indicate the order and major components of each command within the programming sequence. Each output display will be printed as MAP and SUMMARY commands are encountered within this sequence. In order to annotate this structure in the output stream, headings or titles of up to forty characters may be assigned to each keyword instruction. MODEL and MAP keyword titles will also appear on all graphic output. Additional descriptive text may also be inserted at any point in the input sequence by using the TEXT and ENDTEXT keyword format. Up to thirty full cards of information may be included in each TEXT and ENDTEXT package and reproduced directly without affecting actual processing. All TEXT input is temporary and must be repeated with each job submission. Storage and manipulation keyword titles, on the other hand, are automatically stored in 
an element record file to identify each data element as it is stored, created, or redefined. RENAME may be used to assign such element titles directly and the LIST keyword may be specified to produce a tabular listing of all titles for selected series of element file locations.

Single Element Procedures: RENAME. The RENAME keyword assigns a new name in the element record file to the element specified as NV. The new name is specified in the columns $40-79$.

Multiple Element Procedures: SUMMARY and SUMMARY with REJECT.

The SUMMARY keyword relates to the output of data element values in a tabular rather than graphic format. This command summarizes a given set of values over any predefined units (e.g., population of towns). The summary can be in two forms: either the sum of the values for each unit will be calculated or the frequency distribution of integer values in the element to be summarized will be counted. Initial values to be displayed must range from $0-19$ and a nonpermanent REJECT condition may be incorporated without affecting stored values. The controls are:

NV Specifies the element to be summarized.

IV Specifies the element to define the units of which NV is. IV $=0$ will cause the summary over the total study area.

IU Specifies the element containing the reject condition. IU $=0$ will cause the summary over all cells.

IW Specifies the maximum value which occurs in the element specifying the units of the summary. IW defaults to 19 and all units with values greater than IW will be included in the unit number IW.

IX Specifies the summary options as follows:

$I X=0$ causes the values in NV to be summed over the units, IX $>0$ causes the frequencies to be calculated. IX must specify the maximum value for which the frequencies are to be 
counted. Values larger than IX will be included in the count for IX.

Multiple Element Procedures: LIST. The LIST command will cause a list of the status of each element in the system to be generated. A partial list may be obtained as follows:

IV Specifies the element to begin the list (default IU $=1$ ).

IU Specifies the element to end the list (default IU = maximum number of elements).

Data Independent Procedures: TEXT. This keyword command permits the insertion of descriptive information into the output stream at any point. All text is processed as 80 column card images with a maximum of thirty cards permitted. The end of the text is specified by a card with ENDT in columns 1-4. If should be noted that as the MAP instruction issues a page skip after the bar chart any text referring to display should precede the MAP instruction.

Data Independent Procedures: MODEL. The MODEL keyword performs all the functions of the CLEAR keyword (to be discussed in the next section) as well as initializing a group of instructions. The IMGRID System simply processes the keywords one after another and it is indifferent as to the purposes of the instructions. The MODEL keyword is used to separate distinct groups of instructions and it provides a group title for those instructions which follow it. This is particularly useful when a large run is being made as it helps to understand the output. 
System Control Procedures

The fourth major group of IMGRID keywords includes system control operations CLEAR and END. CLEAR deals directly with the overall status of internal programming parameters. These include a variety of temporary values, conditional options, and logical states set automatically by the programming system in order to optimize processing efficiency. With every new MODEL command or through CLEAR, each of these is reset to a standard default value to avoid an accumulation which might affect subsequent processing. While CLEAR is seldom used, the END keyword must be included, once and only once, as the last IMGRID card in every input deck. END signals the end of the keyword program and stores the current contents of the element record file including any new symbol sets or new element titles assigned during that run. END also calls for an automatic LIST of all data element titles stored at that point.

CLEAR resets all working buffers and logicals to their default status. No other specifications are needed. END causes the system to cease execution and stores the current system parameters in the element record file. No other specifications are needed. 
APPENDIX B

MASS MOVEMENT SUSCEPTIBILITY MAPS 


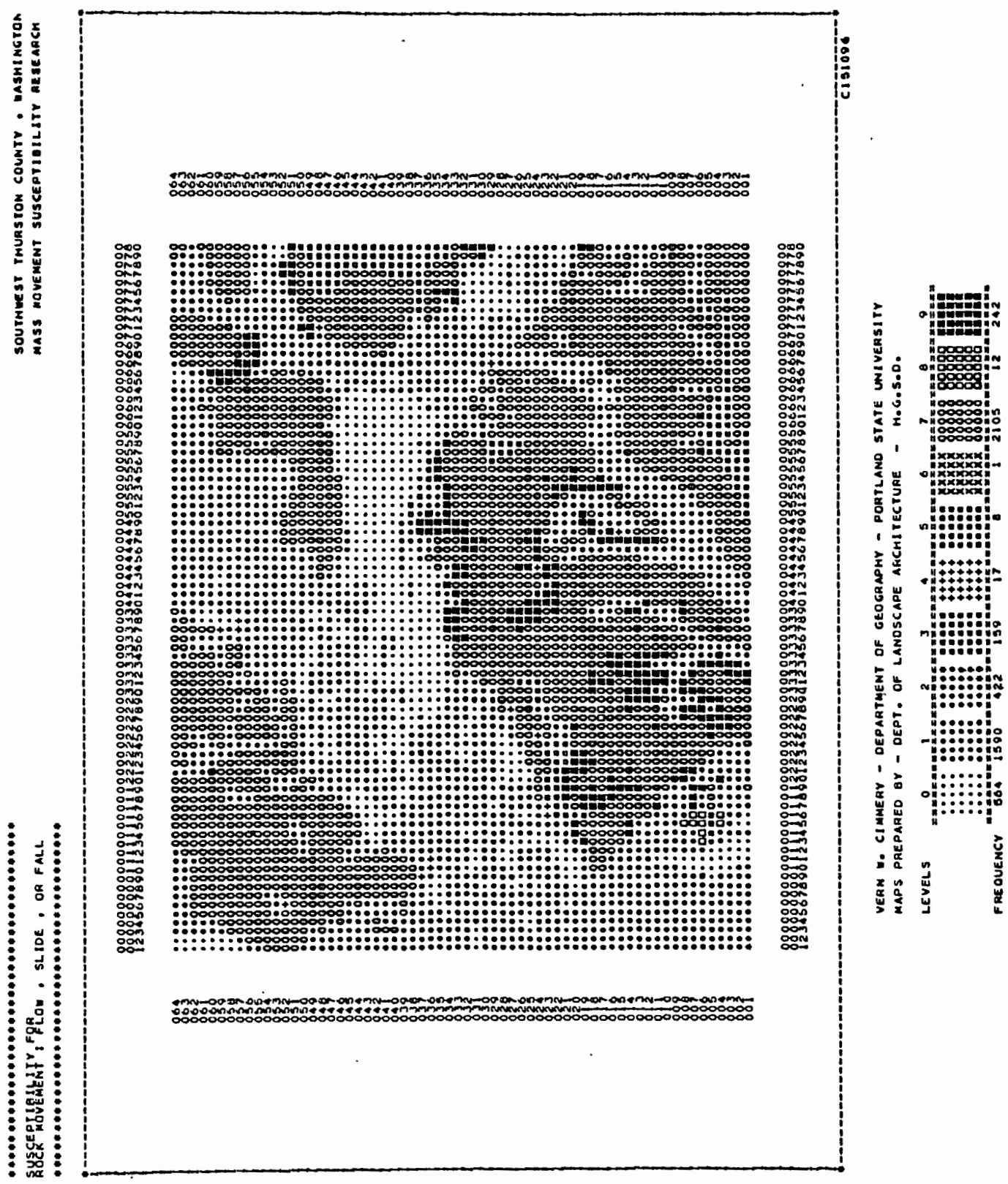




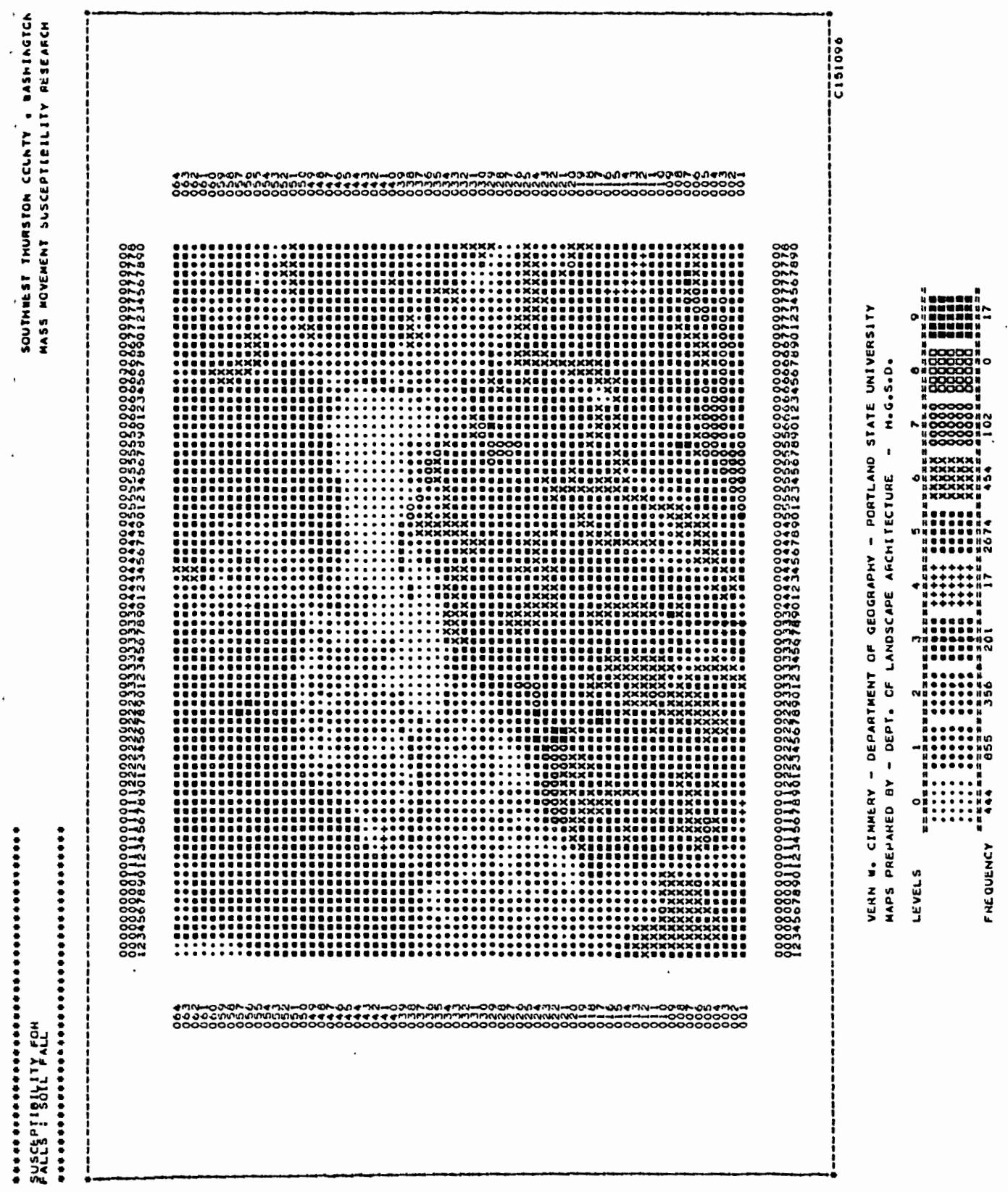




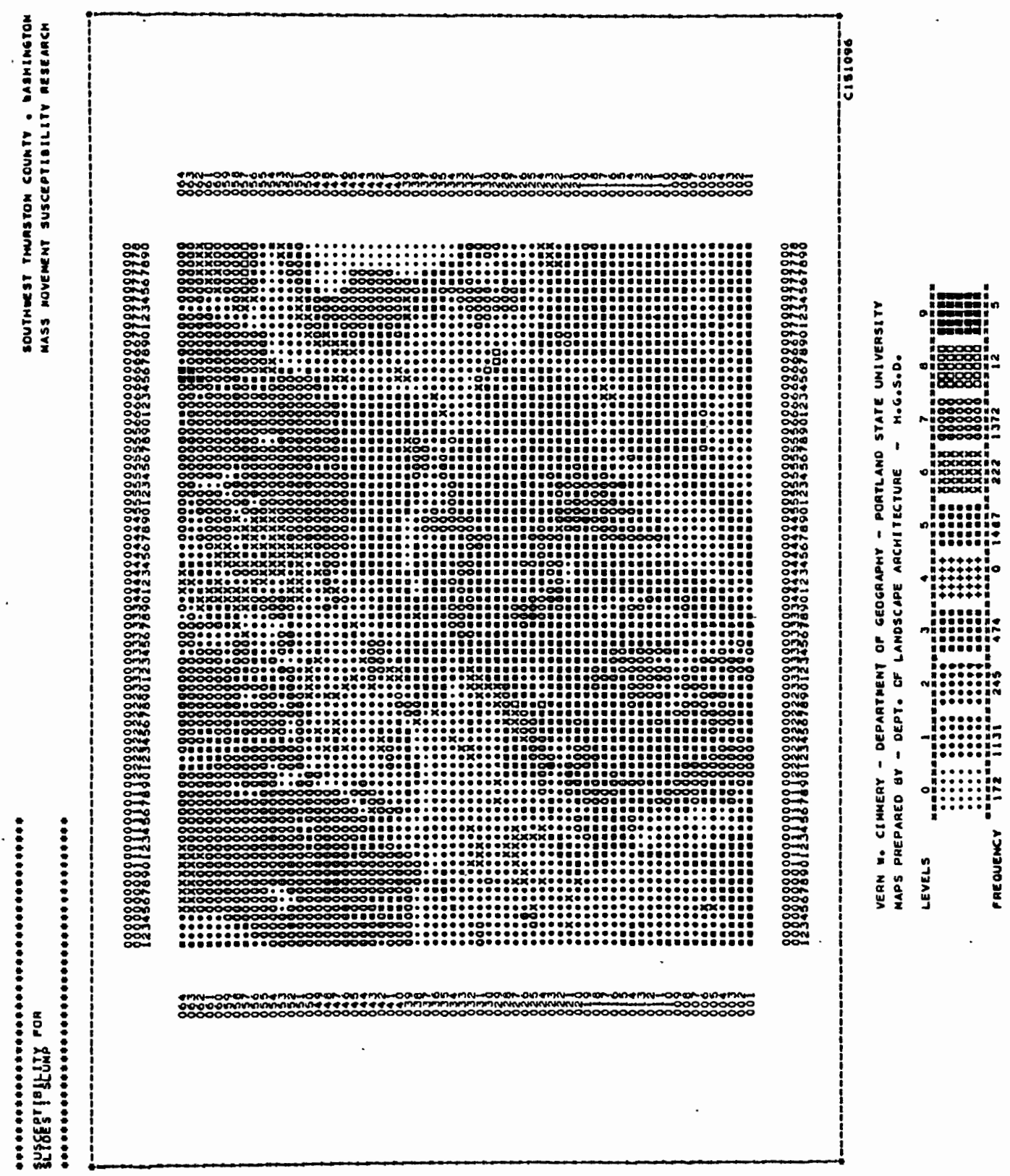




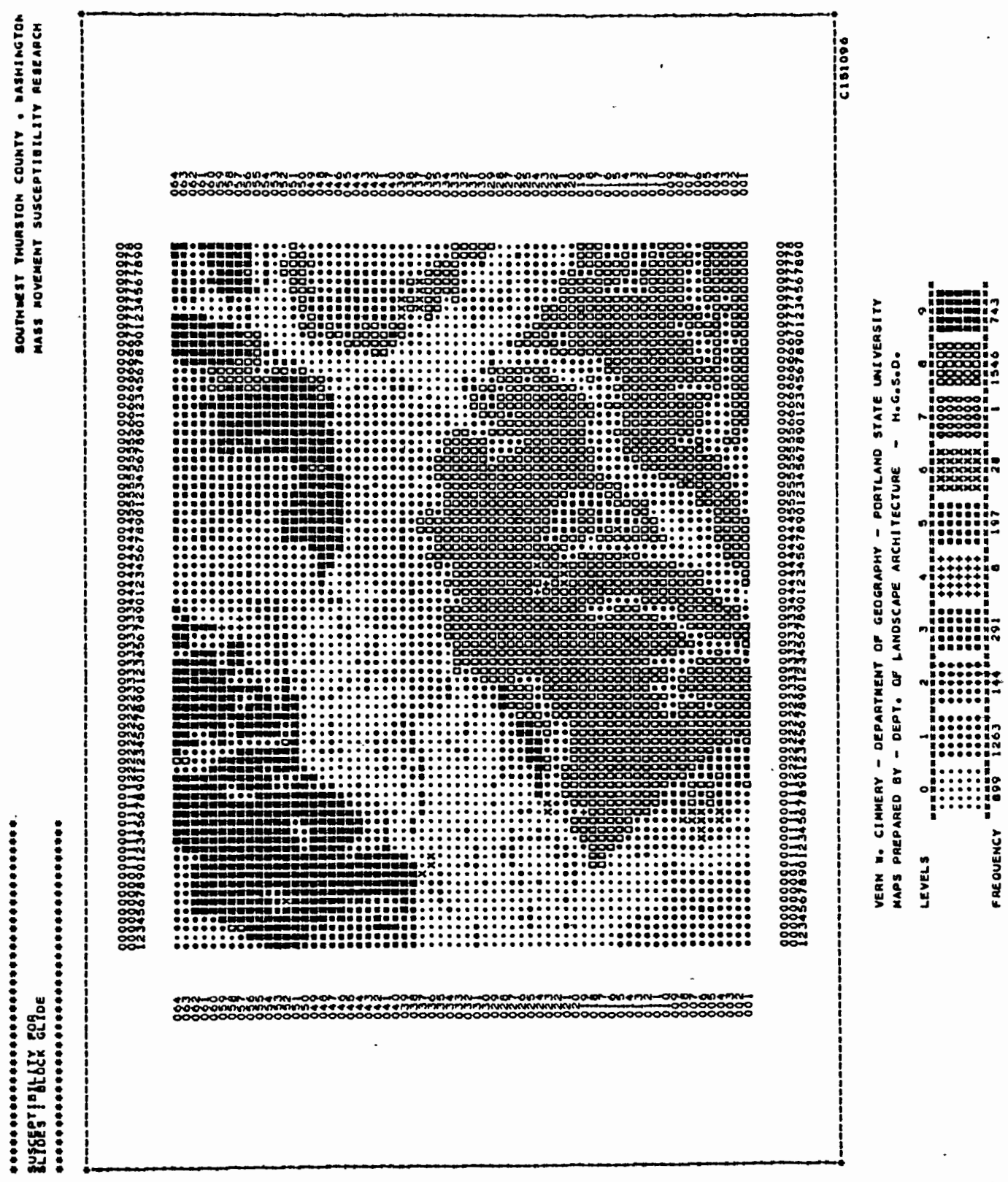




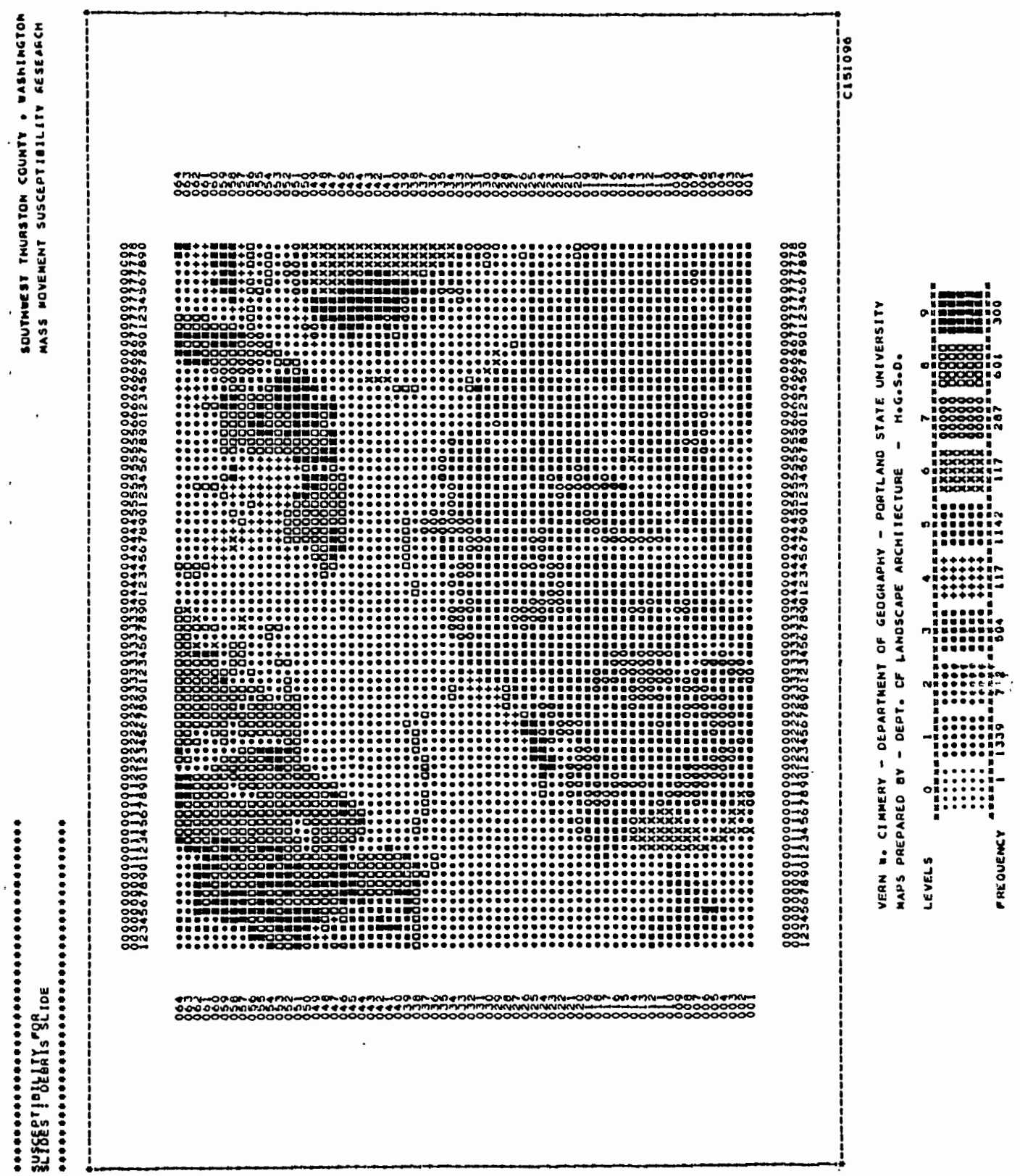




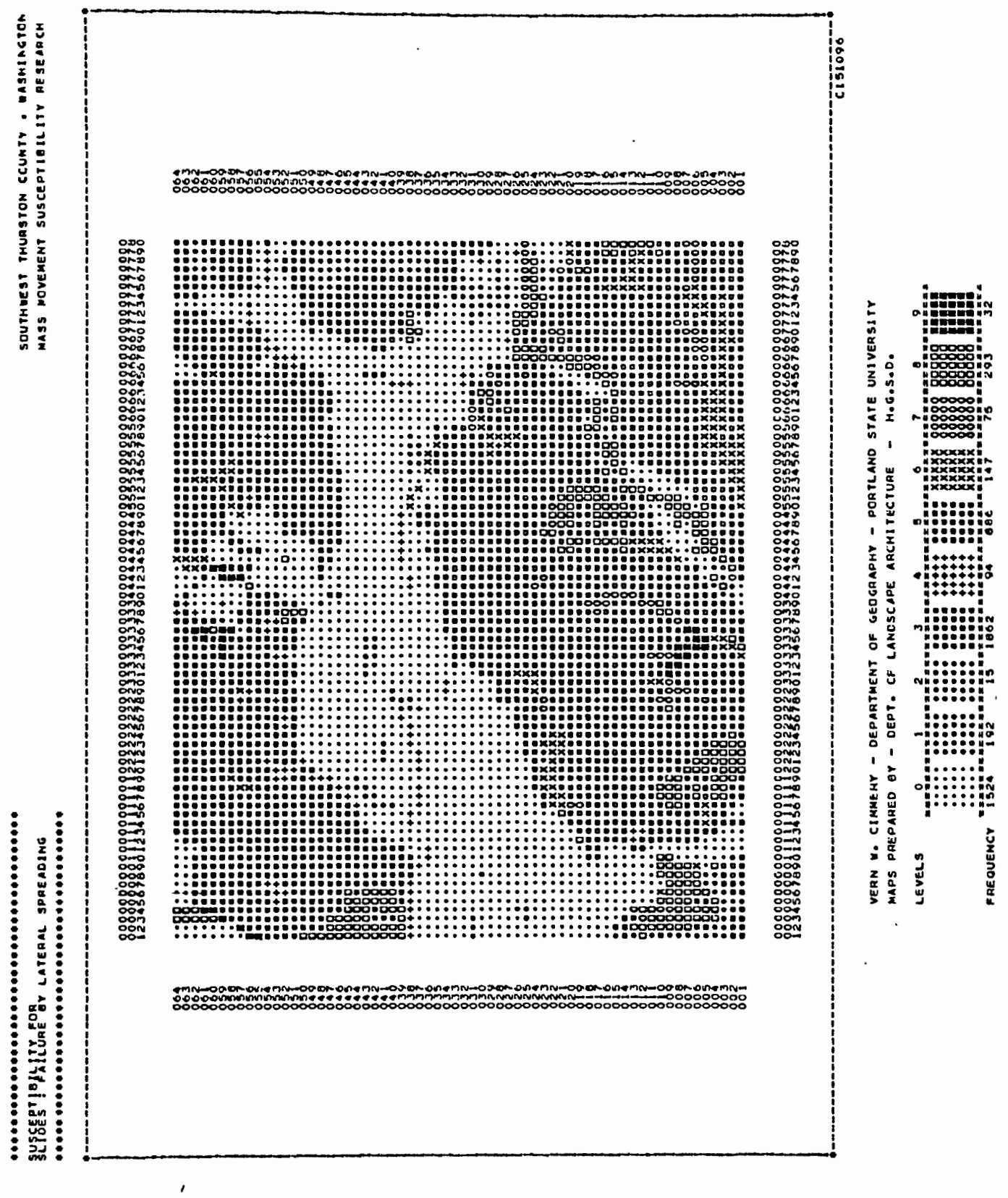




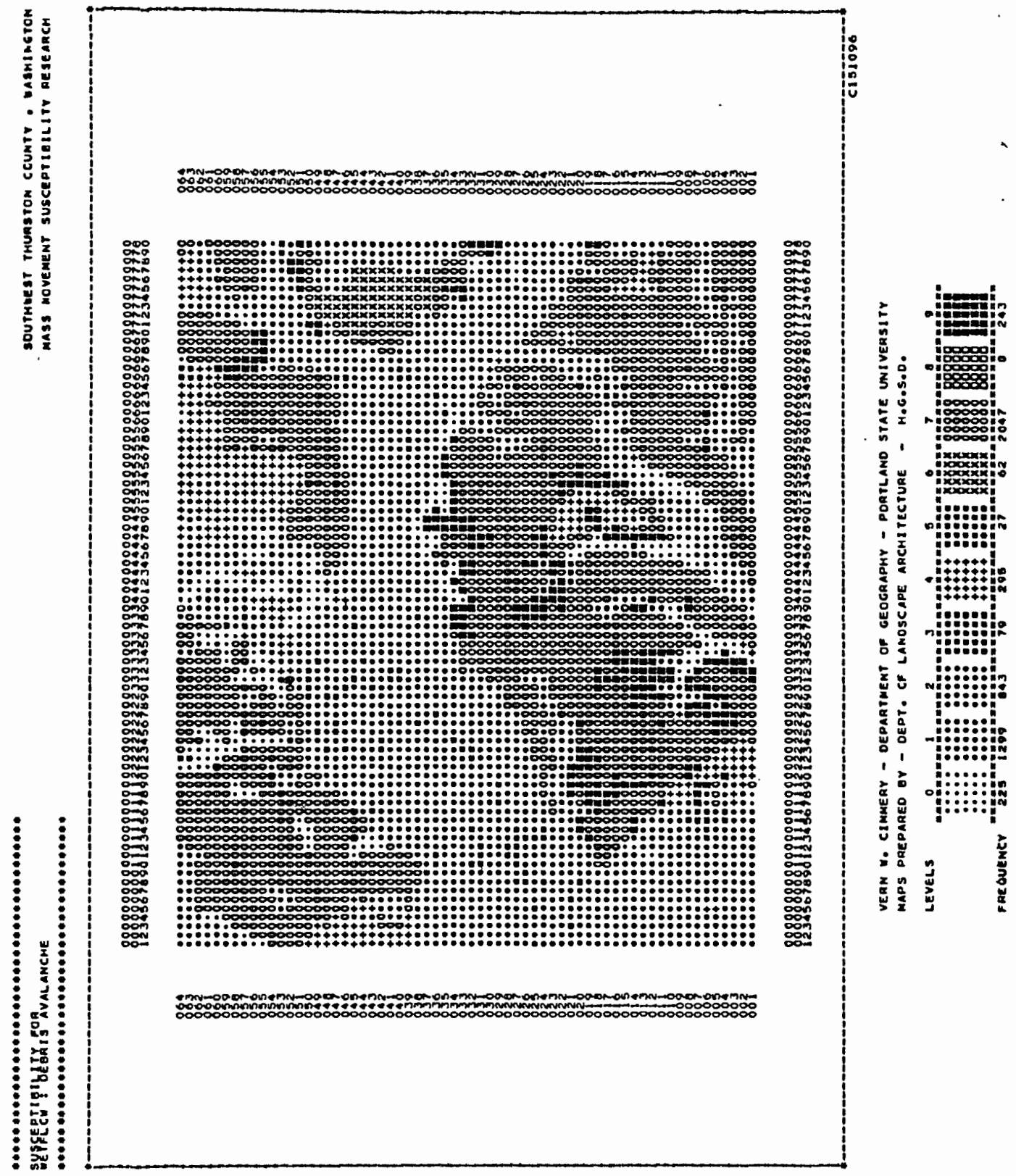




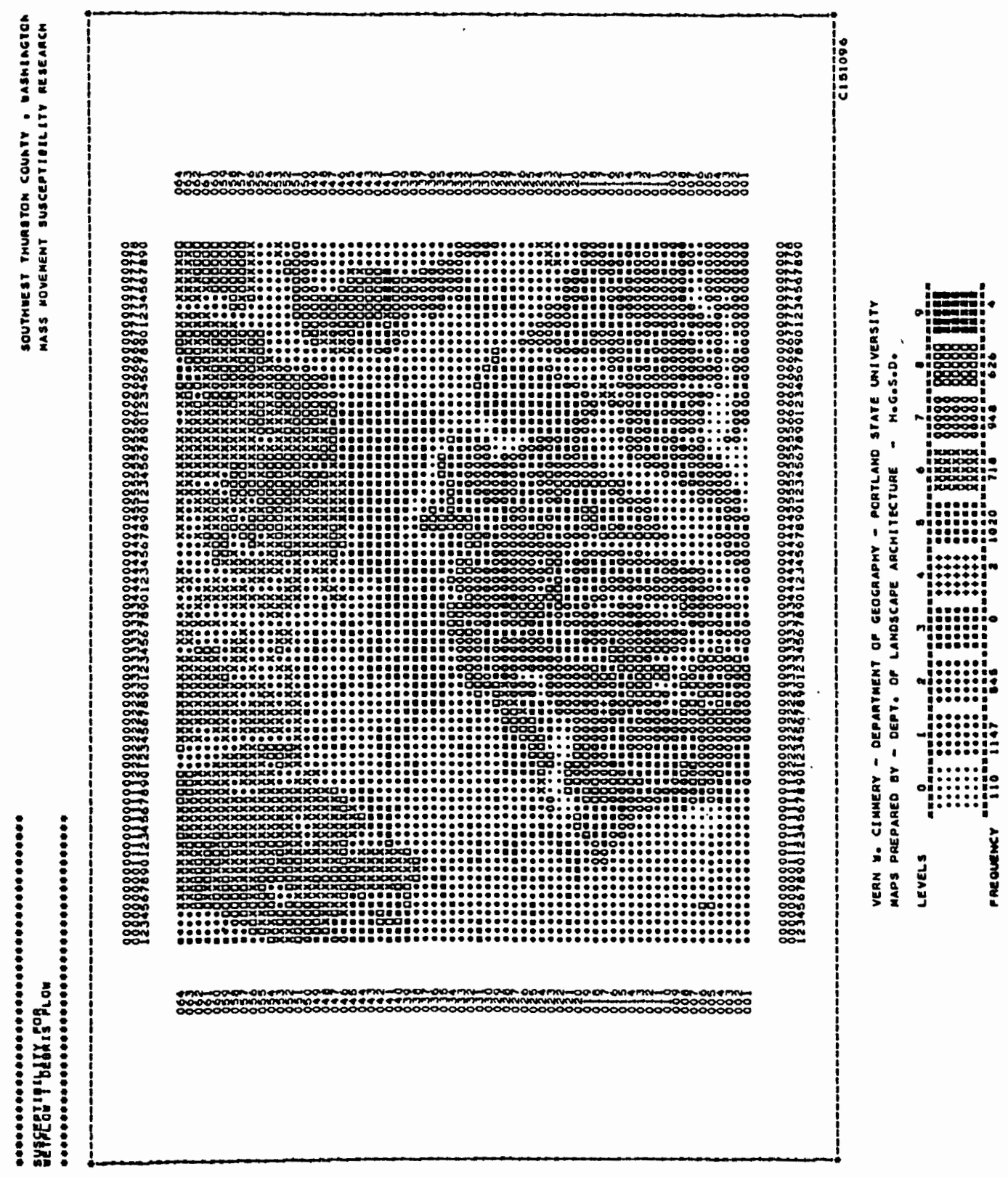




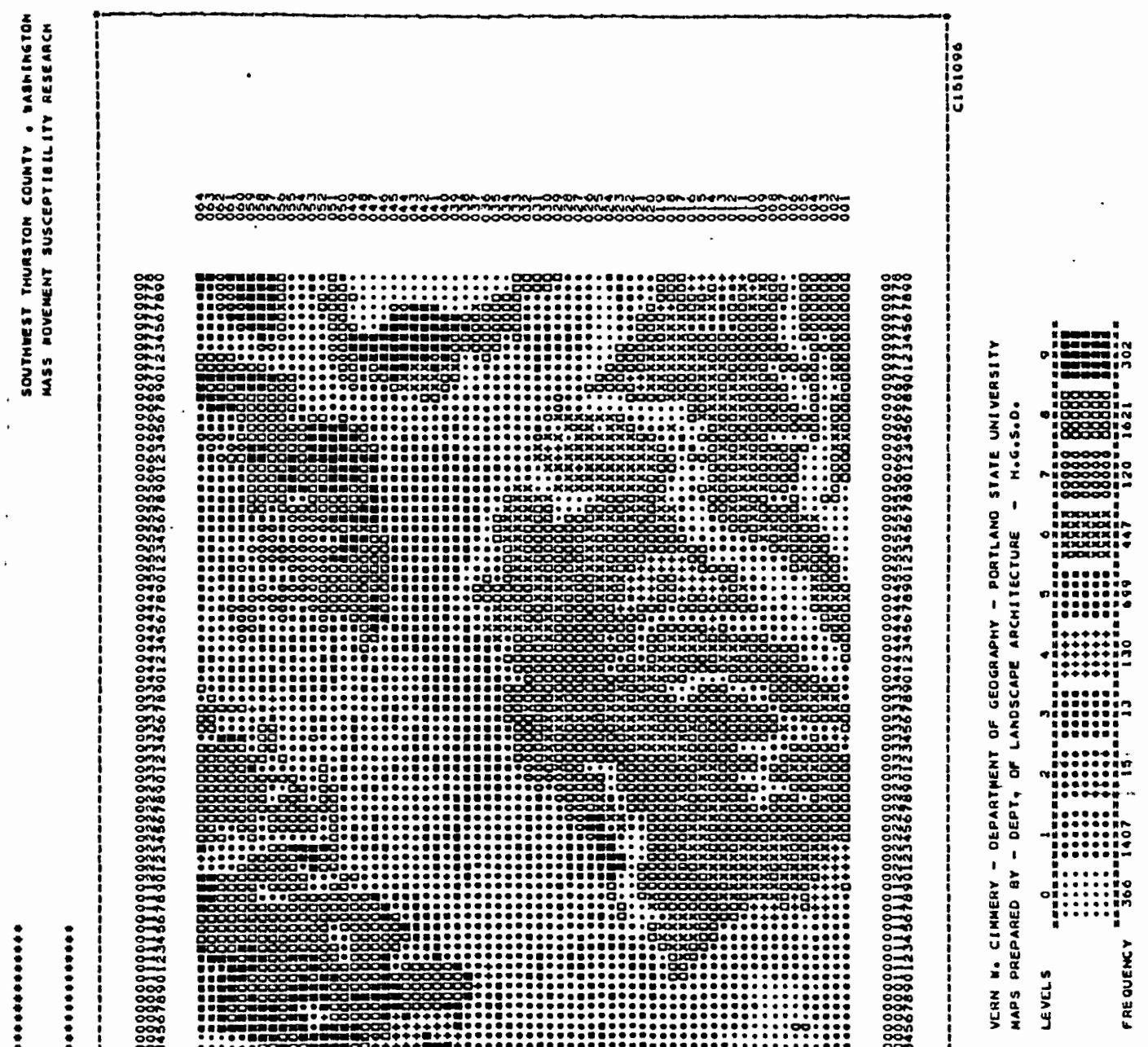



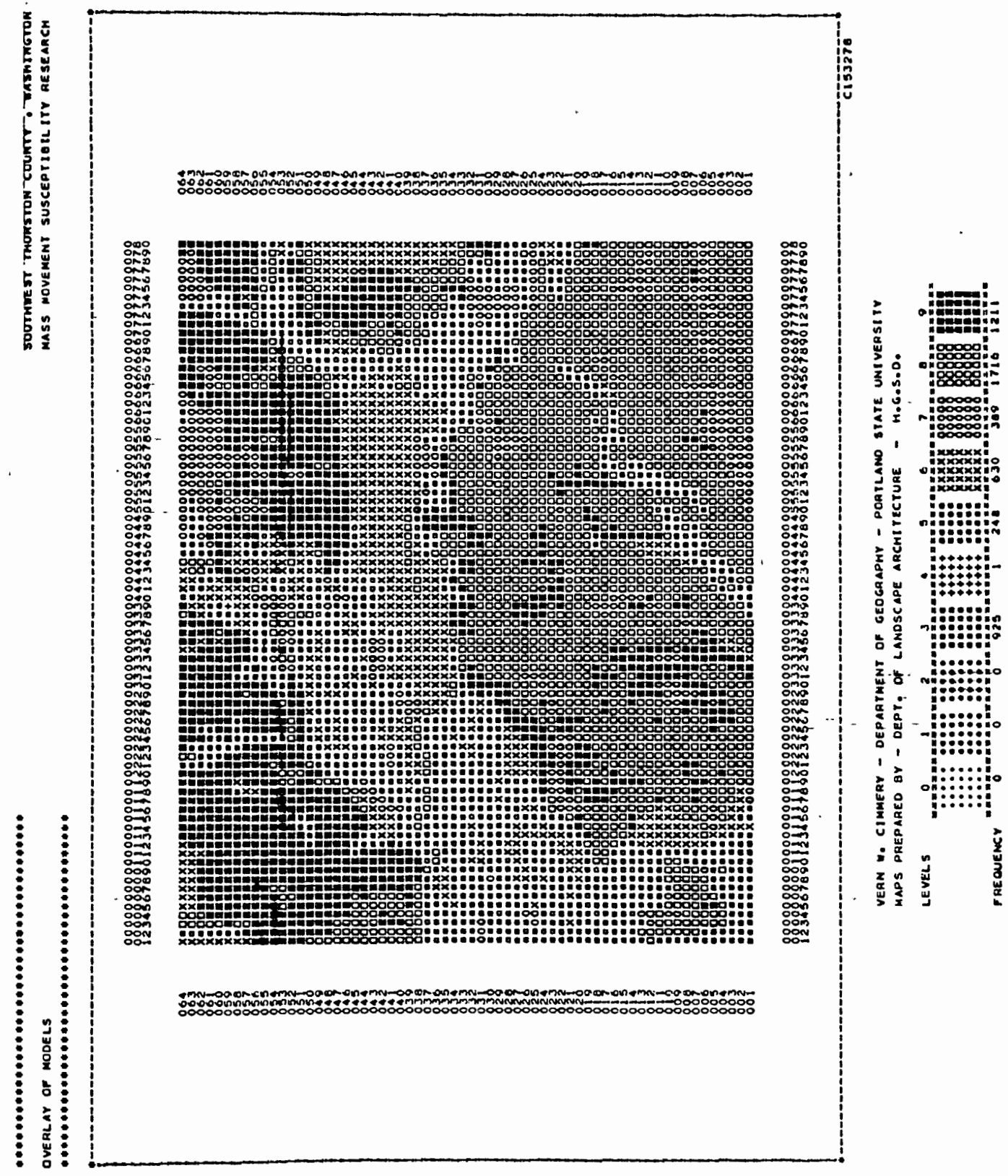
APPENDIX C

DATA VARIABLE MAPS 


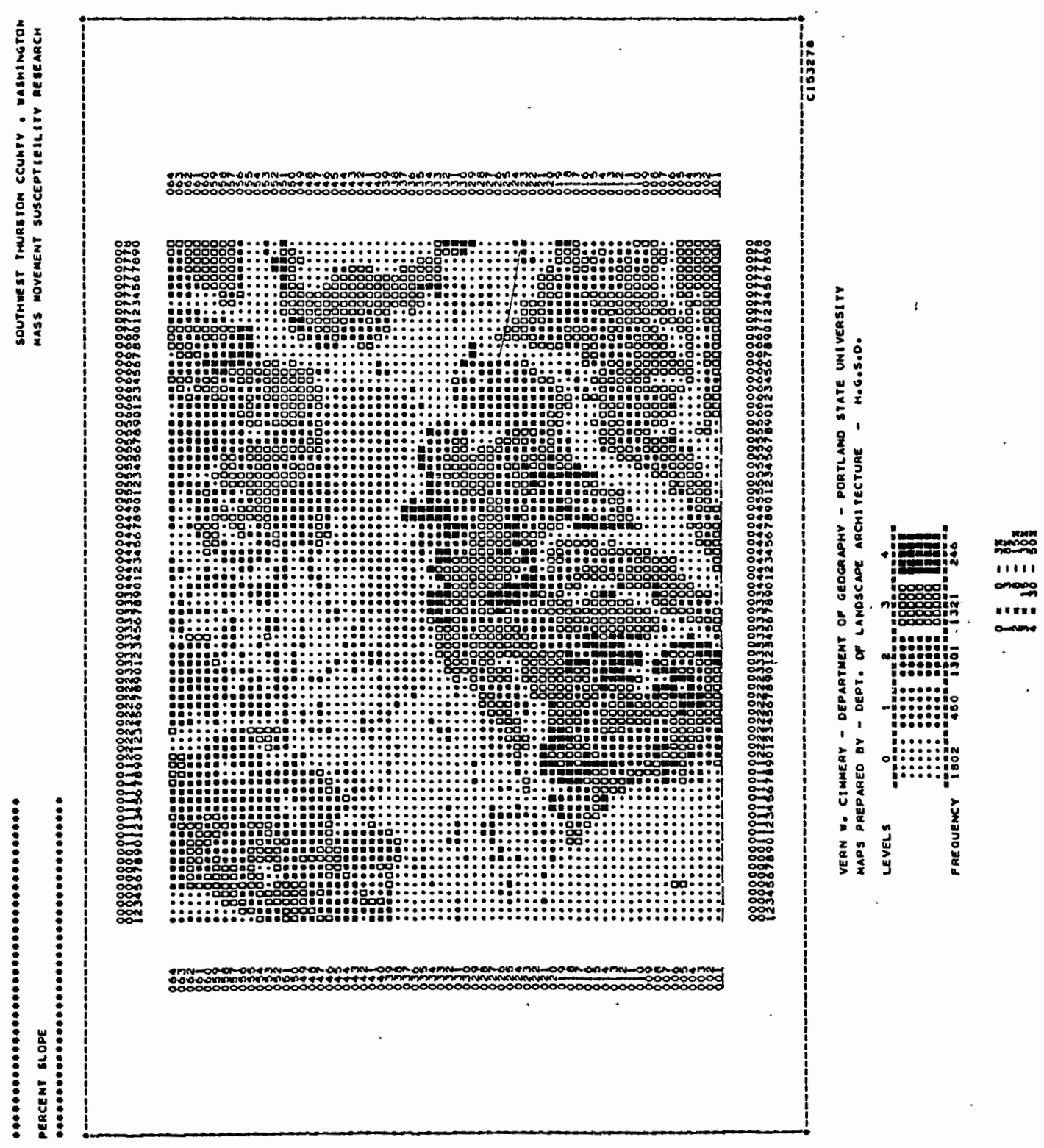




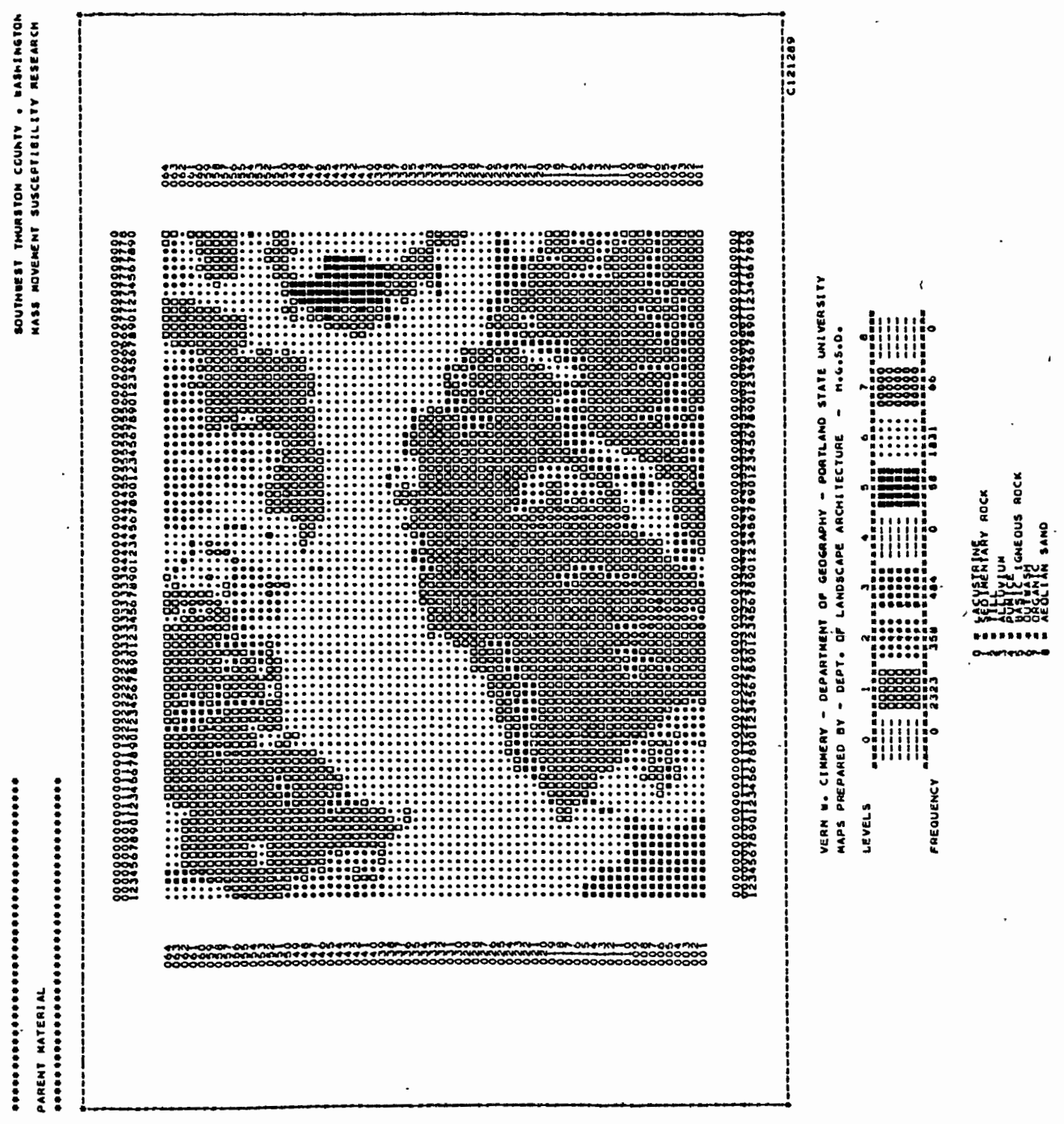




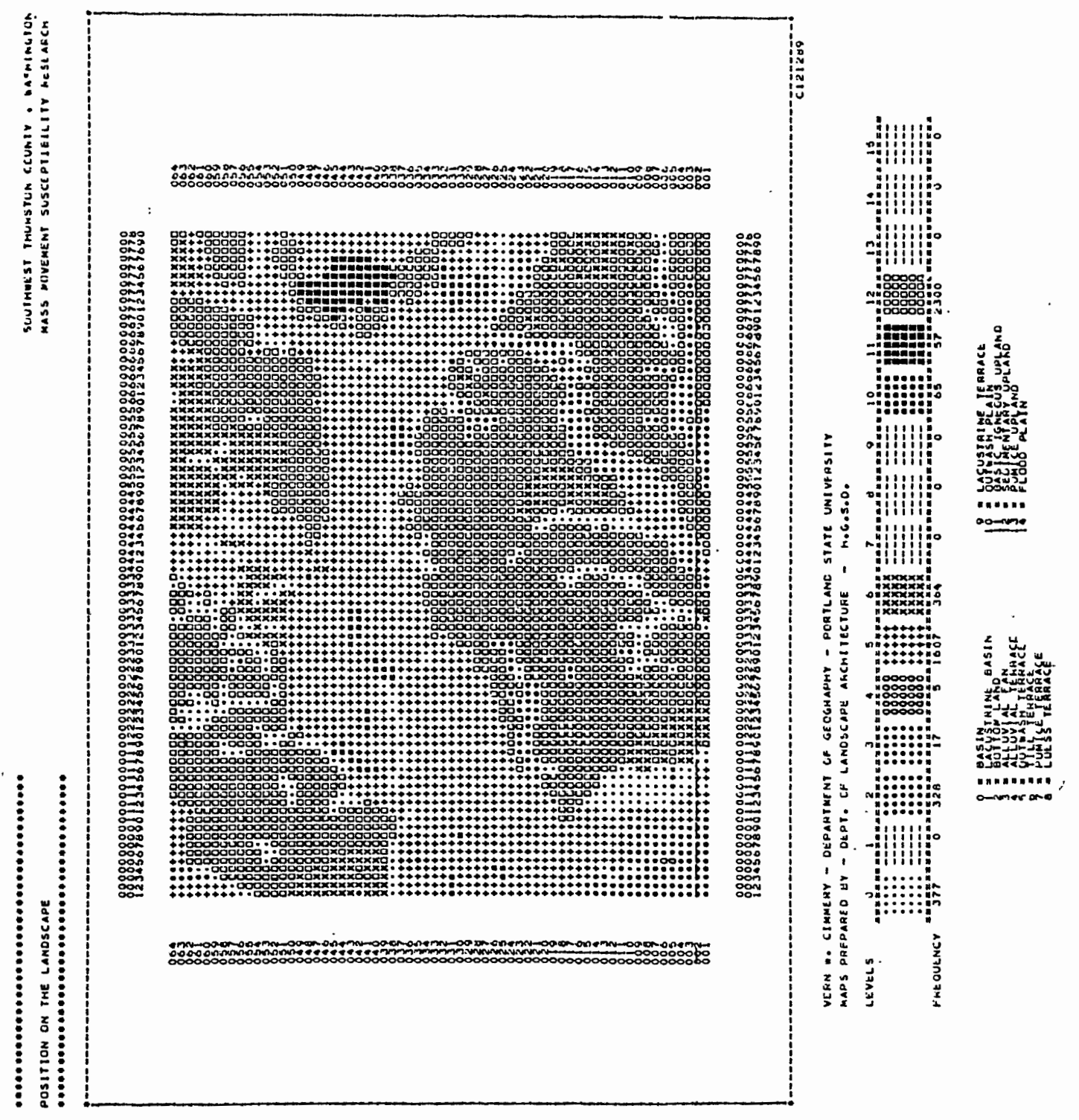




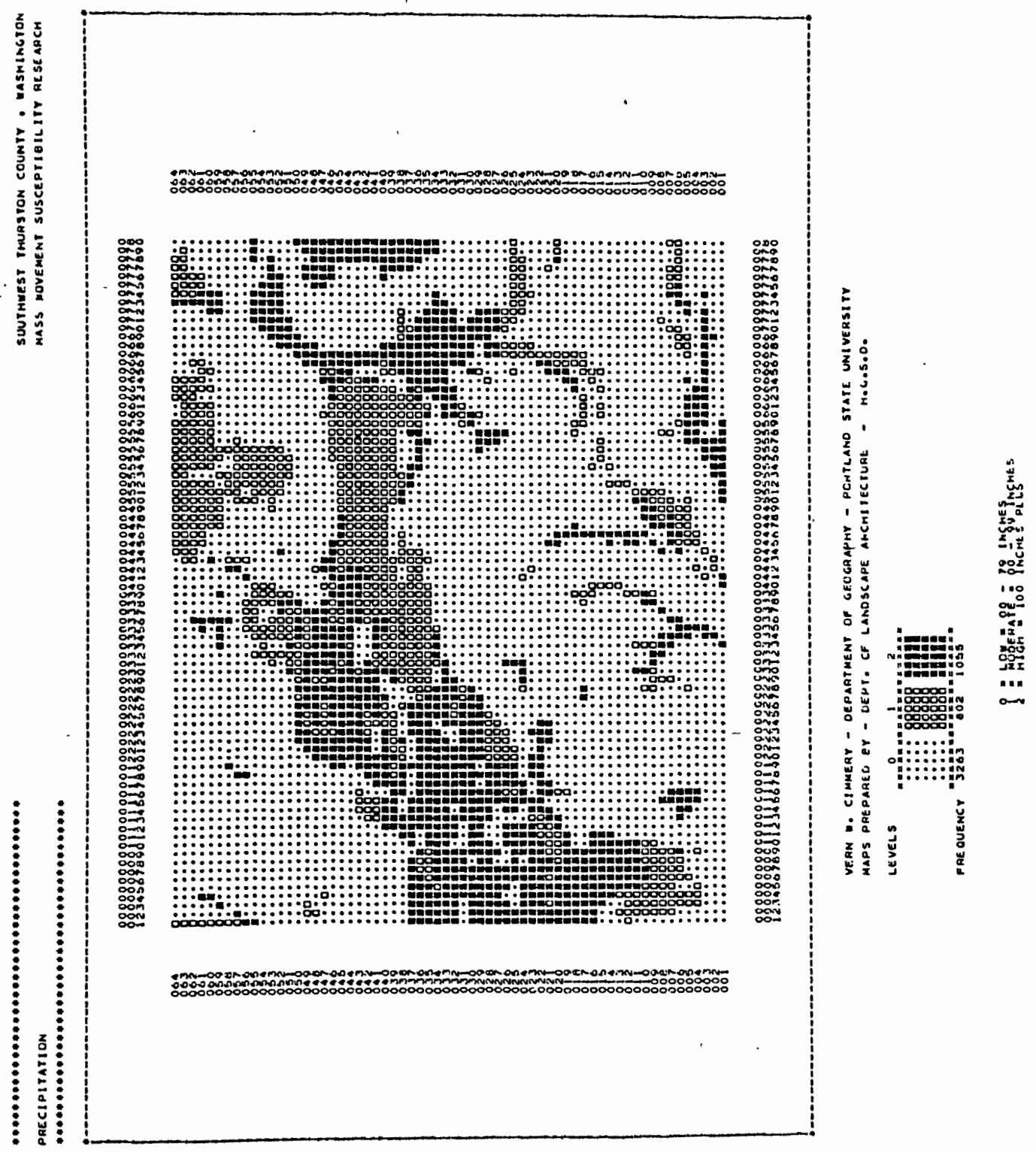




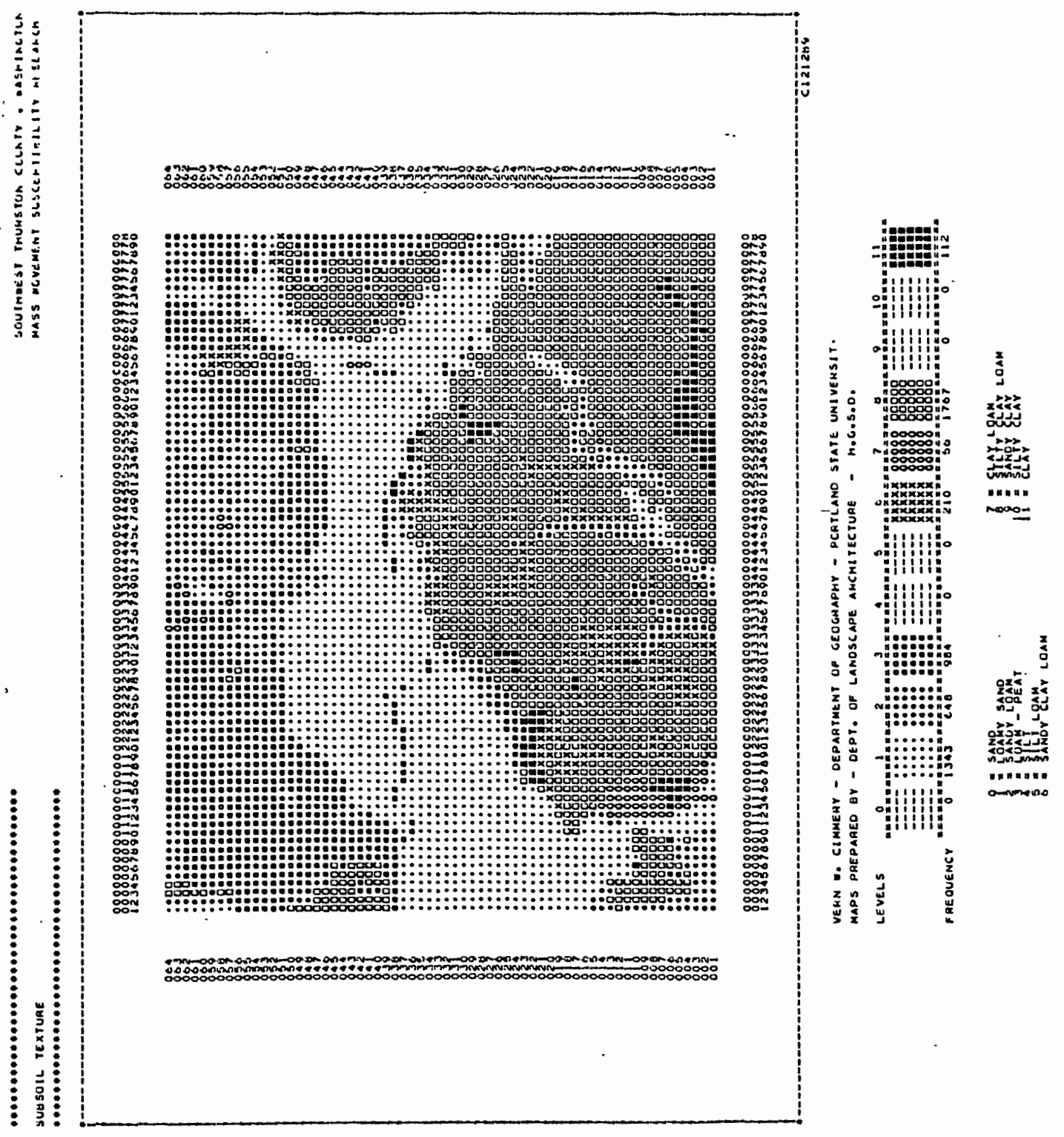




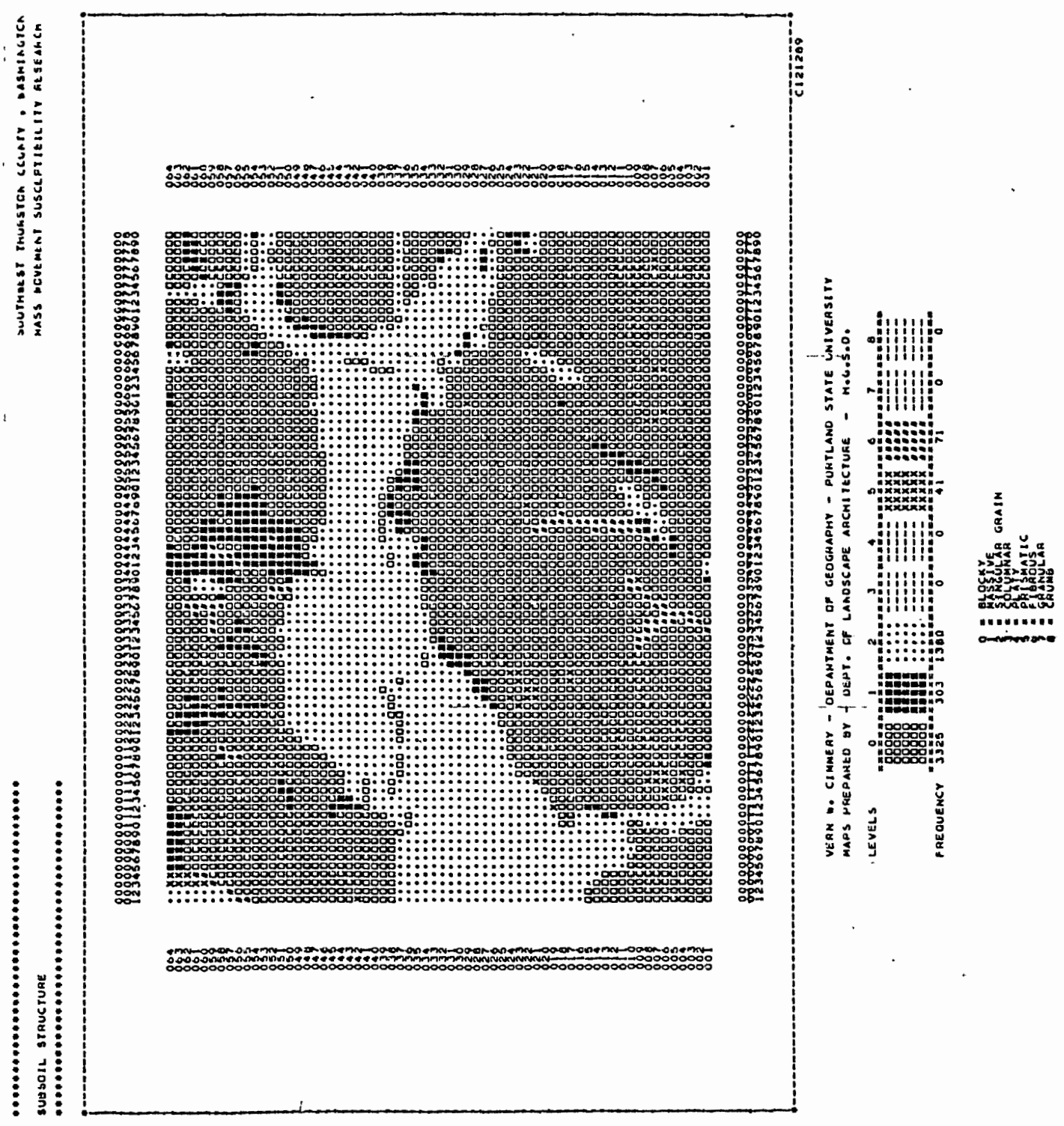




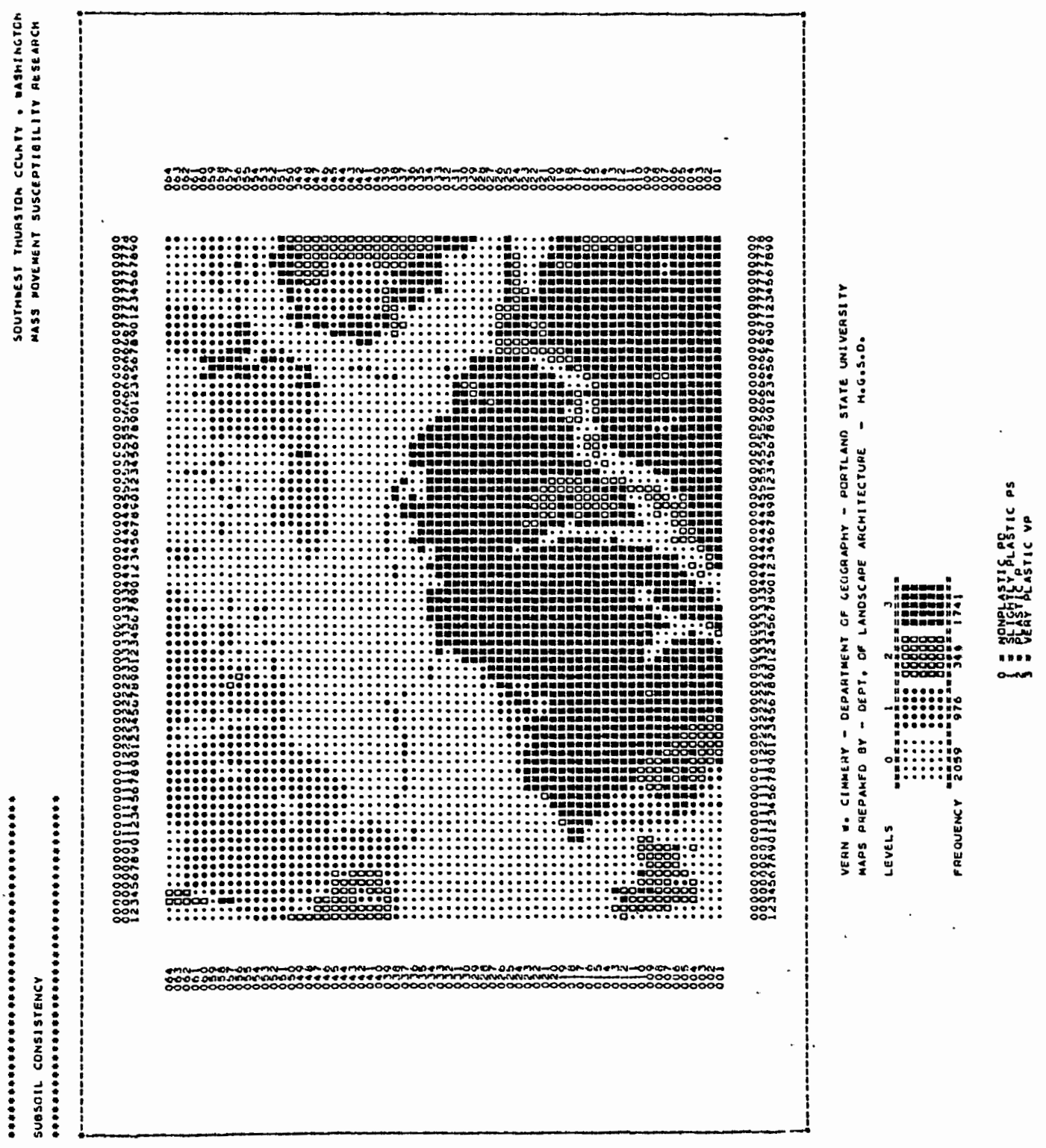




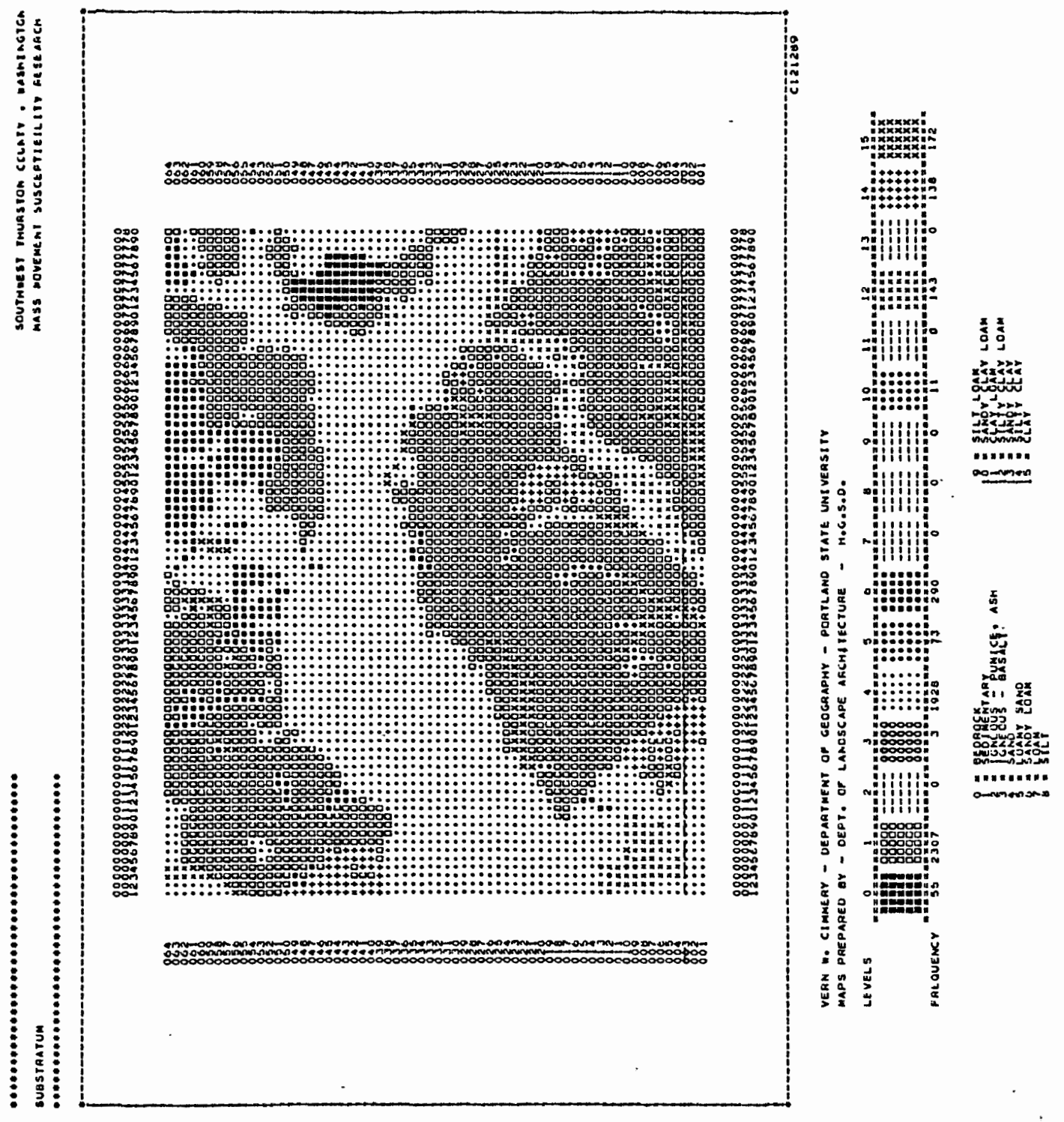




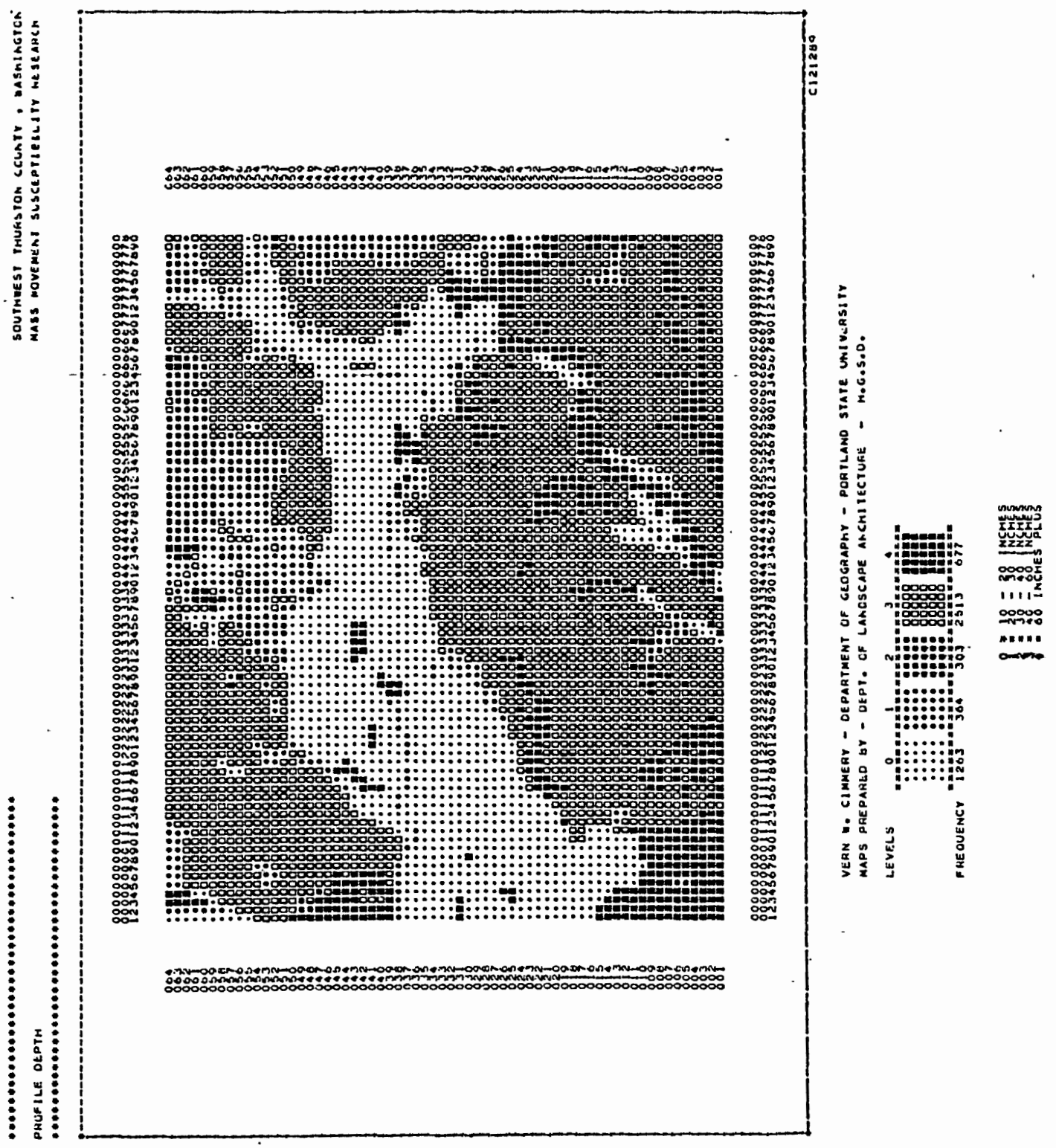




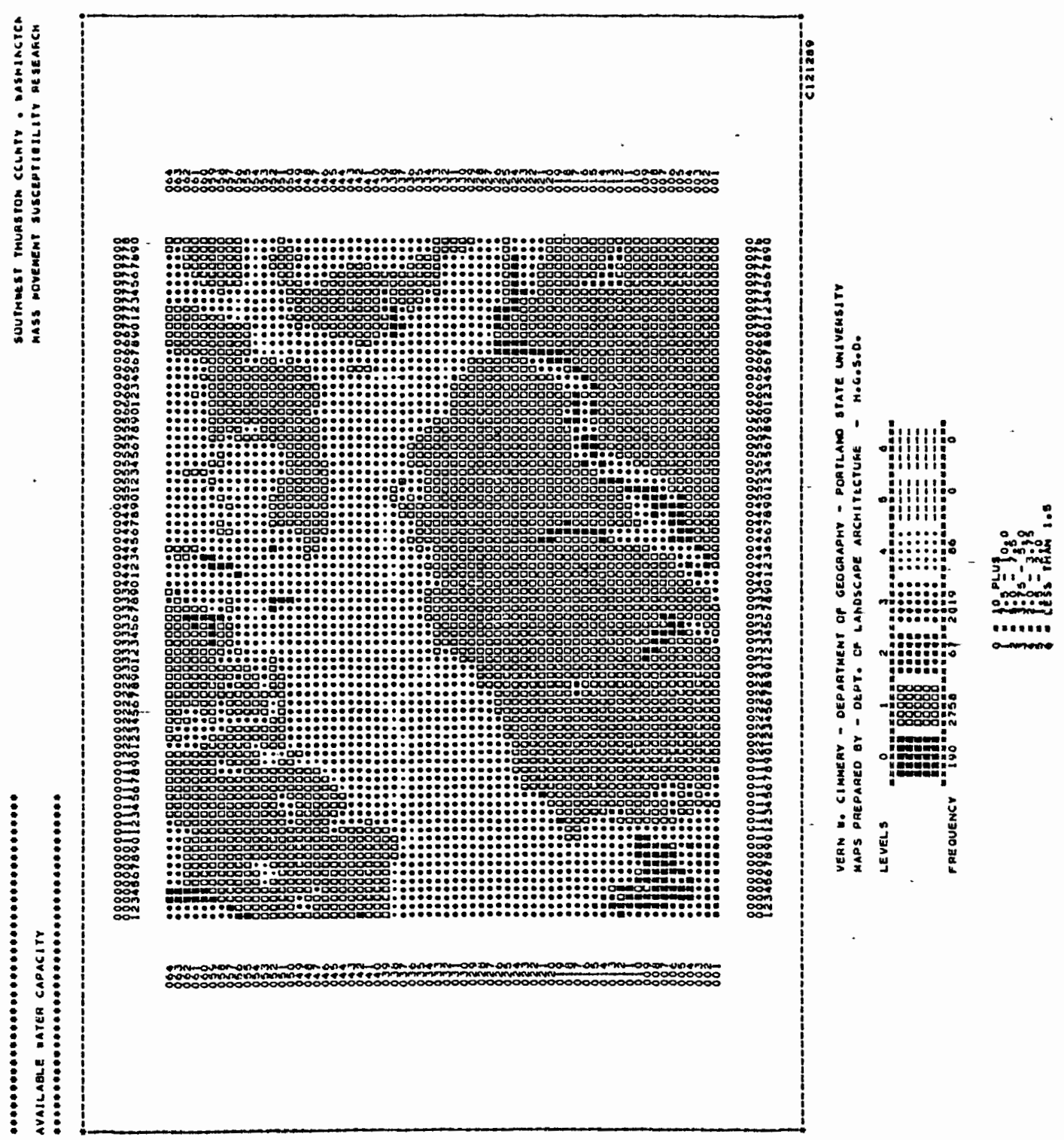



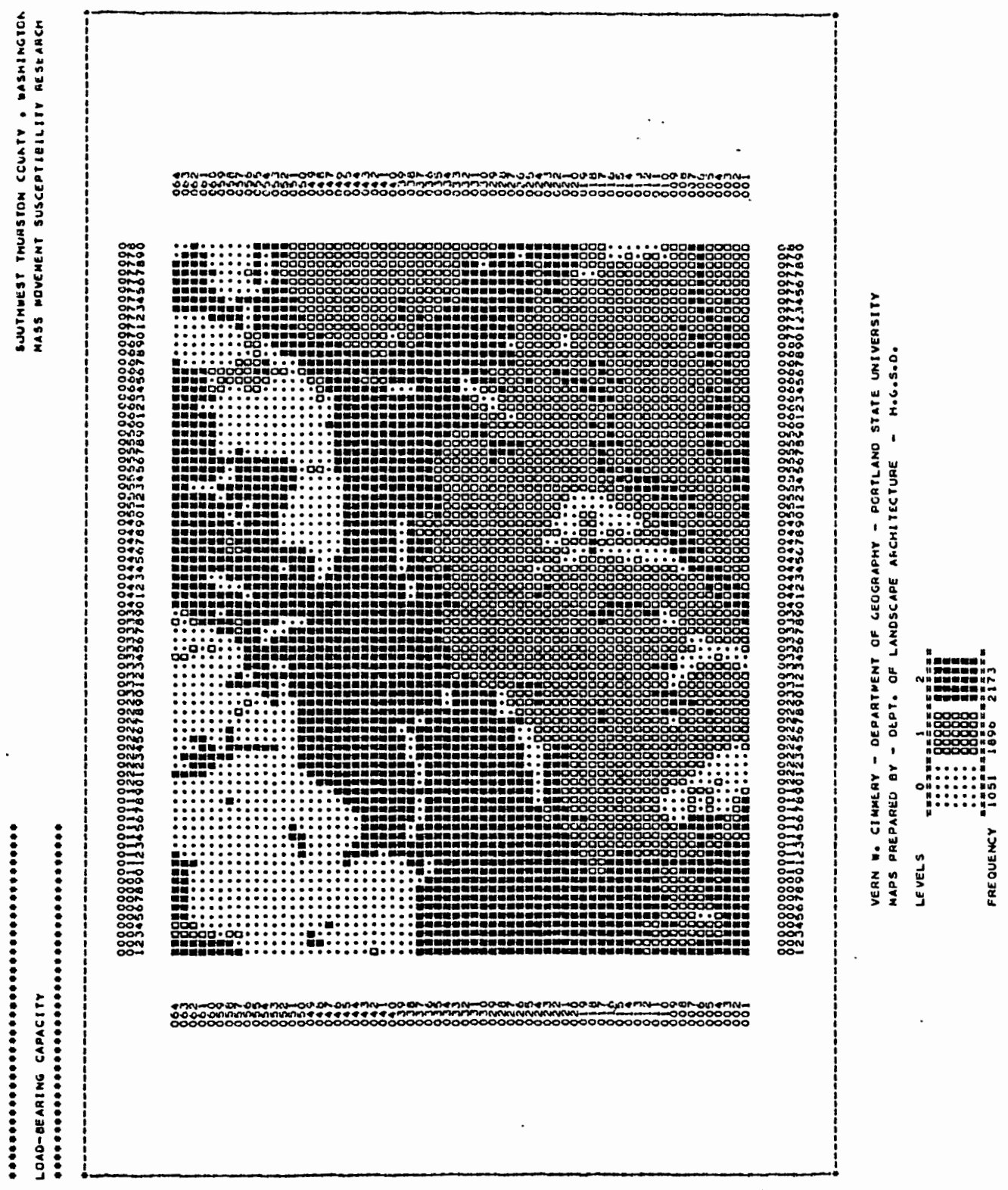
APPENDIX D

MODEL BOOKLETS 


\section{APPENDIX D}

\section{MODEL BOOKLETS}

\section{MASS MOVEMENT SUSCEPTIBILITY MODEL NO. I ROCK MOVEMENT: FLOW, SLIDE, OR FALL}

This failure involves material in motion which may travel through the air by free falling, moving by leaps and bounds, and rolling. It involves material which appears to move as a mass, similar to a viscous fluid or it may be a movement caused by finite shear failure along one or several surfaces which are visible or whose presence may be reasonably inferred. This failure consists of predominantly bedrock material.

The variables and data items identified as important to this mass movement type are:

$$
\begin{array}{ll}
01 & \multicolumn{3}{l}{\text { Percent slope }} \\
00 & 0-3 \% \\
01 & 3-8 \% \\
02 & 8-15 \% \\
03 & 15-30 \% \\
04 & 30-50 \% \\
05 & 50-65 \% \\
06 & 65 \%+
\end{array}
$$

02 Parent material

00 lacustrine

01 sedimentary rock

02 till

03 alluvium

04 pumice 


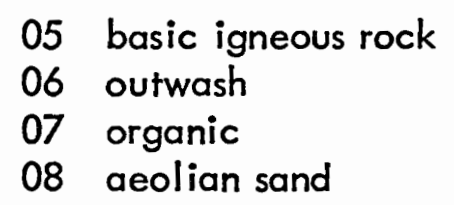

04 Precipitation
00 low $=00-79 n$
01 moderate $=00-99$ "
02 high $=00-100^{\prime \prime}+$

06 Subsoil structure
00 blocky
01 massive
02 singular grain
03 columnar
04 platy
05 prismatic
06 fibrous
07 granular
08 crumb

08 Substratum
00 bedrock
01 sedimentary
02 igneous-pumice, ash
03 igneous-basalt
04 sand
05 loamy sand
06 sandy loam
07 loam
08 silt
09 silt loam
10 sandy clay loam
11 clay loam
12 silty clay loam
13 sandy clay
14 silty clay
15 clay 
Rock Movement Flow, Slide, or Fall

$\begin{array}{lll}2.00 & \text { Slope (1) } & 0000789000000000000 \\ 1.50 & \text { Parent Material (2) } & 0900090000000000000 \\ 1.50 & \text { Substratum (8) } & 9909000000000000000 \\ 1.00 & \text { Subsoil Structure (6) } & 9609990000000000000 \\ 1.00 & \text { Precipitation (4) } & 3690000000000000000\end{array}$

\section{MASS MOVEMENT SUSCEPTIBILITY MODEL NO. 2 FALLS: SOIL FALL}

The purpose of this model is to evaluate every grid cell within the study area for its susceptibility to soilfalls. A soil fall failure is a sub-category of the movements termed falls. A fall involves a mass in motion which travels most of the distance through the air. This travel includes free fall, movement by leaps and bounds, and rolling of rock and debris fragments without much interaction of one fragment with another. This failure involves the fall of soil material. Soil material is defined as clastic material, including rock fragments, sheared bedrock, organic material, etc. The evaluation is to be accomplished by considering the coincidental occurrence of specific physical characteristics that have been identified by researchers as characteristics of areas experiencing soilfall type mass movements.

The variable and data items identified as important to this mass movement type are:

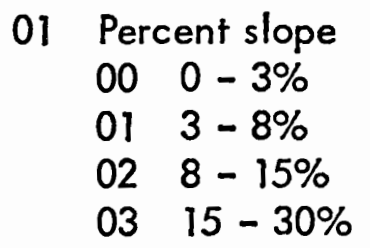


$\begin{array}{ll}04 & 30-50 \% \\ 05 & 50-65 \% \\ 06 & 65 \%+\end{array}$

03 Position on the landscape

00 basin

01 lacustrine basin

02 bottom land

03 alluvial fan

04 alluvial terrace

05 outwash terrace

06 till terrace

07 pumice terrace

08 loess terrace

09 lacustrine terrace

10 outwash plain

11 basic igneous upland

12 sedimentary upland

04 Precipitation

00 low $=00-79 "$

01 moderate $=00-99^{\prime \prime}$

02 high $=00-100^{\prime \prime}+$

06 Subsoil structure

00 blocky

01 massive

02 singular grain

03 columnar

04 platy

05 prismatic

06 fibrous

07 granular

08 crumb

09 Profile depth

$0010-20 "$

$0120-30^{\prime \prime}$

$0230-40^{\prime \prime}$

03 40-60"

$0460^{\prime \prime}+$ 
Soilfall Flow, Slide, or Fall

$2.00 \quad$ Slope (1).

0000369000000000000

1.50 Subsoil Structure (6)

9609990000000000000

1.00

Precipitation (4) 3690000000000000000

1.50

Position on Landscape (3)

0009300000000000000

1.00

Profile Depth (9)

0036900000000000000

\section{MASS MOVEMENT SUSCEPTIBILITY MODEL NO. 3 SLIDES: SLUMP}

The purpose of this model is to evaluate every grid cell within the study area for its susceptibility to slump. A slump failure is a sub-category of the movements termed slides. A slide is a movement caused by finite shear failure along one or several surfaces which are visible or whose presence may be reasonably inferred. A slump type slide consists of material in motion which is not greatly deformed. The moving mass may consist of one or a few units. The maximum dimension of units is greater than displacement between units. Movement may be controlled by surfaces of weakness such as faults, bedding planes or joints. In a slump, movement is only along internal slip surfaces, which are usually concave upward. Backward tilting of units is common.

The variables and data items identified as important to this mass movement type are:

\begin{tabular}{ll}
01 & \multicolumn{3}{l}{ Percent slope } \\
00 & $0-3 \%$ \\
01 & $3-8 \%$ \\
02 & $8-15 \%$ \\
03 & $15-30 \%$ \\
04 & $30-50 \%$ \\
05 & $50-65 \%$ \\
06 & $65 \%+$
\end{tabular}


04 Precipitation

00 low $=00-79 "$

01 moderate $=00-99$ "

02 high $=00-100^{\prime \prime}+$

07 Subsoil consistence

00 nonplastic po

01 slightly plastic ps

02 plastic $p$

03 very plastic vp

09 Profile depth

$0010-20 "$

$0120-30 "$

$0230-40^{\prime \prime}$

$0340-60^{\prime \prime}$

$0460^{\prime \prime}+$

Slump

Flow, Slide, or Fall

$2.00 \quad$ Slope (1)

0366999000000000000

1.00 Subsoil Consistency (7)

9630000000000000000

2.00

Precipitation (4)

1.00

Profile Depth (9)

9990000000000000000

0036900000000000000

\section{MASS MOVEMENT SUSCEPTIBILITY MODEL NO. 4 SLIDES: BLOCK GLIDE}

The purpose of this model is to evaluate every grid cell within the study area for its susceptibility to block glide. A block glide failure is a sub-category of the movements termed slides. A slide is a movement caused by finite shear failure along one or several surfaces which are visible or whose presence may be reasonably inferred. A block glide slide involves material which is not greatly deformed. The moving mass consists of one or a few units. The maximum dimension of units is greater than displacement between units. Movement may be controlled by surfaces of weakness such as faults, bedding planes or joints. In a 
block glide, movement of a single unit is out and down along a more or less planar surface of weakness, generally a bedding plane.

The variables and data items identified as important to this mass movement type are:

$$
\begin{array}{ll}
01 & \text { Percent slope } \\
00 & 0-3 \% \\
01 & 3-8 \% \\
02 & 8-15 \% \\
03 & 15-30 \% \\
04 & 30-50 \% \\
05 & 50-65 \% \\
06 & 65 \%+
\end{array}
$$

02 Parent material

00 lacustrine

01 sedimentary rock

02 till

03 alluvium

04 pumice

05 basic igneous rock

06 outwash

07 organic

08 aeolian sand

04 Precipitation

00 low $=00-79 "$

01 moderate $=00-99 "$

02 high $=00-100^{\prime \prime}+$

06 Subsoil structure

00 blocky

ol massive

02 singular grain

03 columnar

04 platy

05 prismatic

06 fibrous

07 granular

08 crumb 
08 Substratum

00 bedrock

01 sedimentary

02 igneous-pumice, ash

03 igneous-basalt

04 sand

05 loamy sand

06 sandy loam

07 loam

08 silt

09 silt loam

10 sandy clay loam

11 clay loam

12 silty clay loam

13 sandy clay

14 silty clay

15 clay

11 Load-carrying capacity

00 low

01 moderate

02 high

Block Glide

Flow, Slide, or Fall

2.00

Slope (1)

1.50

Subsoil Structure (6)

1.00

Precipitation (4)

2.00

Parent Material (2)

1.50

Substratum (8)

1.50

Load Carrying Capacity (11)

0666999000000000000

9609990000000000000

9990000000000000000

0900060000000000000

0906000000000000000

9000000000000000000

\section{MASS MOVEMENT SUSCEPTIBILITY MODEL NO. 5 SLIDES: DEBRIS SLIDE}

The purpose of this model is to evaluate every grid cell within the study area for its susceptibility to debris slides. A debris slide is a sub-category of the movements termed slides. A slide is a movement caused by finite shear failure along one or several surfaces which are visible or whose presence may be 
reasonably inferred. The material involved is natural soil and rock detritus that contains a relatively high percentage of coarse fragments. Other features are similar to those of a rock slide.

The variables and data items identified as important to this mass movement type are:

$$
\begin{array}{ll}
01 & \multicolumn{3}{l}{\text { Percent slope }} \\
00 & 0-3 \% \\
01 & 3-8 \% \\
02 & 8-15 \% \\
03 & 15-30 \% \\
04 & 30-50 \% \\
05 & 50-65 \% \\
06 & 65 \%+
\end{array}
$$

05 Subsoil texture

00 sand

01 loamy sand

02 . sandy loam

03 loam

04 silt

05 silt loam

06 sandy clay loam

07 clay loam

08 silty clay loam

09 sandy clay

10 silty clay

11 clay

07 Subsoil consistence

00 nonplastic po

01 slightly pastic ps

02 plastic $p$

03 very plastic vp
Debris Slide

2.00

2.00

1.00

Flow, Slide, or Fall

Slope (1)

Subsoil Consistency (7)

Subsoil Texture (5)
0003699000000000000 0963060000000000000 6699996363330000000 


\section{MASS MOVEMENT SUSCEPTIBILITY MODEL NO. 6 \\ SLIDES: FAILURE BY LATERAL SPREADING}

The purpose of this model is to evaluate every grid cell within the study area for its susceptibility to failure by lateral spreading. Failure by lateral spreading is a sub-category of the movements termed slides. A slide is a movement caused by finite shear failure along one or several surfaces which are visible or whose presence may be reasonably inferred. This failure is caused by the spreading of softer material beneath firmer material.

The variables and data items identified as important to this mass movement type are:
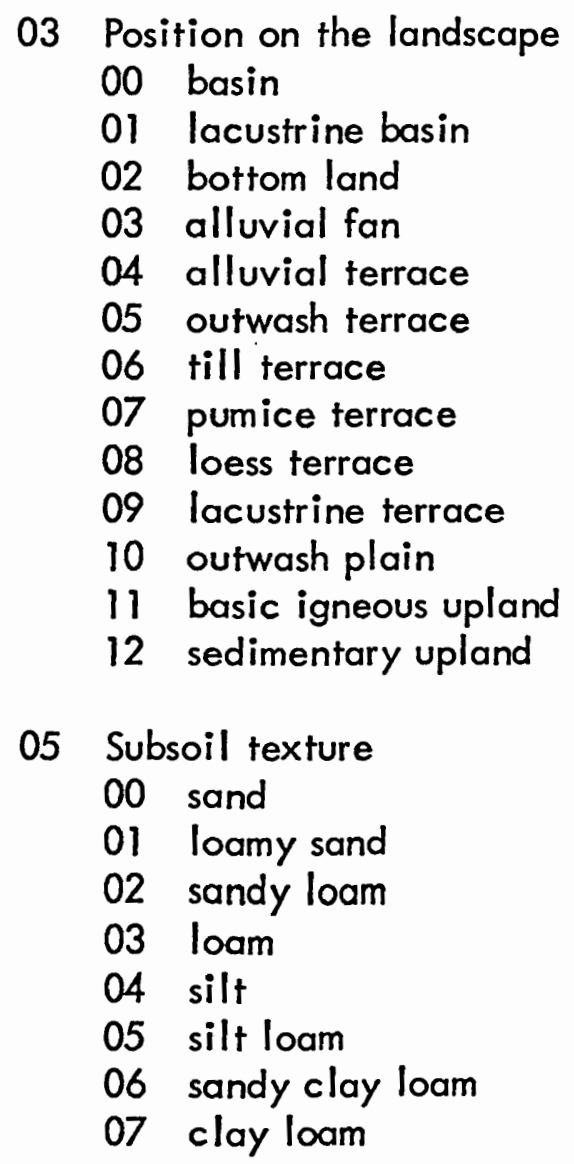


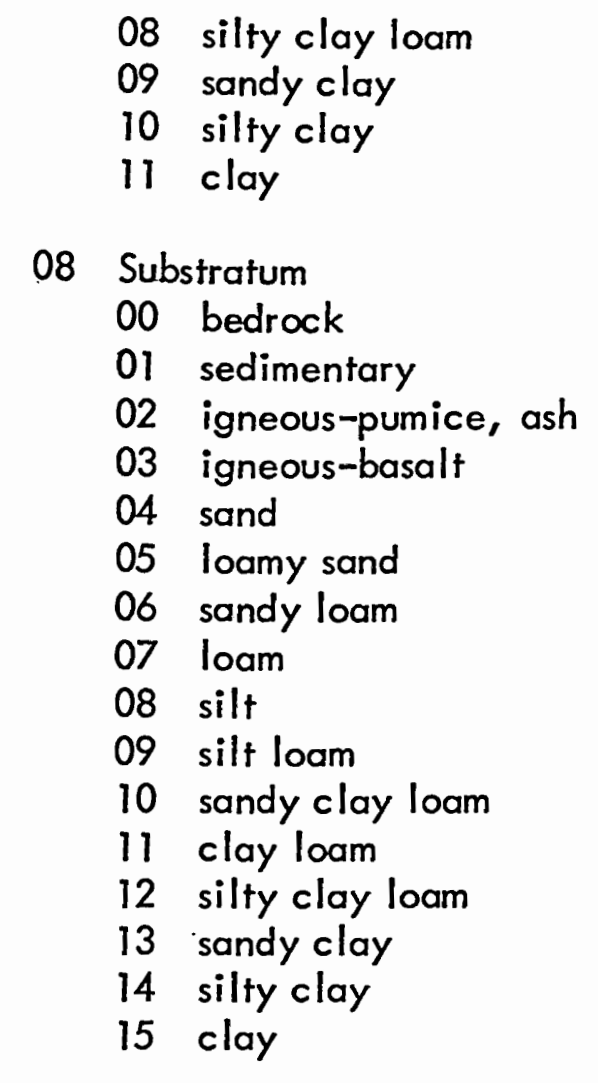

10 Available water capacity $00 \quad 10+$

$017.5-10.0$

$02 \quad 5.0-7.5$

$03 \quad 3.75-5.0$

$04 \quad 2.0-3.75$

$05 \quad 1.5-2.0$

$06<1.5$

11 Load carrying capacity

00 low

01 moderate

02 high

Failure by Lateral Spreading

\section{Flow, Slide, or Fall}

2.00 Substratum (8)

1.00 Position on Landscape (3)

2.00 Subsoil Texture (5)

1.50 Available Water Capacity (10)

1.50 Load Carrying Capacity (11)
3333399999996669600 9993333393933393000 3000960000000000000 9630000000000000000 9630000000000000000 


\section{MASS MOVEMENT SUSCEPTIBILITY MODEL NO. 7 WETFLOW: DEBRIS AVALANCHE}

The purpose of this model is to evaluate every grid cell within the study area for its susceptibility to debris avalanches. This failure is a sub-category of the movements termed wet flows. A wet flow is a mass movement for which the mass or moving material appears to take a form of a viscous fluid or the apparent distribution of velocities and displacements within the moving mass resemble those of a viscous fluid. Slip surfaces within the mass are usually not visible or are short lived. The boundary between moving mass and material in place may be sharp or a zone of distributed shear. The material is unconsolidated at the time of flow but may consist of rock fragments, fine granular material, mixed debris and water, or plastic clay. A debris avalanche is the rapid failure of an entire mass consisting of natural soil and rock detritus. Generally it is quite wet and moves as a tumbling flow downward, commonly along a stream channel.

The variables and data items identified as important to this mass movement type are:

02 Parent material
00 lacustrine
01 sedimentary rock
02 till
03 alluvium
04 pumice
05 basic igneous rock
06 outwash
07 organic
08 aeolian sand


04 Precipitation

00 low $=00-79 "$

01 moderate $=00-99$ "

02 high $=00-100^{\prime \prime}+$

06 Subsoil structure

00 blocky

01 massive

02 singular grain

03 columnar

04 platy

05 prismatic

06 fibrous

07 granular

08 crumb

\section{Debris}

Avalanche

Flow, Slide, or Fall

2.00

Slope (1)

0033690000000000000

1.50

Precipitation (4)

1.00

Subsoil Structure (6)

9990000000000000000

1.00

Parent Material (2)

\section{MASS MOVEMENT SUSCEPTIBILITY MODEL NO. 8 WETFLOW: DEBRIS FLOW}

The purpose of this model is to evaluate every grid cell within the study area for its susceptibility to debris flows. Debris flow failure is a sub-category of the movements termed wet flow. A flow is a mass movement for which the mass or moving material appears to take the form of a viscous fluid or the apparent dismibution of velocities and displacements within the moving mass resemble those of a viscous fluid. Slip surfaces within the mass are usually not visible or are short lived. The boundary between moving mass and material in place may be sharp or a zone of distributed shear. The material is unconsolidated at the time 
of flow but may consist of rock fragments, fine granular material, mixed debris and water, or plastic clay. A debris flow involves material that contains a relatively high percentage of coarse fragments and moves as a flow with a high water content.

The variables and data items identified as important to this mass movement type are:

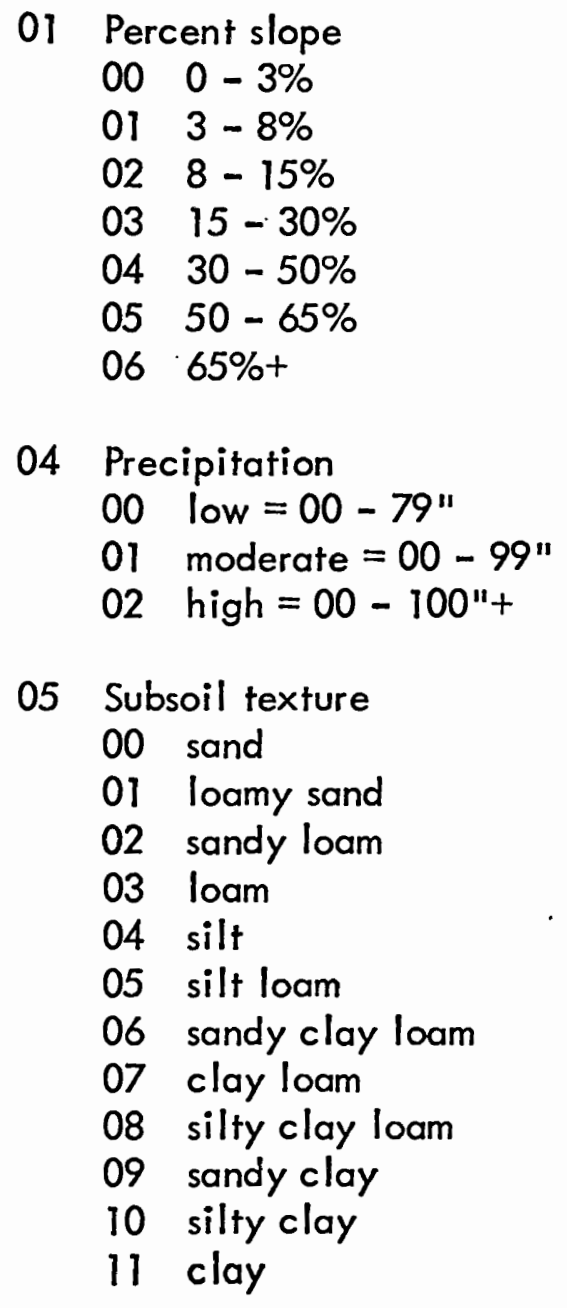

08 Substratum

00 bedrock

01 sedimentary

02 igneous-pumice, ash

03 igneous-basalt 


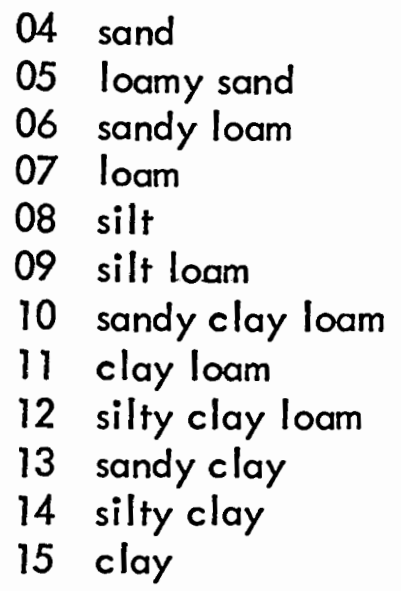

Debris Flow

Flow, Slide, or Fall

$2.00 \quad$ Slope (1)

1.50 Precipitation (4)

1.00 Subsoil Texture (5)

1.00 Substratum (8)

0669999000000000000 9990000000000000000 3699999666630000000 3000000009600000000

\section{MASS MOVEMENT SUSCEPTIBILITY MODEL NO. 9 FLOW: EARTHFLOW}

The purpose of this model is to evaluate every grid cell within the study area for its susceptibility to earthflows. Earthflow failure is a sub-category of the movements termed flow. A flow is a mass movement for which the mass or moving material appears to take a form of a viscous fluid or the apparent distribution of velocities and displacements within the moving mass resemble those of a viscous fluid. Slip surfaces within the mass are usually not visible or are short lived. The boundary between moving mass and material in place may be sharp or a zone of distributed shear. The material is unconsolidated at the time of flow but may consist of rock fragments, fine granular material, mixed debris and water, 
or plastic clay. An earthflow is slow to very rapid in velocity involving mostly plastic or fine-grained non-plastic material.

The variables and data items identified as important to this mass movement type are:

$$
\begin{array}{ll}
01 & \multicolumn{3}{l}{\text { Percent slope }} \\
00 & 0-3 \% \\
01 & 3-8 \% \\
02 & 8-15 \% \\
03 & 15-30 \% \\
04 & 30-50 \% \\
05 & 50-65 \% \\
06 & 65 \%+
\end{array}
$$

02 Parent material

00 lacustrine

01 sedimentary rock

02 till

03 alluvium

04 pumice

05 basic igneous rock

06 outwash

07 organic

08 aeolian sand

04 Precipitation

00 low $=00-79^{\prime \prime}$

01 moderate $=00-99$ "

02 high $=00-100^{\prime \prime}+$

07 Subsoil consistence

00 nonplastic po

01 slightly plastic ps

02 plastic $p$

03 very plastic vp

Earthflow Flow, Slide, or Fall

2.00 Slope (1)

1.50 Precipitation (4)

0669999000000000000

1.00

Subsoil Consistency (7)

1.00

Parent Material (2) 9990000000000000000 9963000000000000000 0900060000000000000 
APPENDIX E

SOIL TYPES AND CHARACTERISTICS OF STUDY

AREA IN SOUTHWEST THURSTON

COUNTY, WASHINGTON 


\section{APPENDIX E}

\section{SOIL TYPES AND CHARACTERISTICS OF STUDY AREA IN SOUTHWEST THURSTON COUNTY, WASHINGTON}

The source for information contained in this appendix is the Type 4: Southwest Washington River Basin Study (1974).

The following definitions apply to terms used in Tables III, IV, and V.

\section{SOIL TEXTURE}

The relative proportions of the various soil separates in a soil. The textural classes may be modified by the addition of suitable adjectives when coarse fragments are present in substantial amounts. The limits of the various classes are indicated below.

\section{Sand}

A soil particle between 0.05 and $2.00 \mathrm{~mm}$ in diameter. Soil material that contains 85 percent or more of sand; percentage of silt, plus 1.5 times the percentage of clay, shall not exceed 15.

\section{Loamy Sand}

Soil material that contains at the upper limit 85 to 90 percent sand, and the percentage of silt plus 1.5 times the percentage of clay is not less than 15; at the lower limit it contains not less than 70 to 80 percent sand, and the percentage of silt plus twice the percentage of clay does not exceed 30 . 
Sandy Loam

Soil material that contains either 20 percent clay or less, and the percentage of silt plus twice the percentage of clay exceeds 30 , and 52 percent or more sand; or $\leq 7$ percent clay, $\leq 50$ percent silt, and between 43 percent and 52 percent sand.

Loam

Soil material that contains 7 to 27 percent clay, 28 to 50 percent silt, and $\leq 52$ percent sand.

Silt

A soil separate consisting of particles between 0.05 and $0.002 \mathrm{~mm}$ in equivalent diameter. Soil material that contains 80 percent or more silt and 12 percent clay.

\section{Silt Loam}

Soil material that contains 50 percent or more silt and 12 to 27 percent clay or 50 to 80 percent silt and $\leq 12$ percent clay.

Sandy Clay Loam

Soil material that contains 20 to 35 percent clay, $\leq 28$ percent silt, and 45 percent or more sand.

Clay Loam

Soil material that contains 27 to 40 percent clay and 20 to 45 percent sand.

Silty Clay Loam

Soil material that contains 27 to 40 percent clay and $\leq 20$ percent sand.

Sandy Clay

Soil material that contains 35 percent or more clay and 45 percent or more sand. 
Silty Clay

Soil material that contains 40 percent or more clay and 40 percent or more silt.

\section{Clay}

A soil separate consisting of particles $\leq 0.002 \mathrm{~mm}$ in equivalent diameter. Soil material that contains 40 percent or more clay, $\leq 45$ percent sand, and $\leq 40$ percent silt.

\section{PARENT MATERIAL}

The unconsolidated and more or less chemically weathered mineral or organic matter from which the solum of soils is developed by pedogenic processes.

\section{Sedimentary Rock}

A rock formed from materials deposited from suspension or precipitated from solution and usually being more or less consolidated.

Unstratified glacial drift deposited directly by ice and consisting of clay, sand, gravel, and boulders intermingled in any proportion.

\section{Alluvium}

A general term for all detrital deposits resulting from the operations of modern rivers, thus including the sediments laid down in river beds, flood plains, lakes, fans at the foot of mountain slopes, and estuaries.

\section{Basic Igneous Rock}

Rock formed from the cooling and solidification of magma, and that has not been changed appreciably since its formation. 
Outwash

Drift deposited by meltwater streams beyond active glacier ice.

\section{Organic}

Soil, a soil which contains a high percentage ( $\leq 15$ or 20 percent) or organic matter throughout the solum.

\section{SUBSOIL STRUCTURE}

The combination or arrangement of primary soil particles into secondary particles, units, or peds. These secondary units may be, but usually are not, arranged in the profile in such a manner as to give a distinctive characteristic pattern. The secondary units are characterized and classified on the basis of size, shape, and degree of distinctness into classes, types, and grades, respectively.

\section{Blocky}

(1) Blocklike; polyhedronlike, or spheroidal, with three dimensions of the same order of magnitude, arranged around a point. (2) Blocklike; blocks or polyhedrons having plane or curved surfaces that are casts of the molds formed by the faces of the surrounding peds.

\section{Single Grain}

A soil structure classification in which the soil particles occur almost completely as individual or primary particles with essentially no secondary particles or aggregates being present.

\section{Prismatic}

Prismlike; prismlike with two dimensions (the horizontal) limited and considerably less than the vertical; arranged around a vertical line; vertical faces well defined; vertices angular. Also, without rounded caps. 


\section{SUBSOIL CONSISTENCE}

Consistence is a measure of the property of a soil to adhere or cohere or to resist deformation or rupture. This property varies with moisture content and is measured when dry, when wet, and about midway between when moist.

\section{Dry Consistence}

lo $=$ loose, noncoherent

so = weakly coherent, easily crushes to powder or single grain

sh = slightly hard, easily broken between thumb and forefinger

$\mathrm{h}=$ hard, can be broken in the hands without difficulty but difficult to break between thumb and forefinger

vh = very hard, can be broken in the hands with difficulty

eh = extremely hard, cannot be broken in hands

\section{Moist Consistence}

lo $=$ loose, noncoherent

vfr = very friable, crushes under gentle pressure

fr $\quad$ friable, crushes easily under gentle to moderate pressure between thumb and forefinger

$\mathrm{fi}=$ firm, crushes under moderate pressure between thumb and forefinger but resistance is distinctly noticeable

vfi = very firm, crushes under strong pressure, barely crushable between thumb and forefinger

efi = extremely firm, crushes under very strong pressure, cannot be crushed between thumb and forefinger

\section{Wet Consistence}

Stickiness is measured by pressing the wet soil between the thumb and forefinger and noting its adherence.

so $=$ nonsticky; practically no adherence when pressure released

ss = slightly sticky; after pressure, soil adheres to both thumb and finger but comes off one rather cleanly. Does not appreciably stretch.

s = sticky; after pressure soil adheres to both thumb and finger and tends to stretch somewhat before pulling apart from either digit

vs = very sticky; after pressure, soil adheres strongly to both digits and is markedly stretched when they are separated 


\section{Plasticity}

Is measured by rolling the wet soil between the thumb and finger and observing whether or not a wire or thin rod can be formed.

po = nonplastic; no wire is formable

ps = slightly plastic; wire forms, but soil mass easily deformed

$p$. = plastic; wire forms, moderate pressure required to deform soil mass

$\mathrm{vp} \quad=$ very plastic; wire forms, much pressure required to deform soil mass

The following textural abbreviations and modifiers will be used:

$$
\begin{array}{ll}
\text { st } & =\text { stones and stony } \\
k & =\text { cobbles and cobbly } \\
g & =\text { gravel and gravelly } \\
\mathrm{vsOc} & =\text { very coarse sand } \\
\mathrm{fsl} & =\text { fine sandy loam } \\
\mathrm{vfsl} & =\text { very fine sandy loam } \\
\mathrm{l} & =\text { loam } \\
\mathrm{si} & =\text { silt } \\
\mathrm{cos} & =\text { coarse sand } \\
\mathrm{s} & =\text { sand } \\
\mathrm{fs} & =\text { fine sand } \\
\mathrm{vfs} & =\text { very fine sand }
\end{array}
$$

$$
\begin{array}{ll}
\text { lcos } & =\text { loamy coarse sand } \\
\text { sil } & =\text { silt loam } \\
\text { scl } & =\text { sandy clay loam } \\
\text { cl } & =\text { clay loam } \\
\text { sicl } & =\text { silty clay loam } \\
\text { ls } & =\text { loamy sand } \\
\text { lfs } & =\text { loamy fine sand } \\
\text { cosl } & =\text { coarse sandy loam } \\
\text { sl } & =\text { sandy loam } \\
\text { sc } & \text { sandy clay } \\
\text { sic } & \text { silty clay } \\
\text { c } & \text { clay }
\end{array}
$$


TABLE III

SOIL CHARACTERISTICS OF STUDY AREA: TYPE, PERCENT SLOPE, PARENT MATERIAL, AND POSITION ON LANDSCAPE

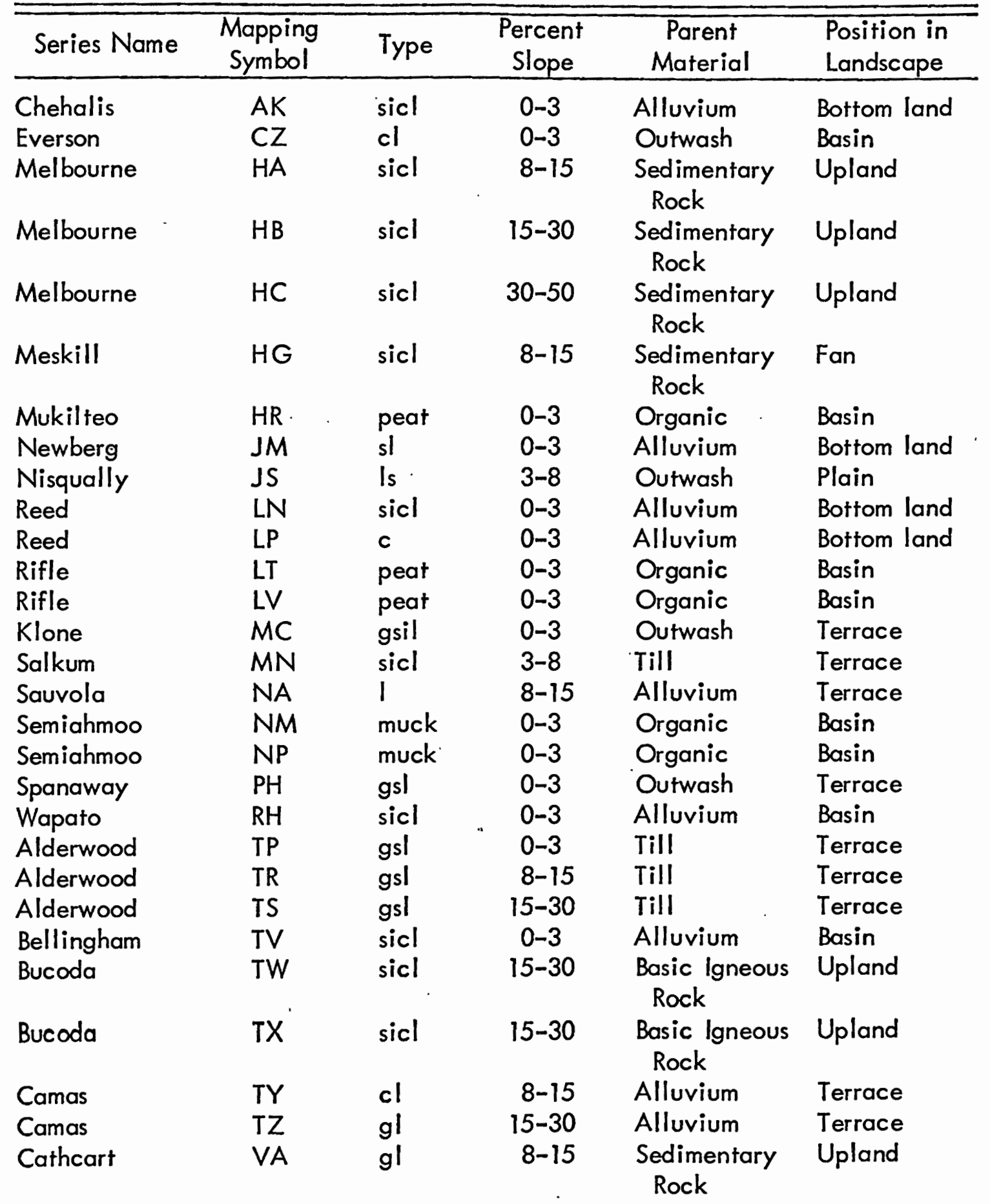


TABLE III--Continued

\begin{tabular}{|c|c|c|c|c|c|}
\hline Series Name & $\begin{array}{l}\text { Mapping } \\
\text { Symbol }\end{array}$ & Type & $\begin{array}{c}\text { Percent } \\
\text { Slope }\end{array}$ & $\begin{array}{c}\text { Parent } \\
\text { Material } \\
\end{array}$ & $\begin{array}{l}\text { Position in } \\
\text { Landscape }\end{array}$ \\
\hline Cathcart & VB & gl & $15-30$ & $\begin{array}{l}\text { Sedimentary } \\
\text { Rock }\end{array}$ & Upland \\
\hline Chehalis & VC & 1 & $0-3$ & Alluvium & Bottom land \\
\hline Everett & VM & gsl & $0-3$ & Outwash & Terrace \\
\hline Everett & VN & gsl & $8-15$ & Outwash & Terrace \\
\hline Everett & VP & gsl & $15-30$ & Outwash & Terrace \\
\hline Everett & VR & gsl & $30-50$ & Outwash & Terrace \\
\hline Everett & VT & stsl & $8-15$ & Outwash & Terrace \\
\hline Meskill & VV & sil & $0-3$ & $\begin{array}{l}\text { Sedimentary } \\
\text { Rock }\end{array}$ & Basin \\
\hline Everson & VW & sil & $0-3$ & Outwash & Basin \\
\hline Fitch & VY & gs! & $0-3$ & Outwash & Terrace \\
\hline Fitch & $V Z$ & gsl & $8-15$ & Outwash & Terrace \\
\hline Galvin & WA & sil & $0-3$ & Alluvium & Fan \\
\hline Giles & WC & fsl & $0-3$ & Outwash & Terrace \\
\hline Lynden & $W L$ & Is & $0-3$ & Outwash & Terrace \\
\hline Maytown & WP & sicl & $0-3$ & Alluvium & Bottom land \\
\hline McKenna & WR & $\mathrm{gcl}$ & $0-3$ & Outwash & Basin \\
\hline McKenna & WS & gl & $0-3$ & Outwash & Basin \\
\hline Newberg & WW & 1 & $0-3$ & Alluvium & Bottom land \\
\hline Norma & $w X$ & $\mathrm{cl}$ & $0-3$ & Alluvium & Basin \\
\hline Norma & WY & 1 & $0-3$ & Alluvium & Basin \\
\hline Olympic & $X B$ & stcl & $15-30$ & $\begin{array}{l}\text { Basic Igneous } \\
\text { Rock }\end{array}$ & Upland \\
\hline Prather & $x C$ & sicl & $3-8$ & Till & Terrace \\
\hline Prather & $X D$ & sicl & $8-15$ & Till & Terrace \\
\hline Prather & $X E$ & sic! & $15-30$ & Till & Terrace \\
\hline Spanaway & XJ & gsl & $8-15$ & Outwash & Terrace \\
\hline Spanaway & $X K$ & gsl & $3-8$ & Outwash & Terrace \\
\hline Tromp & $X S$ & fsl & $0-3$ & Outwash & Basin \\
\hline Tumwater & $X V$ & Ifs & $0-3$ & Outwash & Terrace \\
\hline Tumwater & $X W$ & Ifs & $8-15$ & Outwash & Terrace \\
\hline
\end{tabular}


TABLE IV

SOIL CHARACTERISTICS OF STUDY AREÁ: PRECIPITATION

(INCHES), SUBSOIL TEXTURE, SUBSOIL STRUCTURE, AND SUBSOIL CONSISTENCE

\begin{tabular}{|c|c|c|c|c|c|}
\hline Series Name & $\begin{array}{c}\text { Mapping } \\
\text { Symbol }\end{array}$ & $\begin{array}{l}\text { Precipi- } \\
\text { tation } \\
\text { (Inches) }\end{array}$ & $\begin{array}{l}\text { Subsoil } \\
\text { Texture }\end{array}$ & $\begin{array}{l}\text { Subsoil } \\
\text { Structure }\end{array}$ & $\begin{array}{c}\text { Subsoil } \\
\text { Consistence }\end{array}$ \\
\hline Chehalis & AK & $45-80$ & sicl & Blocky & $v h, f i, s, p$ \\
\hline Everson & $C Z$ & $40-60$ & $\mathrm{cl}$ & Blocky & $h, f i, s s, p s$ \\
\hline Melbourne & $\mathrm{HA}$ & $45-70$ & sicl & Blocky & $v h, f i, s, v p$ \\
\hline Melbourne & $H B$ & $45-70$ & sicl & Blocky & $v h, f i, s, v p$ \\
\hline Melbourne & $\mathrm{HC}$ & $45-70$ & sicl & Blocky & $v h, f i, s, v p$ \\
\hline Meskill & $H G$ & $45-100$ & c & Prismatic & $\begin{array}{c}\text { vh, fi, vs, } \\
v p\end{array}$ \\
\hline Mukilteo & $H R$ & $40-100$ & peat & Fibrous & $\begin{array}{c}\text { so, }-\cdots \text {, so, } \\
\text { po }\end{array}$ \\
\hline Newberg & $J M$ & $40-70$ & sl & Blocky & $\begin{array}{l}\text { lo, } 10, \text { so, } \\
\text { po }\end{array}$ \\
\hline Nisqually & JS & $45-60$ & Is & Single Grain & $\begin{array}{l}\text { lo, lo, so, } \\
\text { po }\end{array}$ \\
\hline Reed & LN & $45-120$ & c & Blocky & $c h, f i, s, v p$ \\
\hline Reed & LP & $45-120$ & c & Blocky & $e h, f i, s, v p$ \\
\hline Rifle & LT & $40-100$ & peat & Fibrous & $\begin{array}{l}\text { so, --, so, } \\
\text { po }\end{array}$ \\
\hline Rifle & LV & $40-100$ & peat & Fibrous & $\begin{array}{l}\text { so, --, so, } \\
\text { po }\end{array}$ \\
\hline Klone & $M C$ & $80-170$ & $v k l$ & Blocky & $h, f r, s s, p$ \\
\hline Salkum & MN & $40-60$ & sicl & Blocky & $\begin{array}{l}\text { eh, efi, vs, } \\
\text { vp }\end{array}$ \\
\hline Sauvola & NA & $45-55$ & sicl & Prismatic & eh, vfi, s, vp \\
\hline Semiahmoo & NM & $40-100$ & peat & Fibrous & $\begin{array}{l}\text { sh, vfr, so, } \\
\text { po }\end{array}$ \\
\hline Semiahmoo & NP & $40-100$ & peat & Fibrous & $\begin{array}{l}\text { sh, vfr, so, } \\
\text { po }\end{array}$ \\
\hline Spanaway & $\mathrm{PH}$ & $45-80$ & $\mathrm{vgls}$ & Single Grain & $\begin{array}{l}\text { lo, lo, so, } \\
\text { po }\end{array}$ \\
\hline Wapato & RH & $45-80$ & sicl & Blocky & $v h, f i, s, v p$ \\
\hline Alderwood & $T P$ & $50-90$ & gsl & Blocky & $h, v f r, s s, p o$ \\
\hline Alderwood & TR & $50-80$ & gsl & Blocky & $h$, vfr, ss, po \\
\hline Alderwood & TS & $50-80$ & gsl & Blocky & $h, v f r, s s$, po \\
\hline Bellingham & TV & $33-55$ & sicl & Prismatic & $h, f i, s, p$ \\
\hline Bucoda & TW & $45-55$ & sicl & Blocky & $h, f r, s s, p s$ \\
\hline
\end{tabular}


TABLE IV--Continued

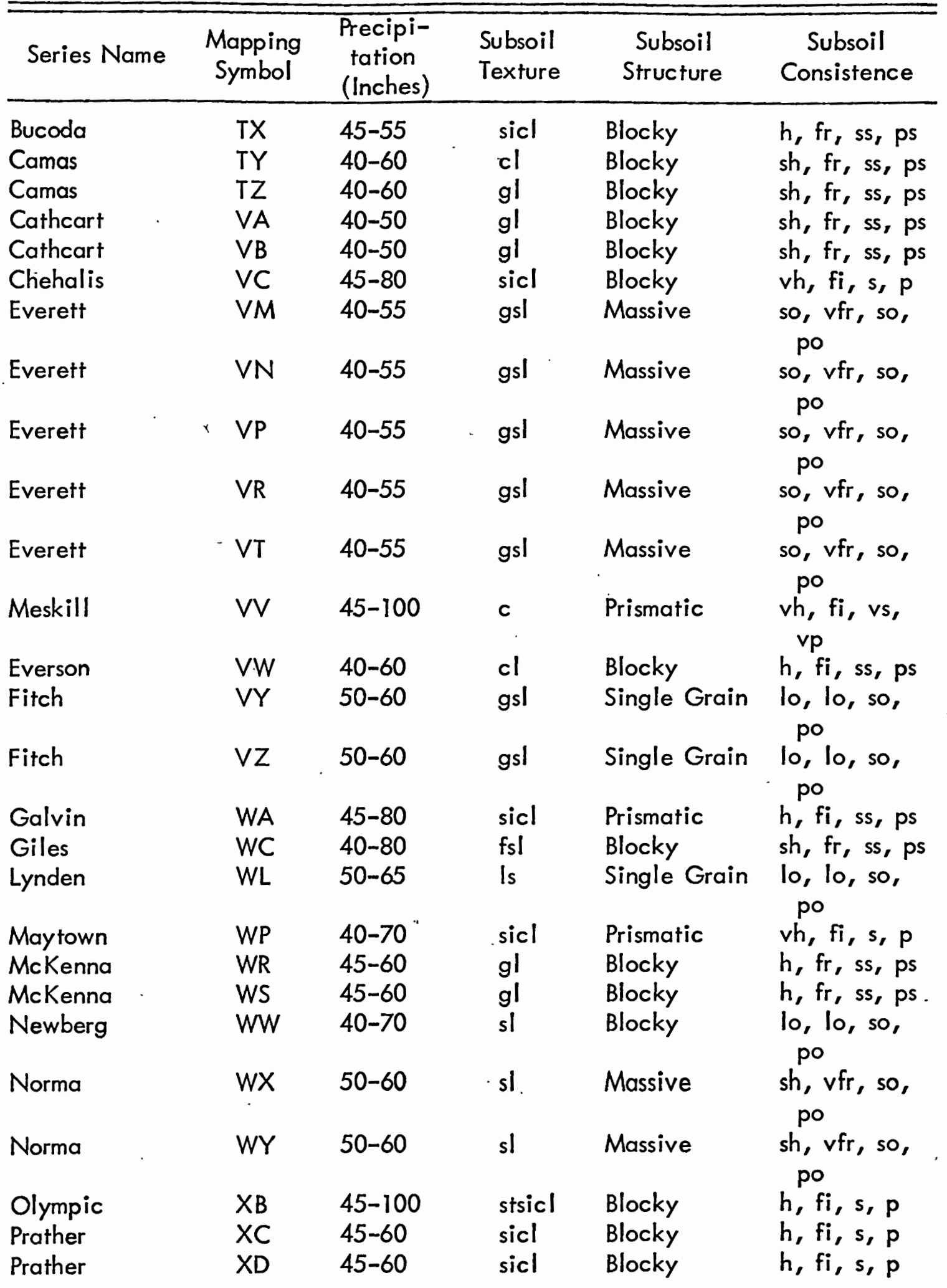


TABLE IV--Continued

\begin{tabular}{|c|c|c|c|c|c|}
\hline Series Name & $\begin{array}{c}\text { Mapping } \\
\text { Symbol }\end{array}$ & $\begin{array}{l}\text { Precipi- } \\
\text { tation } \\
\text { (Inches) }\end{array}$ & $\begin{array}{l}\text { Subsoil } \\
\text { Texture }\end{array}$ & $\begin{array}{l}\text { Subsoil } \\
\text { Structure }\end{array}$ & $\begin{array}{c}\text { Subsoil } \\
\text { Consistence }\end{array}$ \\
\hline Prather & $X E$ & $45-60$ & sicl & Blocky & $h, f i, s, p$ \\
\hline Spanaway & XJ & $45-80$ & vgls & Single Grain & $\begin{array}{l}\text { lo, lo, so, } \\
\text { po }\end{array}$ \\
\hline Spanaway & $\mathrm{XK}$ & $45-80$ & vgls & Single Grain & lo, lo, so, \\
\hline Tromp & $X S$ & $40-60$ & Is & Massive & $\begin{array}{l}\mathrm{vh}, \mathrm{vfl}, \mathrm{ss}, \\
\text { ps }\end{array}$ \\
\hline Tumwater & $X V$ & $45-60$ & Ifs & Single Grain & $10, \mathrm{fr}$, so, po \\
\hline Tumwater & $X W$ & $45-60$ & Ifs & Single Grain & $\mathrm{lo}, \mathrm{fr}, \mathrm{so}, \mathrm{ps}$ \\
\hline
\end{tabular}




\section{TABLE $\vee$}

SOIL CHARACTERISTICS OF STUDY AREA: PROFILE

DEPTH (INCHES), AVAILABLE WATER CAPACITY

(INCHES/PROFILE), LOAD CARRYING

CAPACITY, AND SUBSTRATUM

\begin{tabular}{|c|c|c|c|c|c|}
\hline Series Name & $\begin{array}{l}\text { Mapping } \\
\text { Symbol }\end{array}$ & $\begin{array}{l}\text { Profile } \\
\text { Depth } \\
\text { (Inches) }\end{array}$ & $\begin{array}{c}\text { Available } \\
\text { Water } \\
\text { Capacity } \\
\text { (In, profile) }\end{array}$ & $\begin{array}{l}\text { Load Carrying } \\
\text { Capacity }\end{array}$ & Substratum \\
\hline $\begin{array}{l}\text { Chehalis } \\
\text { Everson } \\
\text { Melbourne }\end{array}$ & $\begin{array}{l}A K \\
C Z \\
H A\end{array}$ & $\begin{array}{l}60+ \\
40-60 \\
40-60\end{array}$ & $\begin{array}{l}+10.0 \\
7.5-10.0 \\
7.5-10.0\end{array}$ & $\begin{array}{l}\text { Moderate } \\
\text { Moderate } \\
\text { Moderate }\end{array}$ & $\begin{array}{l}\text { sicl } \\
\text { s (compact) } \\
\text { Bedrock (sand- } \\
\text { stone and } \\
\text { shale) }\end{array}$ \\
\hline Melbourne & $H B$ & $40-60$ & $7.5-10.0$ & Moderate & $\begin{array}{l}\text { Bedrock (sand- } \\
\text { stone and } \\
\text { shale) }\end{array}$ \\
\hline Melbourne & $\mathrm{HC}$ & $40-60$ & $7.5-10.0$ & Moderate & $\begin{array}{l}\text { Bedrock (sand- } \\
\text { stone and } \\
\text { shale) }\end{array}$ \\
\hline Meskill & $H G$ & $40-60$ & $5.0-7.5$ & High & $\begin{array}{l}\text { Bedrock } \\
\text { (shale) }\end{array}$ \\
\hline Mukilteo & $H R$ & $40-60$ & +10.0 & Low & fs (compact) \\
\hline Newberg & $J M$ & $60+$ & $3.75-5.0$ & High & $s$ \\
\hline Nisqually & JS & $60+$ & $3.75-5.0$ & High & s \\
\hline Reed & $\mathrm{LN}$ & $60+$ & $7.5-10.0$ & High & c (dense) \\
\hline Reed & LP & $60+$ & $7.5-10.0$ & High & c (dense) \\
\hline Rifle & LT & $30-40$ & +10.0 & Low & $c$ \\
\hline Rifle & LV & $10-20$ & $7.5-10.0$ & Low & c \\
\hline Klone & $M C$ & $30-40$ & $3.75-5.0$ & Moderate & vgcos \\
\hline Salkum & $M N$ & $30-40$ & $5.0-7.5$ & Moderate & $\begin{array}{l}\text { Till (com- } \\
\text { pacted) }\end{array}$ \\
\hline Sauvola & NA & $60+$ & $7.5-10.0$ & Moderate & sic \\
\hline Semiahmoo & NM & $40-60$ & +10.0 & Low & c \\
\hline Semiahmoo & NP & $10-20$ & $3.75-5.0$ & Low & c \\
\hline Spanaway & $\mathrm{PH}$ & $10-20$ & $3.75-5.0$ & High & $\begin{array}{c}g, \text { cob. \& } \\
\text { sand. }\end{array}$ \\
\hline $\begin{array}{l}\text { Wapato } \\
\text { Alderwood }\end{array}$ & $\begin{array}{l}\text { RH } \\
\text { TP }\end{array}$ & $\begin{array}{l}60+ \\
30-40 \\
\text { (over } \\
\text { hardpan) }\end{array}$ & $\begin{array}{l}7.5-10.0 \\
3.75-5.0\end{array}$ & $\begin{array}{l}\text { High } \\
\text { High }\end{array}$ & $\begin{array}{l}\text { Is } \\
\text { gfsl (ce- } \\
\text { mented) }\end{array}$ \\
\hline
\end{tabular}


TABLE V--Continued

\begin{tabular}{|c|c|c|c|c|c|}
\hline Series Name & $\begin{array}{l}\text { Mapping } \\
\text { Symbol }\end{array}$ & $\begin{array}{l}\text { Profile } \\
\text { Depth } \\
\text { (Inches) }\end{array}$ & $\begin{array}{l}\text { Available } \\
\text { Water } \\
\text { Capacity } \\
\text { (In /profile) }\end{array}$ & $\begin{array}{c}\text { Load Carrying } \\
\text { Capacity }\end{array}$ & Substratum \\
\hline Alderwood & $T R$ & $\begin{array}{l}30-40 \\
\text { (over } \\
\text { hardpan) }\end{array}$ & $3.75-5.0$ & High & $\begin{array}{l}\text { gfsl (ce- } \\
\text { mented) }\end{array}$ \\
\hline Alderwood & TS & $\begin{array}{l}30-40 \\
\text { (over } \\
\text { hardpan) }\end{array}$ & $3.75-5.0$ & High & $\begin{array}{l}\text { gfsl (ce- } \\
\text { mented) }\end{array}$ \\
\hline Bellingham & TV & $60+$ & $5.0-7.5$ & Moderate & $\begin{array}{l}\text { clay }(30-40 " \\
\text { deep) }\end{array}$ \\
\hline Bucoda & TW & $40-60$ & $7.5-10.0$ & Moderate & Bedrock \\
\hline Bucoda & TX & $40-60$ & $7.5-10.0$ & Moderate & Bedrock \\
\hline Camas & TY & $40-60$ & $7.5-10.0$ & Moderate & gs \\
\hline Camas & $T Z$ & $30-40$ & $5.0-7.5$ & Low & gs \\
\hline Cathcart & VA & $40-60$ & $7.5-10.0$ & Low & $\begin{array}{l}\text { Bedrock (sand- } \\
\text { stone and } \\
\text { shale) }\end{array}$ \\
\hline Catheart & VB & $40-60$ & $7.5-10.0$ & Low & $\begin{array}{l}\text { Bedrock (sand- } \\
\text { stone and } \\
\text { shale) }\end{array}$ \\
\hline Chehalis & VC & $60+$ & +10.0 & Moderate & sicl \\
\hline Everett & $V M$ & $20-30$ & $3.75-5.0$ & High & $\begin{array}{l}\text { Sand, gravel, } \\
\text { cobbles }\end{array}$ \\
\hline Everett & VN & $20-30$ & $3.75-5.0$ & High & $\begin{array}{l}\text { Sand, gravel, } \\
\text { cobbles }\end{array}$ \\
\hline Everett & VP & $20-30$ & $3.75-5.0$ & High & $\begin{array}{l}\text { Sandy, grav- } \\
\text { el, cobbles }\end{array}$ \\
\hline Everett & VR & $20-30$ & $3.75-5.0$ & High & $\begin{array}{c}\text { Sandy, grav- } \\
\text { el, cobbles }\end{array}$ \\
\hline Everett & VT & $20-30$ & $3.75-5.0$ & High & $\begin{array}{l}\text { Sandy, grav- } \\
\text { el, cobbles }\end{array}$ \\
\hline Meskill & W & $40-60$ & $5.0-7.5$ & High & $\begin{array}{l}\text { Bedrock } \\
\text { (shale) }\end{array}$ \\
\hline Everson & VW & $20-30$ & $5.0-7.5$ & Moderate & $s$ (compact) \\
\hline Fitch & $V Y$ & $20-30$ & $3.75-5.0$ & High & $\begin{array}{l}\text { Sand and } \\
\text { gravel }\end{array}$ \\
\hline Fitch & $V Z$ & $20-30$ & $3.75-5.0$ & High & $\begin{array}{l}\text { Sand and } \\
\text { gravel }\end{array}$ \\
\hline Galvin & WA & $60+$ & $7.5-10.0$ & Moderate & $\begin{array}{c}\text { c (dense, 30- } \\
40^{\prime \prime} \text { deep) }\end{array}$ \\
\hline
\end{tabular}


TABLE V--Continued

\begin{tabular}{|c|c|c|c|c|c|}
\hline Series Name & $\begin{array}{l}\text { Mapping } \\
\text { Symbol }\end{array}$ & $\begin{array}{l}\text { Profile } \\
\text { Depth } \\
\text { (Inches) }\end{array}$ & $\begin{array}{c}\text { Available } \\
\text { Water } \\
\text { Capacity } \\
\text { (In, profile) }\end{array}$ & $\begin{array}{l}\text { Load Carrying } \\
\text { Capacity }\end{array}$ & Substratum \\
\hline Giles & WC & $60+$ & $7.5-10.0$ & High & Is (compact) \\
\hline Lynden & WL & $60+$ & $3.75-5.0$ & High & $\mathbf{s}$ \\
\hline Maytown & WP & $60+$ & +10.0 & Moderate & sicl \\
\hline McKenna & WR & $20-30$ & $2.0-3.75$ & Low & $\begin{array}{l}\text { Till (ce- } \\
\text { mented) }\end{array}$ \\
\hline McKenna & WS & $20-30$ & $2.0-3.75$ & Low & $\begin{array}{l}\text { Till (ce- } \\
\text { mented) }\end{array}$ \\
\hline Newberg & WW & $60+$ & $5.0-7.5$ & High & s \\
\hline Norma & $W X$ & $40-60$ & $3.75-5.0$ & High & $\begin{array}{l}\text { gfsl (till ce- } \\
\text { mented) }\end{array}$ \\
\hline Norma & WY & $40-60$ & $3.75-5.0$ & High & $\begin{array}{l}\text { gfsl (till ce- } \\
\text { mented) }\end{array}$ \\
\hline Olympic & $X B$ & $40-60$ & $5.0-7.5$ & High & $\begin{array}{l}\text { Bedrock } \\
\text { (basalt) }\end{array}$ \\
\hline Prather & $x C$ & $60+$ & $7.5-10.0$ & Low & Till (sic) \\
\hline Prather & $X D$ & $60+$ & $7.5-10.0$ & Low & Till (sic) \\
\hline Prather & $X E$ & $60+$ & $7.5-10.0$ & Low & Till (sic) \\
\hline Spanaway & XJ & $10-20$ & $3.75-5.0$ & High & $\begin{array}{l}g \text {, cob., and } \\
\text { sand }\end{array}$ \\
\hline Spanaway & XK & $10-20$ & $3.75-5.00$ & High & $\begin{array}{l}g \text {, cob., and } \\
\text { sand }\end{array}$ \\
\hline Tromp & XS & $60+$ & $5.0-7.5$ & High & s \\
\hline Tumwater & $X V$ & $60+$ & $3.75-5.0$ & High & s \\
\hline Tumwater & $X W$ & $60+$ & $3.75-5.0$ & High & s \\
\hline
\end{tabular}


A SELECTED BIBLIOGRAPHY 


\section{A SELECTED BIBLIOGRAPHY}

American Geological Institute, 1962. Dictionary of Geological Terms, Doubleday and Company, Inc., Garden City, New York.

Blank, Myron A.,' 1974. Computers: Their Place in Land Use Analysis, Unpublished M.Sc. thesis, Utah State University, Logan, Utah.

Carson, M. A. and M. J. Kirkby, 1972. Hillslope Form and Process, Cambridge University Press, New York.

Cooke, R. U. and J. C. Doornkamp, 1974. Geomorphology in Environmental Management, Clarendon Press, Oxford.

Hopps, Howard C., 1969. Computerized Mapping of Diseases and Environmental Data, Geographic Pathology Division, Armed Forces Institute of Pathology, Washington, D. C.

Hutchinson, J. N., 1968. "Mass Movement," The Encyclopedia of Geomorphology, edited by Rhodes W. Fairbridge, Reinhold Book Corporation, New York.

Jones, F. O., O. R. Embody, W. L. Peterson, and R. M. Hazelwood, 1961. Landslides Along the Columbia River Valley, Northeastern Washington, U. S. Geological Survey, Professional Paper 367, U. S. Government Printing Office, Washington, D. C.

Ladd, G. E., 1935. "Landslides, Subsidences and Rock-Falls as Problems for the Railroad Engineer," American Railway Engineering Association Bulletin, Vol. 37, No. 377.

Massey, Daniel L., 1968. Computer Basics for Management, General Learning Press, Morristown, New Jersey.

Miller, Allen H. and Bernard J. Niemann, Jr., 1972. An Interstate Corridor Selection Process-- The Application of Computer Technology to Highway Location Dynamics--Phase 1, Environmental Awareness Center, University of Wisconsin, Madison, Wisconsin. 
Morton, Douglas M. and Robert Streitz, 1967. "Landslides," Mineral Information Service, Vol. 20, No. 10, pp. 123-130.

Savage, C. N., 1968. "Mass Wasting," The Encyclopedia of Geomorphology, edited by Rhodes W. Fairbridge, Reinhold Book Corporation, New York.

Sharpe, C. F. S., 1938. Landslides and Related Phenomena, Columbia University Press, New York.

Sinton, David F., 1975a. "I.M.G.R.I.D.: A System for Manipulating Information in a Grid Cell Data File, Version 2.1, "Cambridge, Massachusetts (Mimeographed).

Sinton, David F., 1975b. "Introduction to the IMGRID Keywords," Cambridge, Massachusetts (Mimeographed).

Steinitz, Carl, Timothy Murray, David Sinton, and Douglas Way, 1969. A Comparative Study of Resource Analysis Methods, Harvard University, Cambridge, Massachusetts.

Terzaghi, Karl, 1950. "Mechanisms of Landslides," Applications of Geology to Engineering Practice, Berkey Volume, Geological Society of America, New York.

Tsao, Albert C., 1975. ERGIS Data Bank for Land and Resource Utilization, Energy Planning Division, Montana State Department of Natural Resources and Conservation, Helena, Montana.

U. S. Department of Agriculture, Soil Conservation Service, 1974. Type 4: Southwest Washington River Basin Study, Spokane, Washington.

Varnes, David J., 1958. "Landslide Types and Processes," Landslides and Engineering Practice, edited by Edwin B. Eckel, Highway Research Board Special Report 29, Washington, D. C.

Ward, William H., 1945. "The Stability of Natural Slopes," The Geographical Journal, Vol. 105, Nos. 5, 6, pp. 170-197. 


$$
8
$$

